\title{
Essay
}

\section{Sharing Nicely: On Shareable Goods and the Emergence of Sharing as a Modality of Economic Production}

\author{
Yochai Benkler ${ }^{\dagger}$
}

CONTENTS

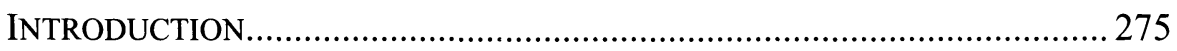

I. CASE StUdies: CARPoOling AND Distributed Computing ...........281

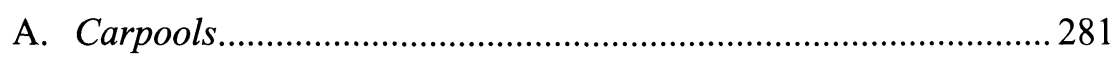

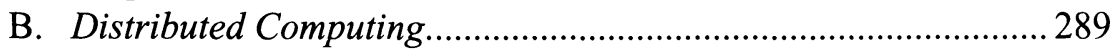

II. LUMPINESS, GRANULARITY, AND SHAREABLE GOODS.......................296

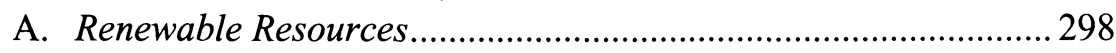

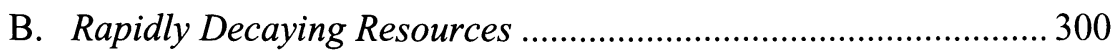

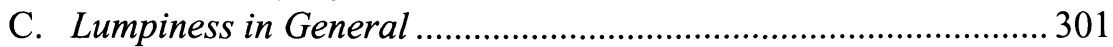

D. Shareable Goods: Conclusion ....................................................... 304

III. SHARING AND MARKETS: TRANSACTION COSTS AND MOTIVATIONS ... 305

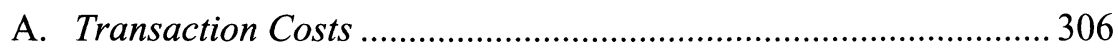

$\dagger$ Professor of Law, Yale Law School. I owe thanks to Bruce Ackerman, Ian Ayres, Bob Ellickson, Dan Kahan, Al Klevorick, Michael Levine, Orly Lobel, Daniel Markovits, Richard McAdams, Robert Post, Judith Resnik, Carol Rose, Susan Rose-Ackerman, Jed Rubenfeld, Alan Schwartz, Henry Smith, and Jim Whitman, who read prior versions of this Essay and provided helpful comments. 
1. Choosing a Transactional Framework

2. The General Shape of Transaction-Costs-Based Choice Among Frameworks

3. Transaction Costs Analysis of Markets and Sharing...............315

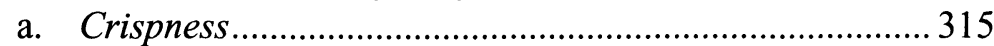

b. Rendering Requirements and Lossiness.............................318

c. Decentralized Systems and Information ............................320

B. Motivation

C. Motivation and Information

IV. SHARING AS A MODALITY OF PRODUCTION.

A. Sharing Is a Common and Underappreciated Modality of Production

B. Sharing Is Sensitive to Technology Because Individual Efficacy Is Subject to Physical-Capital Constraints

C. Decentralized, Loosely Coupled Social Sharing Is an Economically Attractive Modality of Production

V. SOME CURRENT POLICY IMPLICATIONS

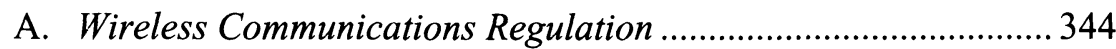

B. Information, Knowledge, and Cultural Production Policy........... 348

C. Network Design for a Network of Shareable Goods. 


\section{INTRODUCTION}

The world's fastest supercomputer and the second-largest commuter transportation system in the United States function on a resourcemanagement model that is not well specified in contemporary economics. Both SETI@home, a distributed computing platform involving the computers of over four million volunteers, and carpooling, which accounts for roughly one-sixth of commuting trips in the United States, rely on social relations and an ethic of sharing, rather than on a price system, to mobilize and allocate resources. Yet they coexist with, and outperform, price-based and government-funded systems that offer substitutable functionality. Neither practice involves public goods, network goods, or any other currently defined category of economically "quirky" goods as either inputs or outputs. PCs and automobiles are privately owned, rival goods, with no obvious demand-side positive returns to scale when used for distributed computing or carpooling. ${ }^{1}$ The sharing practices that have evolved around them are not limited to tightly knit communities of repeat players who know each other well and interact across many contexts. They represent instances where social sharing ${ }^{2}$ is either utterly impersonal or occurs among

1. Computers as communications devices do have demand-side returns to scale, or network externalities. But as processing units, the paramount value of personal computers is the intrinsic value of their computation speed and memory, not the network externalities they enable owners to capture. SETI@home and other distributed computing projects harness these intrinsic-value aspects of personal computers rather than their capacities as communication devices.

2. "Sharing" is an uncommon usage in the economics literature, though it is common in some of the anthropology literature. I choose it because it is broader in its application than other, more common, but narrower terms for associated phenomena-most importantly, "reciprocity" or "gift." I hesitate to use "reciprocity" because of its focus on more or less directly responsive reciprocated reward and punishment as a mechanism to sustain cooperation in the teeth of the standard assumptions about collective action. See DAN M. KAHAN, THE LOGIC OF RECIPROCITY: Trust, Collective Action, AND Law (Yale Law Sch., Pub. Law Research Paper No. 31 \& Yale Program for Studies in Law, Econ. \& Pub. Policy, Research Paper No. 281, 2002), available at $\mathrm{http}: / / \mathrm{ss}$.com/abstract $=361400$. Given the presence of purely redistributive practices like tolerated theft and demand sharing in the anthropology literature, see infra notes 86-87 and accompanying text, evidence of nonreciprocal pro-social behavior, see BRUNO S. FREY \& STEPHAN MEIER, PRO-SOCIAL BEHAVIOR, RECIPROCITY, OR BOTH? (Inst. for Empirical Research in Econ., Univ. of Zurich, Working Paper No. 107, 2002), and more generally our intuitive experiences of acts of humanity toward others whom we will never encounter again, I suspect that some forms of redistribution are nonreciprocal except in the broadest sense of the reciprocation of living in a humane society. Mutual aid and cooperation without the possibility of reciprocal exchange likely exists, the "Lion and the Mouse" fable notwithstanding. See, e.g., James Woodburn, 'Sharing Is Not a Form of Exchange': An Analysis of Property-Sharing in ImmediateReturn Hunter-Gatherer Societies, in PROPERTY RELATIONS: RENEWING THE ANTHROPOlOGICAL TRADITION 48 (C.M. Hann ed., 1998). I hesitate to use the term "gift exchange" because the highly developed gift literature, see infra note 6 , has focused very heavily on the production and reproduction of social relations through the exchange and circulation of things. As will soon become clear, I am concerned with the production of things and actions/services valued materially, through nonmarket mechanisms of social sharing. "Sharing," 
loosely affiliated individuals who engage in social practices that involve contributions of the capacity of their private goods in patterns that combine to form large-scale and effective systems for provisioning goods, services, and resources.

This Essay seeks to do two things. The first three Parts are dedicated to defining a particular class of physical goods as "shareable goods" that systematically have excess capacity and to combining comparative transaction costs and motivation analysis to suggest that this excess capacity may better be harnessed through sharing relations than through secondary markets. These first three Parts extend the analysis I have performed elsewhere regarding sharing of creative labor, like free software and other peer production, ${ }^{3}$ to the domain of sharing rival material resources in the production of both rival and nonrival goods and services. The characteristics I use to define shareable goods are sufficient to make social sharing and exchange of material goods feasible as a sustainable social practice. But these characteristics are neither absolutely necessary nor sufficient for sharing to occur. Instead, they define conditions under which, when goods with these characteristics are prevalent in the physicalcapital base of an economy, it becomes feasible for social sharing and exchange to become more salient in the overall mix of relations of production in that economy. The fourth Part is then dedicated to explaining how my observation about shareable goods in the domain of physical goods meshes with the literature on social norms, social capital, and common property regimes, as well as with my own work on peer production. I suggest that social sharing and exchange is an underappreciated modality of economic production, alongside price-based and firm-based market production and state-based production, ${ }^{4}$ whose salience in the economy is sensitive to technological conditions. The last Part explores how the recognition of shareable goods and sharing as a modality of economic production can inform policy.

Shareable goods are goods that are (1) technically "lumpy" and (2) of "mid-grained" granularity. By "lumpy" I mean that they provision

then, offers a less freighted name for evaluating mechanisms of social-relations-based economic production.

$\rightarrow$ Yochai Benkler, Coase's Penguin, or, Linux and The Nature of the Firm, 112 YALE L.J. 369 (2002).

4. In this, my position tracks the tripartite mapping of the universe of organizational forms that resulted from the work on nonprofits in the early 1980s. $\rightarrow$ Henry B. Hansmann, The Role of Nonprofit Enterprise, 89 YALE L.J. 835 (1980); see also BURTON A. WEISBROD, THE NONPROFIT ECONOMY 1-15 (1988); Susan Rose-Ackerman, Introduction, in THE ECONOMICS OF NONPROFIT INSTITUTIONS: STUDIES IN STRUCTURE AND POLICY 3, 3-17 (Susan Rose-Ackerman ed., 1986). Unlike the nonprofit literature, my focus is not within the boundaries of firms-whether for- or nonprofit - but on sharing among individuals in informal associations more resembling markets in the price-based economy than firms. 
functionality in discrete packages rather than in a smooth flow. A PC is "lumpy" in that you cannot buy less than some threshold computation capacity, but once you have provisioned it, you have at a minimum a certain amount of computation, whether you need all of it or not. By "granularity" I seek to capture (1) technical characteristics of the functionality-producing goods, (2) the shape of demand for the functionality in a given society, and (3) the amount and distribution of wealth in that society. A particular alignment of these characteristics will make some goods or resources "mid-grained," by which I mean that there will be relatively widespread private ownership of these goods and that these privately owned goods will systematically exhibit slack capacity relative to the demand of their owners. A steam engine is large grained and lumpy. An automobile or PC is mid-grained in the United States, Europe, and Japan, but large grained in Bangladesh. Reallocating the slack capacity of mid-grained goods-say, excess computer cycles or car seats going from $A$ to $B$-becomes the problem whose solution can be provided by secondary markets, sharing, or management. I offer reasons to think that sharing may have lower transaction costs, improve the information on which agents who own these resources act, and provide better motivation for clearing excess capacity. While economists might prefer to call these goods "indivisible" rather than "lumpy," that terminology is less intuitive to non-economists, and, more importantly, it emphasizes a concern with how best to price capacity that is indivisible and coarsely correlated to demand, glossing over the way in which the granularity affects the pattern of distribution of investment in these goods in society. My own concern is how a particular subclass of indivisible goods - those that are mid-grained as I define them here-creates a feasibility space for social sharing rather than requiring a particular model of second-best pricing. While indivisibilities do create challenges for efficient pricing, in my analysis they create conditions in which social relations may provide a more efficient transactional framework to provision and exchange those goods than would the price system.

In particular, both markets and managerial hierarchies require crisp specification of behaviors and outcomes. Crispness is costly. It is not a characteristic of social relations, which rely on fuzzier definitions of actions required and performed, of inputs and outputs, and of obligations. Furthermore, where uncertainty is resistant to cost-effective reduction, the more textured (though less computable) information typical of social relations can provide better reasons for action than the persistent (though futile) search for crisply computable courses of action represented by pricing or managerial commands. Moreover, social sharing can capture a cluster of social and psychological motivations that are not continuous 
with, and may even be crowded out by, the presence of money. Pooling large numbers of small-scale contributions to achieve effective functionality-where transaction costs would be high and percontribution payments must be kept low-is likely to be achieved more efficiently through social sharing systems than through market-based systems. It is precisely this form of sharing-on a large scale, among weakly connected participants, in project-specific or even ad hoc contexts - that we are beginning to see more of on the Internet; that is my central focus.

Social sharing and exchange is becoming a common modality of producing valuable desiderata at the very core of the most advanced economies-in information, culture, education, computation, and communications sectors. Free software, distributed computing, ad hoc mesh wireless networks, and other forms of peer production offer clear examples of such large-scale, measurably effective sharing practices. I suggest that the highly distributed capital structure ${ }^{5}$ of contemporary communications and computation systems is largely responsible for the increased salience of social sharing as a modality of economic production in those environments. By lowering the capital costs required for effective individual action, these technologies have allowed various provisioning problems to be structured in forms amenable to decentralized production based on social relations, rather than through markets or hierarchies.

My claim is not, of course, that we live in a unique moment of humanistic sharing. It is, rather, that our own moment in history suggests a more general observation: that the technological state of a society, particularly the extent to which individual agents can engage in efficacious production activities with material resources under their individual control, affects the opportunities for, and hence the comparative prevalence and salience of, social, market (both price based and managerial), and state production modalities. The capital cost of effective economic action in the industrial economy shunted sharing to its peripheries-to households in the advanced economies, and to the global economic peripheries that have been the subject of the anthropology of gift or common property regime literatures. The emerging restructuring of capital investment in digital networks - in particular the phenomenon of user-capitalized computation and communications capabilities-is at least partly reversing that effect. Technology does not determine the level of

5. This is different from capital intensity. The activity may be capital intensive-like distributed computing - when you consider the total capital cost of the computers, network connections, etc. required for an effective unit of production, in comparison to the cost of labor involved. The capital is, however, highly distributed, which is the key characteristic that enables individual agency in the production process. 
sharing. But it does set threshold constraints on the effective domain of sharing as a modality of economic production. Within the domain of the feasible, the actual level of sharing practices will be culturally driven and cross-culturally diverse.

As the case studies in Part I will underscore, the loose category of "social sharing" that I employ here covers a broad range of social phenomena. Carpooling can largely, though not exclusively, be explained in terms of instrumental exchange. Distributed computing projects look like cases of mass altruism among strangers. What justifies bringing such diverse practices under one umbrella term is that they are instances of productive cooperation that are based neither on the price system nor on managerial commands. Given the focus of current policy debates on improving the institutional conditions for market-based production of various desiderata, even at the expense of substitutable social practices, it becomes important to recognize the presence, sustainability, and relative efficiency of even a loosely defined broad alternative.

Once we come to accept the economic significance of this cluster of social practices, we will have to turn to mapping internal variations and understanding their workings and relationships to each other as economic phenomena. Even from the relatively limited review I offer here, it is clear that social production covers different forms of motivation and organization. There are instrumental and noninstrumental motivations. Instrumental motivations may, in turn, be material - the primary focus of the social norms, social capital, and common property regimes literaturesor social-relational - that is, focused on the production of relations of power within a society, a focus that has been central to the literature on the gift. ${ }^{6}$ The gift literature, however, has meshed the instrumental production of social relations with the noninstrumental, mystical or religious nature of gift giving. This noninstrumental form of motivation-though from a very nonmystical perspective-has also been the focus of the psychological literature on motivation crowding out that I discuss in Section III.B. Understanding how the motivational and organizational forms of this

6. The anthropological literature on sharing and the gift has been vast, starting with BRONISLAW MALINOWSKI, ARGONAUTS OF THE WESTERN PACIFIC (1922), and MARCEL MAUSS, THE GIFT: FORMS AND FUNCTIONS OF EXCHANGE IN ARCHAIC SOCIETIES (Ian Cunnison trans., Free Press 1954) (1925). A combination of a broad intellectual history and a major contemporary contribution to this line is MAURICE GODELIER, THE ENIGMA OF THE GIFT (Nora Scott trans., Univ. of Chi. Press 1999) (1996). See also James G. Carrier, Property and Social Relations in Melanesian Anthropology, in PROPERTY RELATIONS, supra note 2, at 85, 85-97 (providing brief intellectual history of the literature); C.M. Hann, Introduction: The Embeddness of Property, in PROPERTY RELATIONS, supra note 2, at 1, 23-34 (same). As an alternative antithesis to the competition-of-all-against-all model of human society, an early manifestation of a focus on mutual aid and cooperation as a possible path for contemporary societies was PETR KROPOTKIN, MUTUAL AID: A FACTOR OF EVOLUTION (Extending Horizons Books 1955) (1902). 
modality operate will be important whether one seeks to engage in institutional design that takes into consideration the presence of social production as a potential source of welfare, or whether one is concerned with building a business model that harnesses the power of social production-be it for profit, like IBM's relationship with the GNU/Linux development community, or nonprofit, like NASA's relationship with the contributors to SETI@home. For now, however, all we need is to recognize that a broad set of social practices can be sustainable and efficient substitutes for markets, firms, and bureaucracies.

The policy implications of recognizing the relative importance of sharing-based solutions to economic problems are significant. As we manage the transition to a networked information economy, we face diverse questions regarding how best to regulate different areas of this economy: How should we regulate wireless communications systems? How should we regulate music distribution? Should we regulate the design of computers to assure that they are not used to access cultural products without authorization? Usually these policy debates, to the extent they are concerned with efficiency and welfare, assume that the role of policy is to optimize the institutional conditions of attaching prices to marginal actions so as to permit the price system to be the dominant modality of production. This may or may not be wise, but whether it is or is not can only be examined thoughtfully once we have a full picture of the alternatives. If we believe that there are only two alternatives-the price system and some form of hierarchy-we have a very different policy-choice space than if we believe that there is a third modality of production open to us, social production, that may under certain conditions be more efficient.

Radio and communications technologies have reached a point where our policy focus is changing. The Federal Communications Commission is creating an institutional framework to facilitate markets in shareable goods - unlicensed wireless devices and systems - that co-produce wireless transport capacity. Originally, using such devices was prohibited in order to make the world safe for large-grained systems, like broadcast towers or cellular networks, that deliver wireless services based on either the terms of a government license or markets in "spectrum." The music copyright debate around peer-to-peer file sharing can also be explained in terms of the change in the type of goods used in distribution, from large-scale capital goods to mid-grained shareable goods. Understood in these terms, solving this problem by squelching peer-to-peer sharing becomes implausible, both descriptively and prescriptively. Yet current policy analysis largely disregards how institutional changes will affect existing or emerging practices of sharing that may compete with, or substitute for, market-based 
production. If indeed we live in an economic system made up of pricebased, hierarchy-based, and sharing-based modalities of production, if it is true that optimizing our institutional system for price-based production undermines productivity in the sharing modality, and if it is true that our communications, computation, and information sectors are undergoing technological changes that improve the efficiency of social sharing, then we are making systematically mistaken policy choices not on the peripheries of our economies and societies, but at their very engines.

\section{CASE STUDIES: CARPOOLING AND DISTRIBUTED COMPUTING}

The two motivating case studies that follow share four characteristics. First, they involve large-scale sharing practices among individuals who are either weakly related along other social dimensions or are complete strangers. Second, they involve sharing of private economic goods, owned by individuals for their own use. Third, in each case, there exist market models through which the excess capacity of these private goods could be, and sometimes is, cleared. Fourth, the output of the sharing practice in both cases is a rival good-it could be put to uses other than those that the participants in the sharing practice have put it to, and their using it for one purpose rivals the availability of the particular units shared to pursue other practices. In these characteristics carpooling and distributed computing are like peer-to-peer networks, or ad hoc wireless mesh networks, or like the labor individual programmers put into free software development. As I noted in the Introduction, carpooling provides a context to study social exchange as an alternative transactional framework motivated largely by straightforward instrumental reasons. Distributed computing, by contrast, is not readily explained by a simple instrumental perspective and offers an opportunity to explore effective large-scale projects that pay close attention to other forms of motivation.

\section{A. Carpools}

Carpooling is the second-largest commuter transportation system in the United States. It accounts for one-sixth to one-eighth of work-related trips ( $12 \%$ to $17 \%$ of trips, depending on the study)-twice as much as all other modes, except solo driving (75.4\%), combined. ${ }^{7}$ In the United States, carpooling came to prominence during World War II, when oil and rubber

7. John Pucher \& John L. Renne, Socioeconomics of Urban Travel: Evidence from the 2001 NHTS, TRANSP. Q., Summer 2003, at 49, 53 tbl.3 (2003). 
shortages made car sharing a policy goal. ${ }^{8}$ It reappeared as a national priority during the oil crisis of the mid-1970s, but appears to have been on a declining trajectory since $1980^{9}$ - sliding from $19.7 \%$ of work-related trips to between $12 \%$ and $16.8 \%$ in $2000-2001 .{ }^{10}$ Despite its contraction, carpooling remains much more significant than public transit, which accounts for only $3.7 \%$ of work-related trips, in terms of total number of work-related trips nationally. ${ }^{11}$ Transit use drops even further for non-workrelated trips, to $1 \%$ or $2 \%$, while carpooling rises to account for over $50 \%{ }^{12}$ Because non-work-related carpools often are composed only of family members, and because I am concerned primarily with nonintimate social sharing practices, I focus here on work-related carpools, where a majority of sharing appears to occur among non-household members. ${ }^{13}$

The most important characteristic of carpooling from the perspective of this Essay is that money or explicit barter may be present or absent, and that money, where present, is usually limited to explicit cost sharing rather than used as a price. A central concern of this Essay is comparing instances where prices are the primary source of information about, and incentive for, resource allocation to instances where non-price-based social relations play those roles. Taking a coworker to work, rather than another person who is willing and able to pay more, is an instance of social production, not of price-based market production. This is true whether or not part of the social interaction includes sharing the cost of gas and parking-because the market-defined social cost is the unavailability of the seat to the higher bidder, not the operating cost of the vehicle.

Carpool-like arrangements where seats are sold for a price are rare relative to non-price-based carpools. They include mostly jitneys, ${ }^{14}$ which

8. Erik Ferguson, The Rise and Fall of the American Carpool: 1970-1990, 24 TRANSPORTATION 349, 349-51 (1997).

9. Id. at 349-54.

10. According to the 2000 Census, the number is approximately $12 \%$. See Pucher \& Renne, supra note 7, at 50 tbl.1 (reporting data from U.S. Decennial Census, Supplemental Survey: Journey to Work). According to 2001 National Household Travel Survey (NHTS) data, the decline was more moderate, to $16.8 \%$, for more clearly commute-related trips, defined as trips in urban areas for distances shorter than seventy-five miles. See id. at 53 tbl.3.

11. Id.

12. Id.

13. How large a majority is not entirely clear. John Pucher and John Renne claim that "[f]amily members are often passengers on car trips for shopping, recreation, church, and school, while they seldom accompany each other to work." Id. at 52-53. An older study reported that more than $40 \%$ of work-related carpools include members of the same household. Roger F. Teal, Carpooling: Who, How and Why, 21 A TRANSP. RES. (PART A: GEN. RES.) 203, 206 tbl.2 (1987).

14. See Nicole Stelle Garnett, The Road from Welfare to Work: Informal Transportation and the Urban Poor, 38 HARV. J. ON LEGIS. 173, 203-17 (2001) (discussing jitney operations in New York City and Miami and their potential to further help poor communities if allowed to operate legally); Isaac K. Takyi, An Evaluation of Jitney Systems in Developing Countries, 44 TRANSP. Q. 163,170 (1990) (listing typical characteristics of jitney systems). 
may follow predefined routes like buses or offer door-to-door services, and "car sharing" services, club-like arrangements in which members pay on a per-use basis in addition to the membership fee. ${ }^{15}$ But price-based car sharing is the exception, not the rule. The vast majority of carpooling occurs without pricing, though it often includes either explicit barter or cost sharing. Carpools often involve some exchange $-X$ drives Mondays, $Y$ drives Tuesdays, ${ }^{16}$ or Passenger A gets a ride from Driver $B$, Driver $B$ gets to use the HOV lane. ${ }^{17}$ Money does not typically mediate this type of transaction. ${ }^{18}$ The rotation of driving and car-provisioning responsibilities is one major form of barter in this area, ${ }^{19}$ but money does not appear to be used to balance divergent costs or values - the owner of the fuel-efficient subcompact does not compensate the owner of the comfy gas guzzler with more money or added driving days. Where money does change hands, it seems to be structured largely as participation in explicit costs, like gas, tolls, or parking fees. ${ }^{20}$

In terms of organization and governance, practically all carpool arrangements are decentralized. Carpooling can be divided into two stages of activity: (1) formation and scheduling and (2) behavior of participants while carpooling. Other than scattered government- and employer-run voluntary ride-matching programs, ${ }^{21}$ carpool formation and scheduling

15. See Franz E. Prettenthaler \& Karl W. Steininger, From Ownership to Service Use Lifestyle: The Potential of Car Sharing, 28 ECOLOGICAL ECON. 443, 445 (1999). The pricing model follows remarkably well Eitan Berglas's version of efficient pricing of club goods. See $\rightarrow$ Eitan Berglas, On the Theory of Clubs, 66 AM. ECON. REV. (PAPERS \& PROC.) 116, 116-21 (1976).

16. See Aloise B. Heath, The Sociology of the Carpool, 12 NAT'L REV. 360, 360-61 (1962).

17. See Marcela Kogan, Slugs and Body Snatchers, Gov'T EXECUTIVE, June 1997, at 39 (1997).

18. See Ferguson, supra note 8, at 352 ("Most carpools do not involve any financial transactions."). The academic literature on carpooling rarely mentions money.

19. See, e.g., 1 F.W. DAVIS, JR. ET AL., U.S. DEP'T OF TRANSP., INCREASED TRANSPORTATION EFFICIENCY THROUGH RIDESHARING: THE BROKERAGE APPROACH 57 (1977) (describing the "general norm of reciprocity" by which carpoolers alternate driving days and "repay their driving days" if illness or holiday disrupts the rotation schedule); Heath, supra note 16, at 360-61. Davis's report presents a Department of Transportation survey of 4500 Knoxville, Tennessee-area carpoolers in 1974 and 1975.

20. An informal survey of 250 rideshare postings on Craigslist in the San Francisco Bay Area revealed that in $30 \%$ of postings money is not mentioned, and in the vast majority of postings that do mention money, the request or offer modulates the money as being for costs like "gas" or "tolls." Only $10 \%$ of postings state a fixed price for a ride, while only $6 \%$ state a price without modulating the price by characterizing its purpose as cost sharing. The majority of users, whether or not money is asked for or offered, also specify social characteristics they desire in potential carpooling partners, such as being "good company" or having "good tunes." See Rideshare in San Francisco Bay Area, Craigslist (Nov. 6, 2003) (on file with author) (current listings available at http://www.craigslist.org/rid/).

21. See Craig N. Oren, Getting Commuters Out of Their Cars: What Went Wrong?, 17 STAN. ENVTL. L.J. 141, 174-90, 201-02 (1998). Oren provides an in-depth analysis of the Employee Trip Reduction mandate, the most ambitious federal effort to promote carpooling to date. It did not come close to producing the desired gains in alternatives to solo driving and in air pollution 
appears to be highly decentralized. Carpools for work-related trips are usually composed of coworkers who live in rough proximity rather than of neighbors who work in rough proximity. ${ }^{22}$ More generally, household members, coworkers, and parents whose children have common transportation needs typically contact potential carpooling partners and arrange a carpool without government or market involvement. ${ }^{23}$ In highly organized, regularized systems-for example, a carpool in which multiple parents drive children to and from after-school activities according to a written rotation schedule - trip scheduling is an integral part of carpool formation but is typically conducted by the participants. ${ }^{24}$ Sporadic, ad hoc carpools-for example, two roommates who decide to carpool to work on a given morning, or carpool pickup spots-do not require organized scheduling at all. ${ }^{25}$

One of the most rarified forms of carpool formation and scheduling, observed in Northern Virginia and the San Francisco Bay Area, is ad hoc, or dynamic, carpooling. Ad hoc carpooling-in California called "casual carpooling" ${ }^{26}$ and in Virginia, "slugging" ${ }^{27}$-involves solo drivers picking up strangers at known meet points to form a carpool sufficiently large to take advantage of high-occupancy vehicle (HOV) lanes. ${ }^{28}$ The practice has been described as follows:

[One driver] now has the system down cold. Between 7 and 7:15 a.m., she drives to a slug line in the parking lot of a closed ... home-improvement store in her Northern Virginia suburb. [She] waits her turn behind other cars. When her car gets to the front of

reduction. Oren concludes that the mandate fell short because it followed the structure of traditional technology-forcing environmental regulations, failing to account for the complexities inherent in changing individuals' commuting behaviors or for the breadth of factors affecting carpooling. See id. at 143-50; see also Roberto Wolfler Calvo et al., A Distributed Geographic Information System for the Daily Car Pooling Problem, 31 COMPUTERS \& OPERATIONS RES. 2263 (2004), available at http://www.sciencedirect.com (search "Search for a Title" for "Computers and Operations Research"); D.J. Dailey et al., Seattle Smart Traveler: Dynamic Ridematching on the World Wide Web, 7 TRANSP. RES. (PART C: EMERGING TECH.) 17 (1999), available at http://www.its.washington.edu/pubs/trans_c.pdf. The Microsoft Access-based system described by Calvo and his coauthors optimizes the composition of carpool groups and carpooling routes for employees of a large Italian employer and communicates with users via cell phone text messaging, e-mail, and the Internet.

22. Teal, supra note 13, at 204.

23. See 1 DAVIS ET AL., supra note 19, at 56; Heath, supra note 16, at 360-61.

24. See Heath, supra note 16 , at 360-61.

25. See Kogan, supra note 17 , at 39.

26. A list of casual carpooling locations on a Bay Area website devoted to casual carpooling identifies both public transit sites and shopping mall-type locations. Casual Carpool Sites East Bay and San Francisco, http://ridenow.org/carpool/\#locations (last visited Sept. 29, 2004).

27. The slugging community is a font of information about itself. See Slug-Lines.com, http://www.slug-lines.com (last visited Sept. 29, 2004).

28. See Kogan, supra note 17 , at 39. 
the line, the next slug in line comes up to her window and asks [her] where she is going. The slug then shouts the destination to the others in line and gets in the car if he or she wants to go in that direction. The next couple of people in line headed in the same direction climb aboard, too. ${ }^{29}$

The Northern Virginia terminology suggests a tension between this form of carpooling and public transit: The drivers are called "body snatchers," the riders, "slugs" (reportedly named after passengers who drop slugs instead of legitimate tokens into a bus's fare box). ${ }^{30}$ Indeed, a recent study of the practice in Northern Virginia documents substitution between dynamic carpooling and transit use, ${ }^{31}$ and suggests also that dynamic carpools depend on public transit as a fallback option for at least one leg in case the ad hoc carpool fails to form in both directions. ${ }^{32}$ Body snatchers can also find slugs, however, at non-transit pickup spots, which may be marked as dedicated carpool pickup stands, or unmarked - for example, street corners and parking lots-and may be designated by a centralized authority or by custom. ${ }^{33}$ While individual drivers and passengers may see each other on more than one occasion, body snatchers and slugs are typically strangers, and participants of the same functional type are fungible. ${ }^{34}$

Dynamic carpooling appears to be a highly egalitarian activity: Body snatchers seem to take slugs regardless of gender, race, or occupation in order to fulfill their quotas and gain access to HOV lanes. ${ }^{35}$ One set of regularities, however, underscores an obstacle that dynamic carpooling must overcome, and offers a surprising hypothesis about impersonal social cooperation. In a deviation from gender-neutral pickup practices, solo women will not usually enter a car with two men already in it. "Unrelated" slugs on a line, however, will match up, whether male or female, irrespective of the gender of the driver. ${ }^{36}$ This underscores the fact that personal security fears may be a serious obstacle to carpooling with strangers. ${ }^{37}$ The matching practices suggest that security is improved by

29. Id. at 42 .

30. See id.

31. Frank Spielberg \& Phillip Shapiro, Mating Habits of Slugs: Dynamic Carpool Formation in the I-95/I-395 Corridor of Northern Virginia, in TRANSP. RESEARCH BD., TRANSPORTATION RESEARCH RECORD NO. 1711, at 31, 33 (2000).

32. $I d$.

33. Id.; see also Casual Carpool Sites East Bay and San Francisco, supra note 26.

34. Spielberg \& Shapiro, supra note 31 , at 33 .

35. Id. The article reports results of a survey of more than 3000 drivers and passengers using an HOV lane to commute from Northern Virginia to Washington, D.C. Of 28,000 commuters using HOV lanes during their morning commute, the survey counted 3100 slugs. Id. at 34-35.

36. $I d$.

37. The California description of the issue is as follows: 
combining more than one rider with each solo driver, where the riders themselves are not preorganized in groups. Each pair-driver plus each rider, and both riders vis-à-vis the driver-provides each individual with some security against an aggressive stranger. The importance of strength in numbers and lack of personal relationship is indicated by the fact that solo women will join two men in a car if the woman and man were both in line and no relationship between the two men is indicated. ${ }^{38}$ Carpoolers on this model seem to assume a prevalence and distribution of aggressive proclivities in the population that places a low probability on two randomly associated individuals cooperating aggressively. Given such a model of the prevalence and distribution of aggressive tendencies, fully impersonal cooperation can then be seen as safer than partially impersonal cooperation, where some subset of participants have a preexisting relationship. Another aspect of the same problem is "solved" by etiquette, as described in the "etiquette" page of the Northern Virginiaoriented website:

The line does not leave a woman standing alone.... Either a man forfeits his place in line so that he is left standing, or the ride is declined until another slug arrives. Or, it is acceptable to ask the driver if he will take more slugs in order to clear the line. Whatever the situation, the intent is not to leave a woman standing alone on the street, especially at night. ${ }^{39}$

As the reference to the etiquette indicates, though decentralized, ad hoc carpooling is not entirely unregulated; social norms seem to play an important role in the process. A list of such rules is found on the Northern Virginia site, and includes interesting insights. Slugs do not talk-at least, not unless the driver initiates. ${ }^{40}$ This appears to be the rule in the Bay Area as well. ${ }^{41}$ No money, gifts, or tokens of appreciation are offered or requested. No smoking or eating by driver or slug. No going out of lineeither for slugs to push ahead, or drivers to "snatch" slugs before the line,

As far as anyone seems to know, over the history of East Bay casual carpooling, there have been no untoward incidents. The "three-per-car" requirement has helped. A little caution and common sense also have helped. Passengers can always decline a ride. For example, female passengers have been known to decline rides in two-seat cars. They simply let another passenger go first, and wait for a larger vehicle.

What Are Casual Car Pools?, http://ridenow.org/carpool/what.htm (last visited Sept. 29, 2004).

38. See Spielberg \& Shapiro, supra note 31 , at 35.

39. Etiquette and Rules, http://www.slug-lines.com/Slugging/Etiquette.asp (last visited Sept.

29, 2004) (emphasis omitted).

40. Id.

41. What Are Casual Car Pools?, supra note 37. 
except that drivers can call out to a particular friend they see in line. The slug does not adjust the radio station or the heat. ${ }^{42}$

Dynamic carpooling is an entirely impersonal, ad hoc practice with no perceptible socially stable set of participants. Yet participants do not use market mechanisms to clear seats. They rely instead on pure short-term mutual interest with no price (seats in exchange for eligibility for the HOV lane), combined with social norms and practices, to get body snatchers and slugs together. ${ }^{43}$ Behavioral controls may be somewhat more formal, but these are rules of etiquette that are largely under the control of the driver. ${ }^{44}$ The decentralization of governance is paralleled in the normal case of carpools, where key behavioral decisions-driver rotation, seating

42. Etiquette and Rules, supra note 39.

43. Dynamic carpools cannot quite be presented as "proof" that social provisioning is more efficient or desirable, because there is ambiguity as to the legal status of a similar arrangement that would instead operate on, for example, a spot-auction model. At least in some jurisdictions, such a practice could require licensing as a taxicab or otherwise as a vehicle for hire. But in the Northern Virginia corridor, the ambiguity is limited. The Alexandria, Virginia Code, for example, covers only taxicabs and vehicles for hire that are "maintained for . . . hire." ALEXANDRIA, VA., CODE OF ORDINANCES § 9-12-1(7), (14) (2004), available at http://www.municode.com/resources/code_list.asp?stateID $=46$ (follow "Alexandria Code of Ordinances" link). While not impossible, it is highly unlikely that a vehicle used even a few days a week for one or two trips where money changes hands out of an entire weekly schedule would be defined as "maintained for hire." Slightly more ambiguously, the relevant ordinance in Arlington County, Virginia states that a "[t]axicab or other motor vehicle performing taxicab service means any motor vehicle having a seating capacity of not more than six (6) passengers and not operating on a regular route or between fixed terminals used in the transportation of passengers for hire or for compensation." ARLINGTON COUNTY, VA., CODE $§ ~ 25-2$ (2003), available at http://www.municode.com/resources/code_list.asp?stateID=46 (follow "Arlington County Code of Ordinances" link) (emphasis omitted). This definition would seem to include carpooling for compensation, unless the sporadic use for carpooling would not designate the vehicle in general as a taxicab, but rather as falling under the category of an "other motor vehicle performing taxicab services." "Taxicab service," in turn, "means and includes the operation of any motor vehicle upon any street or highway, on call or on demand, accepting or soliciting passengers indiscriminately for transportation for hire between such points along streets or highways as may be directed by the passenger or passengers so being transported." Id. (emphasis omitted). The requirements of indiscriminate acceptance of solicitation, and the structure of the contract as one where the passenger directs the destination and route, would seem to exclude carpooling, even dynamic carpooling. The San Francisco ordinance, on the other hand, sweeps more broadly and probably would capture dynamic carpooling in its scope. S.F., CAL., POLICE CODE art. 16, div. I, $\S$ 1076(a) (2000), available at http://www.sfgov.org/site/government index.asp\#codes (" $A$ 'motor vehicle for hire' is hereby defined to mean and include every type, kind and class of privately owned motor-propelled passenger-carrying vehicle for hire over which the City and County of San Francisco may exercise jurisdiction.").

44. See Kogan, supra note 17 , at 43 . Kogan reports that

etiquette rules inside the car are pretty much up to the driver. "Certain drivers will not talk," says one federal lawyer. "Others won't shut up. You are under their control; you are bumming a ride. Certain people will tell drivers to change the radio station, which I think is bold."

Id. The Department of Transportation study of Knoxville-area commuters posits a general rule: The fewer and more intimate the participants in a carpool, the less formal the arrangements for carpool behavior. See 1 DAVIS ET AL., supra note 19, at 57. But it is not entirely clear what is meant by "formal," or what the source of the formal rules is. 
arrangements, smoking prohibitions, waiting policy in case of tardinessappear largely informal: Participants follow loose norms or ad hoc decisions rather than explicitly articulated rules. ${ }^{45}$

While on its face carpooling seems to be primarily an instrumental exchange relationship, surveys show that carpoolers report a wide range of motivations for carpooling and that there is a wide variation between carpoolers and solo drivers in attitudes toward the costs and benefits of the practice. Carpoolers report reasons for carpooling both instrumental (to take advantage of HOV lanes, ${ }^{46}$ to reduce individual driving burdens,${ }^{47}$ to reduce costs of automobile use and maintenance ${ }^{48}$ ) and noninstrumental (to have company ${ }^{49}$ to be socially and environmentally responsible, to teach their children sociability ${ }^{50}$ ). A review of the existing research suggests that carpooling behavior does not vary by socioeconomic or demographic characteristics, ${ }^{51}$ but does correlate with beliefs that carpooling is good

45. See 1 DAVIS ET AL., supra note 19 , at 56 . When asked how they established rules for their carpools, study participants

indicated that they had briefly discussed [the issues] on the phone or at work before forming the pool, or when they were initially riding together. There appears to be considerable reluctance to meet formally and discuss what will and will not be appropriate in a carpool. ... When there are only two or three carpoolers, the riders 1 id. frequently indicate there are not set rules among "friends."

46. See, e.g., Joy Dahlgren, High Occupancy Vehicle Lanes: Not Always More Effective than General Purpose Lanes, 32 TRANSP. RES. (PART A: POL'Y \& PRAC.) 99, 100 (1998); Spielberg \& Shapiro, supra note 31, at 33; Lior Jacob Strahilevitz, How Changes in Property Regimes Influence Social Norms: Commodifying California's Carpool Lanes, 75 IND. L.J. 1231, 1238-40 (2000); Kogan, supra note 17.

47. See, e.g., Heath, supra note 16, at 361 ("A carpool, after all, has only one raison d'être: to drive as seldom as is necessary to get your own child to school and back every day.").

48. See 1 DAVIS ET AL., supra note 19, at 56 (reporting that surveyed carpoolers cited the price of gas and the price of parking as two of the top three reasons they carpooled); Ferguson, supra note 8, at 359 ("[F]alling real marginal fuel costs 'explain' a third of the observed decline in American carpooling between 1970 and $1990 \ldots$. ..). Consistent with the importance of cost savings, carpooling propensity appears to increase with commuting distance. See David T. Hartgen \& Kevin C. Bullard, What Has Happened to Carpooling: Trends in North Carolina, 1980 to 1990, in TRANSP. RESEARCH BD., TRANSPORTATION RESEARCH RECORD NO. 1390, at 50, 58 (1993); Teal, supra note 13, at 209. In areas where HOVs are excused from paying tolls during rush hour, see, e.g., Golden Gate Bridge: FasTrak \& Tolls, http://www.goldengatebridge.org/ fastraktolls/ (last visited Sept. 29, 2004), carpooling offers additional cost savings. See also Teal, supra note 13 , at 207-08 (finding that commuting cost burden correlates strongly with carpooling); Edward P. Weber et al., Understanding Urban Commuters: How Are Non-SOV Commuters Different from SOV Commuters?, TRANSP. Q., Spring 2000, at 105, 110-11.

49. See 1 DAVIS ET AL., supra note 19, at 56.

50. $₫ \rightarrow$ Patricia A. Adler \& Peter Adler, The Carpool: A Socializing Adjunct to the Educational Experience, 57 SOC. EDUC. 200, 208-09 (1984) (asserting that carpooling is one of the first regular contacts a child has with adults and children outside the immediate family and arguing that the carpool acts as an extremely important socializing arena for children).

51. The 2001 NHTS suggests a minor income effect: Carpooling is slightly less prevalent among households with annual income less than $\$ 20,000$ and has little if any correlation with income above $\$ 20,000$. See Pucher \& Renne, supra note 7 , at 59 tbl.8. Income, education, and gender seem to have little effect on carpooling practices. See Ferguson, supra note 8, at 363-67. 
because of all these desiderata ${ }^{52}$ and with a discount on concerns-freedom to choose your time and route, to be in peace, etc.- typical of solo drivers. ${ }^{53}$ Whether these attitudinal differences are a reason for carpooling or a coherence-seeking realignment of the carpoolers' preferences to fit their practices is not obvious. ${ }^{54}$ What matters for our purposes, however, is that people report these desiderata to be important to them and to be reasons they give to themselves as to why they carpool.

To conclude, carpooling is a deeply decentralized system, controlled by millions of individual decisions rather than by governments, market actors, or other institutional players. It is organized largely without the use of prices or bureaucratic instructions to clear seats and is usually interpreted and explicitly described by its participants as a social act, even when money does change hands to share explicit costs.

\section{B. Distributed Computing}

The phenomenon of "distributed computing" reflects an economically driven technical trend in computation, coupled with a social innovation. The first thing to understand is the idea of parallel computing. Imagine that I have a computational problem that can be solved by performing 100 mathematical operations. I could solve it in one second using a computer that could perform 100 operations in one second, or I could solve it by dividing the operations to be performed into two batches of 50 operations and running them simultaneously on two computers, each capable of performing 50 operations per second. If the cost of improving the computation speed of a single processor increases superlinearly (that is, it costs more than twice as much to build a computer capable of 100 operations per second than a computer capable of 50 operations per second), then I can achieve the same result at lower cost by lashing together two cheaper processors than I can achieve by building a faster processor.

This does not mean that carpooling is entirely divorced from economic considerations. Many commuters report that trip-cost reduction is a significant consideration, see supra note 48 , and trip and fuel cost and vehicle availability do show some correlation to commuting behavior, see Ferguson, supra note 8, at 371; Teal, supra note 13, at 207.

52. See Abraham D. Horowitz \& Jagdish N. Sheth, Ride Sharing to Work: An Attitudinal Analysis, in TRANSP. RESEARCH BD., TRANSPORTATION RESEARCH RECORD NO. 637, at 1 (1977) (concluding that only attitudinal factors - in contrast to socioeconomic and demographic factorsare significant in explaining the carpooling behavior of 822 surveyed commuters); Norbert Oppenheim, Carpooling: Problems and Potentials, 33 TRAFFIC Q. 253, 259 (1979).

53. See Horowitz \& Sheth, supra note 52, at 5 fig.5; Weber et al., supra note 48, at 110-11; see also Paul A.M. Van Lange et al., A Social Dilemma Analysis of Commuting Preferences: The Roles of Social Value Orientation and Trust, 28 J. APPLIED SOC. PSYCHOL. 796 (1998).

$54 . \rightarrow$ Dan Simon, A Third View of the Black Box: Cognitive Coherence in Legal Decision Making, 71 U. CHI. L. REV. 511 (2004). 
Parallel computing, of course, is not costless. One must break up the problem into well-designed pieces that can run simultaneously, rather than having one processor wait for the other to finish, and there is overhead in managing the information input and output flows to and from the processors, both to each other and to the system memory. The tradeoff therefore becomes slightly more complex, but is fundamentally unchanged. Parallel computing will achieve similar results to a single processor at lower cost if the total amount of overhead lost to parallelization is less than the cost differential for building the added computation capacity into one computer. This simplified explanation describes more or less why, by the end of the twentieth century, most supercomputers were made of thousands of simple processors lashed together and why parallelization became an important field of computer science.

Parallelization in supercomputing set the stage for the next step: Internet-based distributed computing. As Michael Shirts and Vijay Pande noted in 2000 , the number of processors that Internet-based distributed computing could in principle harness dwarfs the largest supercomputers. ${ }^{55}$ Supercomputers can lash together thousands of processors at a cost of tens of millions of dollars. But connected to the Internet there are millions of computers, and one can lash together hundreds of thousands of processors, rather than thousands, using their spare cycles, if one can overcome the quite substantial design difficulties involved in structuring problems so that they can efficiently be solved by very large numbers of processors with highly variable availability and orders of magnitude slower communications than those possible among processors located in arrays designed for, and dedicated to working together in, a single physical machine ${ }^{56}$ Once the problem is defined, however, it can be approached by designing new algorithms that trade off processing for communication and focusing on algorithms that restructure the description of solutions to problems so as to assume much looser constraints on the number of processors and much tighter constraints on communications than those used

55. Michael Shirts \& Vijay S. Pande, Screen Savers of the World Unite!, 290 SCIENCE 1903, $1903(2000)$.

56. The overarching ambition of connecting all the computation and storage resources connected to the network in a capacity grid is also known as "grid computing." See, e.g., Ian Foster et al., The Anatomy of the Grid: Enabling Scalable Virtual Organizations, 15 INT'L J. High PERFORMANCE COMPUTING APPLICATIONS 3 (2001); Leon Erlanger, Distributed Computing: An Introduction, EXTREMETECH, Apr. 4, 2002, http://www.extremetech.com/ article2/0,1558,11769,00.asp; Brian Hayes, Collective Wisdom, AM. SCIENTIST, Mar.-Apr. 1998, at 118, 118, available at http://www.americanscientist.org/template/AssetDetail/assetid/20836; Ian Foster, What is the Grid? A Three Point Checklist (July 20, 2002), http://wwwfp.mcs.anl.gov/ foster/Articles/WhatIsTheGrid.pdf. 
in mainstream supercomputers. ${ }^{57}$ While designing an algorithm to achieve such scaling is difficult, it is not impossible, and the organizer of a project obviously has the incentive to develop such algorithms in order to benefit from the potential to mobilize distributed computing to solve his or her problems. $^{58}$

SETI@home is the paradigmatic Internet-based distributed computing project. It harnesses idle processor cycles of about 4,500,000 users around the world. The users download a small screen saver. When the users are not using their computers, the screen saver starts up, downloads problems for calculation-in the case of SETI@home, radio astronomy signals to be analyzed for regularities as part of the search for extraterrestrial intelligence-and calculates the problems it has downloaded. Once the program calculates a solution it automatically sends its results to the main site. The cycle continues for as long as, and every time that, the screen saver is activated, indicating that the computer is idle from its user's perspective. Using this approach, SETI@home became the fastest "supercomputer" in the world, capable of performing, as of the summer of 2003, calculations at a speed sixty percent faster than the NEC Earth Simulator, formally the fastest supercomputer in the world, four times as fast as the next fastest supercomputer, and seven times faster than the following three fastest supercomputers, ${ }^{59}$ including the fastest

57. See, e.g., Michael R. Shirts \& Vijay S. Pande, Mathematical Analysis of Coupled Parallel Simulations, 86 PHYSICAL REV. LETTERS 4983 (2001) (explaining how to use a statistical algorithm to scale the speed of protein folding deducible from a computer simulation linearly with the number of processors added); Stefan M. Larson et al., Folding@Home and Genome@,Home: Using Distributed Computing To Tackle Previously Intractable Problems in Computational Biology, http://folding.stanford.edu/papers/Horizon_Review.pdf (last visited Sept. 29, 2004); see also D. Latorenza, Grid Programming: Some Indications Where We Are Heading, 28 PARALLEL. COMPUTING 1733 (2002) (reviewing contemporary understanding of the design challenges posed by such heterogenous and distributed computing systems).

58. The primary oddity from a rational choice perspective is that scientists would not develop the algorithm unless they thought that users would contribute their processing cycles should the algorithm be developed. In theory, given that there is no easy story to tell about why contributors would volunteer their excess capacity, scientists should not develop these algorithms. Note, however, that there is nothing irrational about the scientists' beliefs that led them to design these systems. It is perfectly coherent for an agent to have a belief that others are like the agent and to hold the belief that conditional upon the agent's behaving in a trusting reciprocal way, others will behave similarly. Given that the scientists who develop these algorithms have no need to believe that any particular individual agent will cooperate, but only that there is some set of others who would behave as the scientist would and cooperate, building the project is not only permissible for a rational agent but represents a high likelihood of finding cooperators.

59. SETI@home statistics showed a speed of over 54 teraflops per second. The more traditional supercomputers, which consist of computation clusters from processors under the ownership or control of a single firm or organization, achieved 35.9 teraflops (NEC Earth Simulator), 13.9 teraflops (HP ASCI-Q at Los Alamos National Laboratories), 7.6 teraflops (Linux Network), and 7.3 teraflops (IBM ASCI at Lawrence Livermore Laboratories). See Top 500 Supercomputer Sites, Top 500 List for June 2003, http://www.top500.org/list/2003/06 (last visited Sept. 29, 2004). These numbers and relationships offer, of necessity, a snapshot. As this 
supercomputer that IBM had built at that point. ${ }^{60}$ The simple fact of the existence and success of SETI@home and similar projects, coupled with the fact that only a tiny fraction of the world's processors participate in similar projects, ${ }^{61}$ suggests that there is, and will continue to be in the foreseeable future, a significant amount of idle computation resources extant in the world. ${ }^{62}$

Another of the largest and best known distributed computing projects is Folding@home, a site run out of Stanford University and dedicated to simulating protein folding. As of late November 2003, a snapshot of its usage statistics reveals that it had amassed contributions of over 572,000 processors, of which about twenty percent were active at a given moment, contributed by 272,000 users, some of whom were self-organized into over 28,000 teams. ${ }^{63}$ The contributions were concentrated largely in the United States and Western Europe. ${ }^{64}$

SETI@home and Folding@home provide a good basis for describing the fairly common characteristics of such projects. First, these are noncommercial projects, engaged in pursuits understood widely as scientific, for the general good, seeking to harness contributions of individuals who wish to contribute to such larger-than-themselves goals. Like SETI@home, projects like Folding@home, Fightaids@home (a Scripps Institute project that uses computational biology to screen candidate drugs for treating HIV based on their shape and chemical characteristics; candidates so identified can then be further tested in laboratories), and

Essay was going to press, IBM announced that it had just surpassed the NEC Earth Simulator by a nose, delivering a 36-teraflops-per-second computer. John Markoff, I.B.M. Supercomputer Sets World Record for Speed, N.Y. TIMES, Sept. 29, 2004, at C4. At that point, SETI@home was averaging between 64 and 69 teraflops per second. See SETI@home, Current Total Statistics, http://setiathome.ssl.berkeley.edu/totals.html (last visited Sept. 29, 2004).

60. See supra note 59. Compare the resulis at Top 500 Supercomputer Sites, supra note 59, with the 54 teraflops per second calculated by SETI@home when this Essay was drafted in late 2003.

61. There is no hard technological block to, for example, using microwave ovens for computation on this model. It is more a question of connectivity and engineering. But as we move to a more highly interconnected environment of pervasive computing, the number of connected computers per person in the industrialized world will be very large. Many of these almost never require their computation capacity. The embedded computer of a microwave oven, for example, has spare capacity whenever the oven is not being used. Assuming an average twenty minutes a day of actual cooking, that is likely around ninety-eight percent of the time.

62. The developers of SETI@home are now also providing the development and deployment of a platform for a potentially next-generation improvement-a cross-project common platform called BOINC, the Berkeley Open Infrastructure for Network Computing, that will allow many projects and many users to be matched dynamically as needs and capacities change rather than having every user dedicate his or her computer to helping one project or another and downloading project-specific software for each project.

63. For daily statistics, see Folding@home, Folding@home Stats, http://folding.stanford.edu/ stats.html (last visited Sept. 29, 2004).

64. See Folding@home, Folding@home Maps, http://www.stanford.edu/group/pandegroup/ folding/maps.html (last visited Sept. 29, 2004). 
Genome@home (a Stanford-based project dedicated to modeling new artificial genes that can create artificial proteins) appeal to broad otherregarding concerns. Other sites, like those dedicated to cryptography or math, have a narrower appeal, but are also "altruistic," or perhaps hobbyist, in their basic motivational appeal. The absence of money is, in any event, typical of the large majority of active distributed computing projects. ${ }^{65}$ Fewer than one-fifth of these projects mention money at all. Most of those that do mention money refer to a share of a generally available prize for solving a scientific or mathematical challenge and mix an appeal to hobby and altruism with the promise of money. Only two of almost sixty projects active in November 2003 were built on a pay-per-contribution basis. ${ }^{66}$

In the SETI@home internal survey, ${ }^{67}$ the project found that users respond to the question, "What is your main reason for running SETI@home?" with a strong emphasis on "good of humanity" (58\%) or "keep my computer productive" (17\%). A little more than $5 \%$ of answers suggested a search for fame or explicit recognition, like getting one's name on the site's top-hundred list. While far from scientific, the SETI survey offers some texture as to the motivational self-descriptions of participants, albeit within a choreographed questionnaire, and certainly reflects the assumptions of those running the site about the kind of motivations for which they design their sites. Similarly, the stated design assumptions of the organizers of Folding@home and Genome@home reflect a belief that users contribute their cycles because they are motivated by lay interest in the projects, a desire not to waste computing resources, or an amateur interest in either computers or the science involved. ${ }^{68}$

65. The aggregate descriptions are based on observations made in November 2003 of fiftyseven projects linked to a site dedicated to collecting links to all distributed processing projects. See Internet-Based Distributed Computing Projects, http://www.aspenleaf.com/distributed/distribprojects.html (last visited Sept. 29, 2004).

66. These sites, Gómez Performance Networks, whose front end is http://www.gomez.com/ and whose peer-network back end is https://www.peer.gomez.com/index.aspx, and Capacity Calibration Network, http://agent.capcal.com/agentfaq.asp, differ functionally from distributed computing projects. The service they offer is running network traffic analysis by placing queries from topologically diverse locations. They require their users' topological diversity, not their processing power. Therefore, not all PCs are equal in their eyes. The specificity of the requirements, which generates the need to reject many putative contributors, likely contributes to the difficulty of attracting volunteers, in addition to the divergent social meanings of calls to "help organizations solve their business problems" as compared to "help fight AIDS." Money then steps in as a reasonably well-understood motivational source for a project ill suited to mobilize contributors socially. Because neither project is trying to aggregate as many users as possible, or crunch as many numbers as possible, overall "success" of these projects is not qualitatively comparable to SETI@home or similar projects.

67. SETI@home, SETI@home Poll Results, http://setiathome.ssl.berkeley.edu/polls.html (last visited Sept. 29, 2004).

68. Larson et al., supra note 57, at 6 . They do not explain how lay interest is different than amateur interest, but one suspects that these stand in for different levels of engagement and hobbyist enthusiasm. 
The assumptions about the motivations of contributors are translated into both the client interface design and the websites supporting the project. Interfaces are explicitly designed to provide participants with feedback about their own contributions, information about the scientific context and output of their contributions, and a platform for both competitive and mutually supportive social interaction. The SETI client shows users how their own processing component is going, as well as offering a graphic representation of the data processed, which is aesthetically pleasing but relatively opaque as an explanation of the science or the results. Folding@home offers a visualization of the actual calculation performed on the computer as a screen saver, providing an intuitive, if still analytically opaque, visualization of the work done.

Climateprediction.net, a project focused on simulating climate change, takes a different approach. Each user downloads a complete simulation, so that the world simulated on his or her computer is a complete single model of what happens if $\mathrm{CO}_{2}$ levels double from pre-industrial levels while a variety of other parameters are tweaked. The screen saver allows participants to see how the world they are simulating changes. The site offers people the ability to compare "their" world to those of others and to a baseline simulation, providing greater opportunity for individual participation in reading the results.

Most of the distributed computing projects provide, on the server side, a series of utilities and statistics intended to allow contributors to attach meaning to their contributions in a variety of ways. The projects appear to be eclectic in their implicit social and psychological theories of the motivations for sharing. Sites describe the scientific purpose of the models and the specific scientific output, including posting articles that have used the calculations. ${ }^{69}$ In these components, the project organizers seem to assume some degree of taste for generalized altruism and the pursuit of

69. See, e.g., Laurence Loewe, Evolution@home: Experiences with Work Units That Span More than 7 Orders of Magnitude in Computational Complexity (May 2124, 2002), http://www.evolutionary-research.org/Science/Papers/2002/Loewe2002-EaHworkunits.pdf; Climateprediction.net, Climate Science Explained, http:/www.climateprediction.net/science/ index.php (last visited Sept. 29, 2004); Climateprediction.net, Publications Related to Climateprediction.net, http://www.climateprediction.net/science/publications.php (last visited Sept. 29, 2004); Eon, A Brief Scientific Overview, http://eon.chem.washington.edu/brief.php (last visited Sept. 29, 2004); Eon, Related Articles, http://eon.chem.washington.edu/papers.php (last visited Sept. 29, 2004); Evolution@home, Scientific Background of the Simulator-Models, http:/www.evolutionary-research.org/Science/index.html (last visited Sept. 29, 2004); Folding@home, Recent Research Papers, http://www.stanford.edu/group/pandegroup/folding/ papers.html (last visited Sept. 29, 2004); Folding@home, Scientific Background, http://www.stanford.edu/group/pandegroup/folding/science.html (last visited Sept. 29, 2004); Genome@home, http://www.stanford.edu/group/pandegroup/genome/ (multiple links under "Scientific Background") (last visited Sept. 29, 2004); SETI@home, Current Progress Summary, http://setiathome.berkeley.edu/process_page/ (last visited Sept. 29, 2004). 
meaning in contributing to a common goal. They also implement a variety of mechanisms to reinforce the sense of purpose, so there are aggregate statistics about total computations performed. ${ }^{70}$ But the sites also seem to assume a healthy dose of agonistic giving, as well. For example, most of the sites allow individuals to track their own contributions, to see their effect accumulating, but some also provide "user of the month" type rankings, noting who contributed the most cycles and similar statistics. ${ }^{71}$

An interesting characteristic of quite a few of these projects is the ability to create "teams" of users, who in turn compete to see who has provided more cycles or work units. SETI@home in particular taps into ready-made nationalisms by offering country-level statistics. ${ }^{72}$ Some of the team names on Folding@home also suggest other out-of-project bonding measures, such as national or ethnic bonds (Overclockers Australia or Alliance Francophone), technical minority status (Linux or MacAddict4Life), organizational affiliation (the University of Tennessee or the University of Alabama), and shared cultural reference points (The Knights Who Say Ni!). ${ }^{73}$ In addition, the sites offer platforms for simple connectedness and mutual companionship by offering user forums to discuss the science and the social participation involved. ${ }^{74}$

It is possible that these sites are shooting in the dark as far as motivating sharing is concerned, but it is also possible that they have tapped into a valuable insight, which is that people behave for all sorts of different reasons, including all sorts of different reasons to act generously, and that at least in this domain adding reasons to participate-some agonistic, some altruistic, some reciprocity seeking-does not have a crowding-out effect.

70. See, e.g., Climateprediction.net, Climateprediction.net Overall Stats, http://cpdn.comlab. ox.ac.uk/user/totstats.php (last visited Sept. 29, 2004); Evolution@home, High Scores of the Evolutionary-Research Supercomputing Adventure, http:/www.evolutionary-research.org/ Scores/index.html (last visited Sept. 29, 2004); Folding@home, supra note 63; SETI@home, supra note 59.

71. See, e.g., Eon, Current Eon Statistics, http://eon.chem.washington.edu/groups/ stats_main.php (last visited Sept. 29, 2004); Evolution@home, supra note 70; Folding@home, Donor Statistics, http://vspx27.stanford.edu/cgi-bin/main.py?qtype=userstats (last visited Sept. 29, 2004); SETI@home, Top Users, http://setiathome.berkeley.edu/stats/users.html (last visited Sept. 29, 2004).

72. SETI@home, Countries, http://setiathome.berkeley.edu/stats/countries.html (last visited Sept. 29, 2004).

73. Folding@home, Team Statistics, http://vspx27.stanford.edu/cgi-bin/main.py?qtype= teamstats (last visited Sept. 29, 2004).

74. See, e.g., Climateprediction.net, Interactive User Area, http://www.climateprediction.net/ user/index.php (last visited Sept. 29, 2004); Folding@home, Folding-community.org, http://forum.folding-community.org/homepage.php (last visited Sept. 29, 2004); SETI@home, Other Message Boards and Chat Rooms, http://setiathome.ssl.berkeley.edu/other_bbs.html (last visited Sept. 29, 2004). 
Further research on the presence and pattern of crowding out between different sharing patterns would be useful in the design of such projects. ${ }^{75}$

\section{LUMPINESS, GRANULARITY, AND SHAREABLE GOODS}

These case studies are intended to motivate the analysis. They show us that there are large-scale sharing phenomena in the world that successfully provision material desiderata through social sharing practices. These practices involve the sharing of private goods-automobiles and personal computers-as inputs. They involve rival outputs-seats in cars going from point $a$ to point $b$, or computer processor cycles devoted to problem $a$ rather than to problem $b$. They exist alongside market mechanisms for delivering substitutable functionality. And they work well; in some cases, better than market mechanisms. This Part and the next will seek to answer, within the framework of economics, why this happens, why it is sustainable, and when it is efficient. This Part is dedicated to describing a class of characteristics that, in combination, define a situation where it is likely that individuals will overinvest in capacity-generating goods, like PCs and automobiles, that will then have excess capacity, widely distributed in small quanta among large numbers of individuals in a society. The next Part will explain why this excess capacity may better be distributed by social sharing than by secondary markets (or administrative allocation). While the goods I call here "shareable goods" could be understood as a subclass of "club goods" "76 or "common pool resources," 77 the additional specification more precisely

75. On crowding out between money and nonmonetary rewards, see infra Section III.B.

76. See MANCUR OlSON, The LOGIC OF COlleCtive ACTION (1965); Berglas, supra note 15, at 116-21; James M. Buchanan, An Economic Theory of Clubs, 32 ECONOMICA 1, 1-14 (1965). A description of the current state of the theory is available in RICHARD CORNES \& TODD SANDLER, THE THEORY OF EXTERNALITIES, PUBLIC GOODS, AND Club GoOdS (2d ed. 1996).

77. An early and broad claim in the name of commons in resources for communication and transportation, as well as human community building-like roads, canals, or social gathering places- $\rightarrow$ Carol Rose, The Comedy of the Commons: Custom, Commerce, and Inherently Public Property, 53 U. CHI. L. REV. 711 (1986). Rose's observations on commons in waterways and highways had far more radical implications in the long term than the direction that the bulk of the literature took over the course of the 1990s, because she focused on cases where commons superseded areas that had previously been private property-like turnpikes or private property over which public paths were later recognized. As such, it suggested that there were areas where commons were strictly superior to private property; that these commons existed at the very heart of our commercial system; and that many of the most important of these commons, like the highways and waterways, were not limited common property regimes but were in fact open for anyone to use under very general usage rules. Condensing around the work of Elinor Ostrom, a different, narrower and less threatening literature developed over the course of the 1990s. It was concerned with showing that there were places where nonproperty regimes, or more accurately, common property regimes, were sustainable and stable over long periods of time. This line of literature was less threatening than Rose's original claims because it inverted all three radical implications of her claims. Common property regimes were shown to be stable, not claimed to be more efficient. They were studied on the peripheries of the main economies, and could be 
isolates individually owned goods that have excess capacity and are available for sharing.

The basic intuition is simple. There are goods that are "lumpy," by which I mean that given a state of technology, they can only be provisioned in certain discrete bundles that offer discontinuous amounts of functionality or capacity. In order to have any computation, for example, a consumer must buy a computer processor, which in turn only comes in certain speeds or capacities. Lumpy goods can, in turn, be fine, mid-, or large grained. A large-grained good is one that is so expensive that it can only be used by aggregating demand for it. Industrial capital equipment, like steam engines, is of this type. Fine-grained goods are of a granularity that allows consumers to buy precisely as much of the goods as has the amount of capacity they require, such as a donut or a cup of coffee. Mid-grained goods are small enough for an individual to justify buying for her own use, given their price and her willingness and ability to pay for the functionality she plans to use. If enough individuals in society buy and use such mid-grained lumpy goods, that society will have a large amount of excess capacity "out there," in the hands of individuals. The problem of how to harness that excess capacity and use it to provision the requirements of others is the problem that Part III deals with. If you are comfortable with this simple intuitive explanation of what mid-grained lumpy goods are and why they would generate excess capacity, you may wish to skip most of the remainder of this Part and go directly to its conclusion in Section D. What follows here is a more or less careful working out of lumpiness and granularity, and the conditions under which we should expect there to be substantial excess capacity in the hands of individual owners of goods that makes large-scale sharing practices feasible.

understood as stable holdovers, rather than as strictly more efficient alternatives that superseded preexisting private property regimes. And they were, in fact, a property regime, except that the outer boundary of the property included many participants, among whom proprietary interests were divided through governance mechanisms rather than through property and contract. The condensation point of this literature was ELINOR OSTROM, GOVERNING THE COMMONS: THE EVOLUTION OF INSTITUTIONS FOR COLLECTIVE ACTION (1992); another seminal study was JAMES M. ACHESON, THE LOBSTER GANGS OF MAINE (1988). A brief intellectual history of the study of common resource pools and common property regimes can be found in Charlotte Hess \& Elinor Ostrom, Artifacts, Facilities, and Content: Information as a Common-Pool Resource (Nov. 9-11, 2001), available at http://www.law.duke.edu/pd/papers/ostromhes.pdf. 
A few assumptions and terms run throughout this Part. ${ }^{78}$ Resources or goods have a usable lifetime-which can be of any length-once put in service. Owning a resource is not intrinsically utility generating. Use of the resource over its lifetime is what generates value to the agent. The welfareproducing use that a resource enables is its "functionality." Agents value a resource or good at the utility that use of its functionality is expected to generate over the lifetime of the resource. The degree to which the functionality of a resource can be used is its "capacity." A good has a lifetime capacity, which is the total amount of functionality it can deliver over its usable life. This may or may not be separate from, and greater than, the good's usable capacity, which is the capacity it can deliver within the time frame necessary for use of the functionality to generate the welfare sought by users. Capacity is technologically given. People purchase, make, or otherwise invest in putting into operation units of goods or resources that are not themselves the utility sought, but rather are resource packages that have the capacity to produce functionalities. I begin with two special cases that are easily grasped and then generalize.

\section{A. Renewable Resources}

Renewable resources are resources that can deliver their functionality within a given time frame and are then capable of delivering that functionality again at a later time. A perfectly renewable good is capable of delivering exactly the same amount of functionality over time, irrespective of whether its functionality was used in full at a prior moment in time. Its expected lifetime is unaffected by use. An imperfectly renewable good either delivers some, but not all, of the amount of its functionality with each successive use, or loses expected lifetime with each use. A nonrenewable good is one that can deliver its functionality only once.

"Spectrum" is a perfectly renewable good. Dining tables, computer processors, and automobiles are slightly less perfectly renewable, but still almost perfectly renewable. Rubber bands, soccer balls, and lithium ion batteries are imperfectly renewable. Apples and matches are strictly nonrenewable. Renewability is equivalent to nonrivalry along the time dimension. A perfectly renewable good is like a nonrival good as among all

78. Part of the reason for the fairly elementary definitions of these terms is that the piece is intended to be readable across disciplines. For economists, "functionality" and "capacity" should be treated as interchangeable words. Shareable goods can be thought of as capital goods with a certain capacity. "Granularity" describes a certain coarseness of partitioning of these goods. "Midgrained" shareable goods describe a technologically determined package size that results in a market in which the goods are sold as consumption goods bundled with capital goods of some capacity. 
and only those uses that can be timed to occur asynchronically without loss of value. Perfectly renewable goods are, in this sense, impure public goods, where the limitation on their use by marginal users is their requirement that time pass before they can deliver additional units of desired functionality. ${ }^{79}$

An individual will decide whether to put a unit of a good into service by comparing the value of its functionality over time, discounted, to its price. Imagine a good that expires after a year in service, irrespective of how it is used. The individual plans to use the functionality once a week, for an hour, a use that the individual values at $v$ and which the individual cannot replicate except by owning a unit of the good. The individual will be willing to pay up to $52 v$ for a unit of the good (ignoring discount). Where, as in this case, an individual's demand for functionality is variable over time and the functionality can be delivered by a renewable good, the individual has an overcapacity to deliver the functionality. This overcapacity is precisely the extent of the divergence between the time necessary for renewal of the good's capacity to provide the functionality and the time lapse between instances where the individual demands the capacity. In the example, assuming the good is perfectly and immediately renewable, the individual owns an overcapacity of $8684 \mathrm{v}$, reflecting the availability of the unit to be used by someone other than the owner for 24 hours a day for six days, 23 hours the seventh day, for 52 weeks, which is the life of the unit (assuming for simplicity that others value the use as much as the individual).

Intuitively, take a renewable resource like a lithium ion battery. Sometimes, the owner of a camcorder or camera will need more power than a full battery can offer, and will need it again as soon as it has recharged. In that setting, the good provides less functionality than desired by its owner, because the time for its renewal is greater than the time demanded for additional capacity. The degree to which this will be common, the lost utility from not having power, and the price of a second battery relative to the owner's budget will determine whether the owner will put a second, backup unit in service. Sometimes, the owner will be able to let the battery lie in the device for weeks, not needing power at all because of a lack of opportunities to shoot videos or photos. During that period, the battery has excess capacity: If held by another, it could have delivered its power, and been renewed, before its owner required it again-multiple times. With batteries, our experience may resist this example because we know that they

79. Another way of thinking about them is that they are club goods with a zero maintenance cost, as to which congestion is measured as the likely divergence, for a reference agent, between the desired time for delivery of the functionality and the actual time at which functionality is available given the sequencing or queuing algorithm used to synchronize use of the resource. 
are not infinitely rechargeable. With computer processing cycles, that is less the case.

\section{B. Rapidly Decaying Resources}

A resource is rapidly decaying when the rate at which it decays is greater than the rate at which one user can consume its capacity. Once a user decides that the capacity he can in fact extract before the good decays is high enough to justify putting a unit into operation, the functionality is overprovisioned as to that individual, and excess capacity is created for the short lifetime of the resource. Unless that capacity is used by others-who may borrow or buy it-it will be wasted. ${ }^{80}$

A single trip in a car (unlike the car itself, which is highly, but not perfectly, renewable) is a rapidly decaying good. Once the owner of a car decides to travel from home to work, the good "four seats going from $A$ to $B$ on Tuesday morning" has been created and will last only for the length of the trip. Carpooling is in this instance a practice of sharing a rapidly decaying good. (In this, carpooling is different from lending a car to a friend for the weekend or for a trip to the grocery shop, which uses the car's renewability, not the rapidly decaying character of a trip the owner is about to undertake.) This category likely covers the observations of some behavioral ecologists, who claim that sharing is particularly common in large-package foods-for example, the observation that in the same community, hunters will share widely the meat from a large sea turtle, but will net no more of finer-grained foods, like small lagoon fish, than they need within the household, and then will not share the fish in the broader community that would normally share in the turtles. ${ }^{81}$

80. Interestingly, Locke bases his praise for money precisely in terms of its capacity to store the value of a rapidly decaying good in the sense described, thereby giving the provisioning agent the value of his labor, while avoiding the predicament that a laborer takes from the common and then wastes what he took. JOHN LOCKE, The Second Treatise of Government, in TwO TREATISES OF Government 265, 292-96, 299-302 (Peter Laslett ed., Cambridge Univ. Press 1988) (1690).

81. See Rebecca L. Bliege Bird \& Douglas W. Bird, Delayed Reciprocity and Tolerated Theft: The Behavioral Ecology of Food-Sharing Strategies, 38 CURRENT ANTHROPOLOGY 49, 49 78 (1997). While the fact may explain the origins of the sharing practices, it does not explain their continued persistence, given that "most households either owned or had access to at least one freezer." Id. at 62. It is important to note also that the bulk of anthropological study of sharing practices is not limited to goods with these characteristics, and may relate to abundant goods, as in the case of potlatch societies, as well as to scarce and unique goods that do not rapidly decay and are not "shareable" in the sense I describe here, like the objects of kula rings. For one of the most important recent contributions to this literature, as well as an intellectual map of its origins, see GODELIER, supra note 6. 


\section{Lumpiness in General}

The two special cases of renewable resources and rapidly decaying resources can be generalized to describe "lumpy" resources of mid-grained granularity. A lumpy resource is one that delivers utility in discrete packages, rather than continuously. Physically, any resource is "lumpy," including rice or even water (at the molecular level). So "lumpiness" is intended as a concept in economics, not physics. It describes a relationship between technically attainable package size and extant demand by agents. It refers to a divergence between the package size (of each unit or of any costeffective aggregation of units) and the extant demand of individual agents for the functionality produced by the good. One might therefore think of the "lumpiness" of a resource as reflecting the capacity of a single unit of a resource to provide its functionality and the probability that that amount of utility or functionality supplied by any physically obtainable number of discrete units of the resource in a time frame will diverge from the amount of functionality demanded by an agent in that time frame.

An agent will invest in owning a unit ${ }^{82}$ of a lumpy resource if the utility the agent achieves over the lifetime of the resource is greater than the price of the unit for its lifetime. The fact that a resource can produce more utility over its lifetime than the agent needs over that lifetime is irrelevant to his decision whether to invest in a unit or not. That decision is made purely by comparing the value over lifetime, expressed as the capacity to produce a functionality flow, with the cost of a unit (bracketing, for now, the possibility of a secondary market or sharing system).

In order to give lumpiness some persistence, both supply and demand of the functionality must be in discrete units. If we were to define the agent's demand as capable of fulfillment incrementally, for example, so that by provisioning a unit of a resource that offers ninety percent of what the agent requires she could fulfill ninety percent of her demand, the analysis would collapse back into smooth demand and supply curves. The assumption must be, then, that, like functionality supply, demand comes in discrete units. Fulfillment of ninety percent of the requirement is no fulfillment at all. Intuitively, an automobile without a gas tank or missing a wheel cannot get one to work, even if the rest of the car is there. Agents,

82. For simplicity of exposition, I will treat a collection of small but discrete units that cannot be aggregated into precisely the amount of functionality desired as a single lumpy unit that delivers functionality in an excess amount equal to the divergence caused by the last incremental unit. This does not change the analysis, but simply obviates the need to talk about units that are small grained but still lumpy in the sense that no combination of obtainable units will deliver precisely the amount of functionality desired. 
then, will not provision units capable of providing less than some threshold of demanded functionality.

The discrete unit of demand, however, remains the single agent. It is possible for agents to aggregate their demand in order to co-provision a very large-grained lumpy good, that is, one whose functionality is multiple times greater than the requirements of any agent, so that it can serve the demand of multiple agents. The obvious example of this is where the labor market provisions the power of a steam engine or other large machine to a number of workers on an assembly line, or where farmers' cooperatives provision harvesters. But I am concerned here with finer-grained goods that do not require aggregating the demand of multiple agents to provision a single unit.

Because demand is discrete, units that underproduce functionality below some required threshold (automobiles without wheels or gas tanks) will not be provisioned. Units that will be put into operation are therefore a subset of those that are lumpy in the general sense defined earlier. That subset consists of those units whose capacity equals or exceeds the threshold functionality demanded by the agent who put them into service, in that time frame. The total social capacity for provisioning the functionality in a given time frame will be the sum of capacity capable of being provisioned by all units of the resource put into operation in that time frame by the agents who have provisioned units. The excess capacity of the units in operation at a given time relative to the requirements of their owners is the "slack" of this resource set. Note that "slack" here refers not to the claim that there will necessarily be overcapacity at an aggregate social level, but rather that there will be some capacity that would be unused if only the owners of units used the capacity generated by the units they owned. Recall that we assume for now no transfers of excess capacity. The amount of excess capacity will be the sum of all capacity of units in operation at a given time, less the amount required by all owners of units in that time frame discounted for each owner by the probability that the unit she placed in operation will produce either exactly as much capacity as she will require or less (in which case the owner of the unit would capture all the capacity produced by the unit she owns).

If units have a technically predefined capacity and agents have variable demand for the functionality, then the larger the number of agents who put units into operation, the higher the probability that some of the agents will own resources that have slack as to their needs and the higher the probability that the universe of agents who own units will have excess capacity among them. The probability that each agent requires exactly as much capacity as his or her unit can supply in the relevant time frame becomes very small as the number of agents who own units increases. 
Because of lumpiness, then, the total set of resources or goods that have these characteristics will usually exhibit slack capacity. This slack will exist unless the excess capacity is somehow transferred to fulfill the demand of nonowners. Because of the relationship of the increase in the likely available slack to the number of unit owners in society, the extent to which a good will be mid-grained and shareable in the sense I describe here, rather than large grained, like a steam turbine, will depend on the extant wealth in a society and its distribution-that is, how many people are able, as well as willing, to pay its price. A PC is a shareable good in North America and Europe, but may be a large-grained capital good in an Indian or Brazilian village.

The intuitive response, at least for economists, to such endemic "overcapacity" of functionality is to create a secondary market in excess capacity. For large-grained lumpy goods, like steam engines or hotels, this could take the form of a labor market or a hotel room market, respectively, where the excess capacity (from the perspective of an individual agent) is not excess capacity at all, because the demand is aggregated so as to match it to the capacity and smooth out the lumpiness. For mid-grained goods, the answer would be a secondary market in capacity so as, once again, to smooth out the lumpiness by aggregating and disaggregating demand, thus reducing the incongruence between functionality provisioned and functionality demanded on a per-unit and per-owner basis. Yard sales and eBay are the relevant intuitive examples of such secondary markets. Part III will consider the reasons why we might nonetheless see the sharing systems that we in fact observe.

Before I outline the comparative advantages of secondary markets and sharing systems, however, we must consider the dynamic effect of any system that transfers excess capacity from owners to nonowners. The more efficient the sharing or secondary market for excess capacity is, the less of an impetus there will be for marginal users to put new units of the goods into service, because they will be able to acquire functionality from the secondary market or sharing system. As fewer new units come on the market and older units are retired, total social capacity declines. When this happens, the difference between the ready availability of capacity from owning a unit and the constrained availability of capacity from the excess capacity market or sharing system will grow. The increasing difference between owning a unit and acquiring someone else's excess capacity will, in turn, increase the attractiveness of putting an additional unit into service for the marginal user, thereby also increasing the amount of excess capacity available.

If there were a perfect secondary market in capacity, the deadweight loss created by the overcapacity would be eliminated. Enough units that 
would generate enough capacity to satisfy demand for the functionality would be purchased, but no more, and their excess capacity would be reallocated to individuals who valued some functionality, but not enough to purchase an additional unit. Consider the following simple numerical example. Imagine that the marginal cost of a unit is the equivalent of the value of a degree of functionality designated as $4 f$, but that because of the technical lumpiness, each unit generates a functionality flow of $6 f$. Imagine further that the demand for the functionality in society is as follows: Five individuals demand a functionality flow of $5 f$, five demand $4 f$, five demand $3 f$, and five demand $2 f$. Total social demand for the functionality would be $70 f$. If there were no secondary market or sharing system, total social demand for capacity-generating units would be 10 units (demanded by the ten individuals whose demand equals or exceeds the cost of a unit, $4 f$ ). Total social supply of functionality from these units would be $60 f$, but only $45 f$ would be consumed by unit owners, and $15 f$ would be wasted, while individuals who demand $25 f$ would remain unserved. With a perfect secondary market, 12 units would be put into operation, generating a total social capacity of $72 f$, and all users who value functionality would be served, with the total social capacity exceeding demand by $2 f$. Now, imagine that technology was such that each unit generated functionality of $10 f$. Some of those who bought units under the first assumption would refrain from doing so, acquiring units instead from the secondary market, and only 7 units would be put in operation. The basic point is obvious. Even if units are lumpy, if functionality can be transferred costlessly and perfectly from unit owners to nonowners, there will be no overcapacity.

Markets, however, are not perfect. Neither is social exchange. In Part III, I describe in detail how transaction costs in general and information shortfalls in particular can be integrated into the analysis. The overarching intuition is this: Secondary markets and social sharing systems are alternative transactional frameworks for transferring the excess capacity of units that are in service at a given time. They differ in the transaction costs associated with their use, and in particular they differ in the quality of information they generate. Which one more efficiently passes through its excess capacity to nonowners will determine which will be more efficient as a system for managing resources that have these technological characteristics.

\section{Shareable Goods: Conclusion}

Goods that meet the focused definitions I offer for shareable goods are not rare phenomena in our daily lives. Automobiles come with standard 
packages of seats, and PCs come with processors and storage disks well beyond what most users will require. There are many other such goods. Books (rather than their content) are an excellent example. In order to read a book one can borrow it from a library or buy it. Once purchased, the book has much more capacity to deliver its primary functionalitycommunicating its content-than a single nonobsessive individual can consume. This overcapacity is the source of the secondhand book market (market provisioning), the public library (state provisioning), and the widespread practice of lending books to friends (social provisioning). Houses and apartments are a ubiquitous, though muted, instance of shareable goods. ${ }^{83}$ Rooms are sometimes disposed of through markets, as in the case of bed and breakfasts, and sometimes through social exchange systems, as when guests come to stay overnight or are invited to use one's bathroom (itself a nested shareable good). The complex systems of market and social provisioning of renewable tissue like blood and sperm, or rapidly decaying overprovisioned tissue like ova, can also be understood in terms of these forms of tissue having the characteristics of shareable goods, capable of being provisioned and exchanged either through markets or through social systems. Finally, toys are shareable goods, and provide the first and central mode of cultural transmission of the values of sharing the excess capacities of one's possessions. Anyone who sits in a New York City playground can only marvel at the paradoxical phenomenon of Wall Street traders admonishing their children to "share nicely," and will appreciate our deep cultural commitment to sharing some of our private, rival possessions as a mode of social provisioning.

\section{SHARING AND MARKETS: TRANSACTION COSTS AND MOTIVATIONS}

Market-based systems ${ }^{84}$ (both the price system and firms), the state, and social relations provide different transactional frameworks through

83. See Robert C. Ellickson, The Household: The Law, Economics, and Sociology of an Underexamined Institution (Sept. 16, 2003), available at http://www.people.hbs.edu/gbaker/oes/ papers/Household_Harv_MIT.pdf.

84. A methodological (or perhaps metaphorical) note is due. One often hears people speaking of "a market in reputation" or "a market in which people compete for esteem." It is important to recognize that such statements are metaphors. Markets as actual institutional forms are a very particular information process, generating information in a very particular form-prices. Other modalities of allowing unorganized individuals to decide on their actions without hierarchical coordination, even if they are fully distributed and atomistic in style, but that rely on other institutional forms and social practices, are not "markets," except metaphorically. The metaphor is a bad one if it leads us to ignore the fact that on any given question of institutional design, there may be different answers depending on whether we think that the most effective system would utilize prices or, for example, esteem. 
which individuals can act. ${ }^{85}$ Each has different setup costs. Each has different marginal transaction costs. Each also, independently but cumulatively, has a different reward structure. The combined effect of the motivational effects and the transaction costs of each system will determine, for any given good or use, whether it will most efficiently be provisioned through the price system, a firm, a bureaucracy, or a social sharing and exchange system. This Part sets to one side the possibility of state provisioning and focuses on comparing social relations to marketbased systems. I first work through the transaction costs analysis, then the question of motivation, and finally combine them, with a particular focus on goods that have the characteristics of contemporary computation and communications devices.

\section{A. Transaction Costs}

\section{Choosing a Transactional Framework}

An agent considering whether or not to allow others to use his or her resources must go through a decision pattern as described in Figure 1. Each decision can be understood as a cost-benefit analysis that compares each of the modalities of the use and exchange of resources-market, state, and social relations-in terms of (1) the transaction costs, under given technological and legal conditions, in the act of complete or partial exclusion and (2) the comparative opportunity costs of inclusion and exclusion. Because I am concerned here with the decisions of agents with regard to privately owned goods and resources, I will ignore state-based options for disposition, although the shape of the comparative analysis is similar. The tree illustrates that the basic decision of whether or not to transact based on a comparison of the transaction costs and the likely benefits of transacting involves not one choice between two options (transact/not transact) but a series of choices among a variety of actions, ranging from no exclusion to perfect exclusion with no transaction, and

85. Note that this tripartite typology is similar to but not the same as the tripartite description of organizations one finds in the discussion of nonprofits. See supra note 4 . The difference is that investor firms, nonprofits, and government agencies are all organizational forms of action. My focus here is more general, and applies to individual domains of action. Nonprofits of the type Henry Hansmann calls "commercial" can work through markets, such as by selling services in competition with for-profits. See Hansmann, supra note 4, at 840-41. For-profit firms can use social relations, by leveraging the social capital of their employees. See NAN LIN, SOCIAL CAPITAL: A THEORY OF SOCIAL STRUCTURE AND ACTION 19-28 $(20 \mathrm{C} \rightarrow$ James S. Coleman, Social Capital in the Creation of Human Capital, 94 AM. J. SOC. (SuPPLEMENT: ORGS. \& INSTITUTIONS) S95, S108 (1988) (describing how employers and employees in the printing industry used the social capital embedded in the Monotype Club as an employment referral service). 
including a variety of alternatives for partial exclusion. Different options for exclusion and different strategies for inclusion will entail different transaction costs.

FIGURE 1. DECISION TO EXCLUDE

Agent / resource
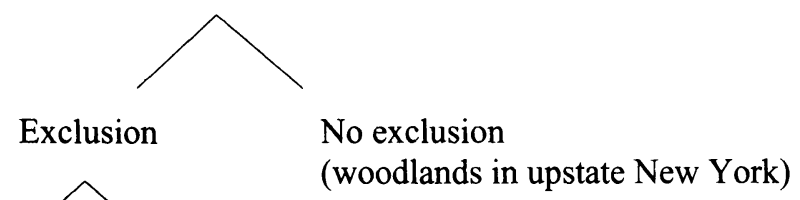

Perfect exclusion (single-occupancy vehicle commuters)

Partial exclusion

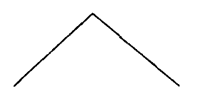

Selective

Nonselective

(first come, first served,

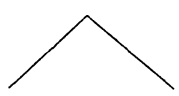

e.g., Internet routers, peerto-peer clients, bodysnatchers and slugs)

Social

(carpooling, distributed

Market computing, dinner parties)

(jitneys, priced distributed computing: any priced transaction selects among those willing and able to pay and those not willing or able)

The first choice point is between some form of exclusion and no exclusion.

No exclusion. Simply leaving the resource open to anyone's use-no fences, no guards, no contracts, etc.--is likely to be the lowest-transactioncost option. However, it is likely to be the highest-cost alternative in terms of congestion costs - opportunity costs incurred by the owner whenever her failure to exclude anyone from the good causes her not to have her unit of the good available for her own use. Congestion costs may be high or low, depending on the nature of the good and the pattern of demand for it. Privately owned woodlands in New Hampshire or upstate New York may be sufficiently abundant, use by hikers and hunters sufficiently sparse, and fencing sufficiently costly that de facto open-access policies may be most efficient for individual landowners to adopt. Otherwise, the owner will choose some form of exclusion. 
The second choice is between perfect exclusion and partial exclusion.

Perfect exclusion. Under perfect exclusion, the owner allows no one else to use his goods. The direct transaction costs of perfect exclusion are likely higher than those of no exclusion, but may be higher or lower than those of partial exclusion. Sometimes, perfect exclusion may be cheaper than partial exclusion - as when one need only build a strong fence to exclude all but must also have a guard at the gate to admit and exclude different people. Other times, however, perfect exclusion may be harder to achieve than partial exclusion, if every discrete act of exclusion requires an independent investment - as when a hunter in a hunter-gatherer society needs to fend off each new claimant to the spoils of the hunt. This latter characteristic underlies the claims of the tolerated theft model in behavioral ecology. This model suggests that sometimes hunters or foragers permit others to share in their catch, without a common social framework of sharing and gift giving and without expectation of reciprocity or the acquisition of social status. Instead, there is "tolerated theft," in the sense that others take from the good with no expectation of retaliation or of reciprocation. This occurs, within that framework of analysis, when the cost of perfect exclusion is higher than the gains from perfect exclusion. ${ }^{86}$ This descriptive phenomenon is also recognized-though not interpreted through the prism of methodological individualism-as "demand sharing" by anthropologists who study sharing practices from a cultural perspective. ${ }^{87}$ This form of sharing becomes a form of partial sharing, rather than of "open access," because the owner will not tolerate everyone, only those within a group that is sufficiently large to prevent outsiders from accessing the shared good.

Whether or not perfect exclusion is more expensive to implement than partial exclusion, it is clear that one of the costs of perfect exclusion is the opportunity cost of partial inclusion. In the case of shareable goods of the type we discuss here, which have an overcapacity relative to the individual owner's needs, the owner has an opportunity to benefit if she can get any positive utility from allowing access to the excess capacity. This is so whether the utility takes the form of economic returns in a secondary market, cost avoidance by permitting open access, social and psychological returns in social sharing arrangements, or the simple pleasure of fulfilling a taste for altruism.

86. See Bird \& Bird, supra note 81 ; N.C. Blurton Jones, A Selfish Origin for Human Food Sharing: Tolerated Theft, 5 ETHOLOGY \& SOCIOBIOLOGY 1 (1984); David Sloan Wilson, Hunting, Sharing, and Multilevel Selection: The Tolerated-Theft Model Revisited, 39 CURRENT ANTHROPOLOGY 73 (1998); Bruce Winterhalder, A Marginal Model of Tolerated Theft, 17 ETHOLOGY \& SOCIOBIOLOGY 37 (1996).

87. See Carrier, supra note 6. 
Partial exclusion. This represents a cluster of strategies that are the most interesting from our perspective. These entail permitting some set of others who are not the owner to use the resource, but nonetheless limiting the set of permitted users to some number less than anyone who wants it.

Nonselective partial exclusion. This option refers to the simplest approach to partial exclusion. Under this category, the selection criterion is unrelated to the characteristics or choices of the owner or the users permitted to use the good. Instead, the total amount shared is set by the capacity of the good, the demand of the owner-which together determine the amount of unused and available capacity-and some nonspecific selection criterion. "First come, first served" is a simple example of such a sharing algorithm. The Northern Virginia corridor practice of body snatchers and slugs is a form of nonselective partial exclusion on a firstcome-first-served basis. Similarly, the Internet Transmission Control Protocol (TCP) manages the capacity of routers on a nonselective, partial exclusion basis. This protocol calls for every router to forward all packets that arrive at it on a first-come-first-served basis and manages congestion by dropping later packets if they arrive when it is overloaded. The dropped packets cause the senders' machines to back off, slow down, and try other routes. Other, more elaborate algorithms can be defined, but will still be nonselective as long as they do not rely on characteristics that are specific to individuals who are seeking permission to use the excess capacity. That the individuals need not be determined on a case-by-case basis is likely to lower the transaction costs involved in instantiating the partial permission framework. The primary cost of nonselective partial exclusion is the opportunity cost of the gains from selective exclusion.

Selective exclusion-market selection. This is the secondary market option. The owner of the unit that produces welfare-enhancing functionality allows those who pay market prices to gain access to the functionality and excludes those who do not pay. This option is typified by the costs commonly associated with market transactions. These include defining the property and use rights, specifying the uses permitted and contracting for them, metering the functionality used, and monitoring and enforcing compliance. We have long understood transaction costs to be sufficiently nontrivial to affect the choice of how the economy organizes access to and use of resources. ${ }^{88}$

Selective exclusion-social selection. Under this option, the owner excludes many putative users of the functionality and only permits use by

88. See R.H. Coase, The Nature of the Firm, 4 EconOMICA 386 (1937); R.H. Coase, The Problem of Social Cost, 3 J.L. \& ECON. 1 (1960). This is, after all, the point for which Ronald Coase was awarded the Nobel Prize in Economics. 
those who meet the owner's social criteria. This obviously includes the lobster gangs in Maine that James Acheson described in the early common property regime literature ${ }^{89}$ and the socially selective swimming pools and golf clubs often analyzed in the club goods literature.$^{90}$ It also includes wide ranges of normal human experience: sharing the refrigerator with one's household members and invited guests but not with others, inviting an acquaintance but not a stranger to share one's usufruct in the table at the café, etc. Once one begins to define the various forms of temporary or stable proprietary-type interests we have in the things in the world around us, and to couple them with the pervasive social sharing practices we usesome of which may be purely redistributive, some reciprocal, some voluntary, some obligation based within a given set of social understandings - one sees that social sharing is ubiquitous in everyday life.

Like markets, social exchange systems entail transaction costs. These may include the definition of social norms, the definition and policing of social group boundaries-who is in and who is out-and the monitoring and enforcement of the terms of social sharing, which has been the subject of much empirical literature on the willingness of individuals to incur costs to enforce reciprocity and compliance with other social expectations. ${ }^{91}$ Just as we have pervasive, longstanding investments in enabling markets-like building and maintaining a legal system, a fiscal system, and physical marketplaces-so too do we have standing investments in social sharing, ranging from widespread cultural schooling in socially acceptable and desirable behavior (like teaching children to share their toys in the sandbox) to the gossips who shame individuals into compliance.

\section{The General Shape of Transaction-Costs-Based Choice Among Frameworks}

It is now fairly simple to outline the shape of (though not necessarily to perform) comparative transaction costs analysis of the choice among these various strategies for disposing of the excess capacity of shareable goods.

When all forms of exclusion are more costly than permitting everyone to use the resource, owners will simply allow others to use the goods or resources they own. When the costs of either permitting everyone to use the

89. See ACHESON, supra note 77.

90. See supra note 76.

91. See ERNST FEHR \& KLAUS M. SCHMIDT, THEORIES OF FAIRNESS AND RECIPROCITY: EVIDENCE AND ECONOMIC APPLICATIONS (Inst. for Empirical Research in Econ., Univ. of Zurich, Working Paper No. 75, 2001); FREY \& MEIER, supra note 2; KAHAN, supra note 2;

$\rightarrow$ Samuel Bowles \& Herbert Gintis, Social Capital and Community Governance, 112 ECON. J. F419 (2002); Ernst Fehr \& Armin Falk, Psychological Foundations of Incentives, 2002 EUR. ECON. REV. 687 (2002). 
resource or good or of sharing it are greater than the cost of simple perfect exclusion, owners will simply exclude everyone from the good. Given that "the cost" includes opportunity costs caused by congestion, and that for perfectly private-rival and nonrenewable-goods, "congestion" means loss of the full value of the good to its owner, this condition would be fulfilled for perfectly private goods that are more valuable than the cost of exclusion. This also includes the Coasean insight that where entitlements are initially inefficiently defined, but the cost of implementing selective market exclusion to find the more efficient allocation is greater than the cost, including opportunity cost, of perfect exclusion - that is, of retaining entitlements where they began-perfect exclusion will be chosen and entitlements will remain where initially assigned. But it also maps the limitation of that insight that characterizes the social norms literature. The fact that the market-based transactional framework may be too costly to transact around inefficiently delineated entitlements does not necessarily mean the same is true of social relations-based transactional frameworks. Social norms may shift around the entitlements if transacting around the entitlements through the social system is less costly than doing so through the market, in which case the inefficiency need not be solved by state or judicial intervention to reallocate the entitlements. ${ }^{92}$

When the costs, including the opportunity cost, of refusing to exclude anyone, or refusing to permit anyone to use the good, are greater than the costs of one or the other form of selective exclusion, selective exclusion will occur. When the costs of market selection are greater than the costs of social selection, social sharing will occur, and when the costs of social sharing are greater than the costs of market selection, market selection will occur. ${ }^{93}$ As Henry Smith has shown, this tradeoff and choice need not be singular for an entire resource. Different uses of the same physical resource may be subject to property-based market arrangements and commons-based social arrangements, mixed in what he called semicommons. ${ }^{94}$

Evaluating competing approaches toward harnessing the excess capacity exhibited by shareable goods requires a comparison of perfect exclusion and partial exclusion, and then of nonselective and selective (market or social) partial exclusion. That is, we should seek to answer why and when it may be more costly for people not to share at all, and then to

92. Indeed, this has been a core claim of the social norms literature for almost twenty years. See Robert C. Ellickson, Of Coase and Cattle: Dispute Resolution Among Neighbors in Shasta Couniy, 38 STAN. L. REV. 623 (1986).

93. See Henry E. Smith, Exclusion Versus Governance: Two Strategies for Delineating Property Rights, 31 J. LEGAL STUD. S453 (2002) (describing the prevalence of commons-based systems and property-based systems as a function of comparative transaction costs of each).

94. Henry E. Smith, Semicommon Property Rights and Scattering in the Open Fields, 29 J. LEGAL STUD. 131 (2000). 
answer why and when it may be more or less costly to exclude on some nonselective model, as opposed to sharing socially or participating in a secondary market for excess capacity.

First, recall that there is some subset of agents who own shareable goods who only use up part of the capacity of their goods and do not require or cannot absorb more of it. Giving that excess capacity away is costless to them, except for the transaction costs. This means that they should prefer to have their excess capacity used rather than be idle whenever there is any positive utility to them from its use, minus the cost of sharing or reselling it. If the costs of perfect exclusion are equal to the costs of partial exclusion, then the owners of shareable goods will choose to exclude only partially whenever there is any positive utility to sharing. It is trivial that if we assume that the cost of perfect exclusion is always higher than the cost of partial exclusion, whether selective or not, then the owner will permit some use of her good as long as the disutility from sharing is no greater than the difference in exclusion costs. And where the costs of partial exclusion are higher than the costs of perfect exclusion, the owner will share or resell her excess capacity when the utility from sharing or reselling will exceed the difference in cost between partial exclusion and perfect exclusion.

Second, we have fairly extensive studies of the costs of the two forms of selective exclusion. The transaction costs literature analyzes the sources and types of transaction costs. ${ }^{95}$ The cluster of literatures concerned with various nonmarket mechanisms-social trust and reciprocity, ${ }^{96}$ common property regimes, ${ }^{97}$ gift and exchange anthropology ${ }^{98}$ - offers us insight into the sources and scope of "transaction costs" associated with social selective exclusion. I assume that selective partial exclusion will always have higher information costs than nonselective partial exclusion because the former will always require more information about specific transactions in order to implement the selection criterion, whereas any nonselective

95. See, e.g., R.H. COASE, THE FIRM, THE MARKET, AND THE LAW 6 (1988) (defining the relevant costs as "'search and information costs, bargaining and decision costs, policing and enforcement costs"" (quo1 $\rightarrow$ Carl J. Dahlman, The Problem of Externality, 22 J.L. \& ECON. 141, $148(1979 \rightarrow$ Robert C. Ellickson, The Case for Coase and Against "Coaseanism," 99 YALE L.J. 611, 614-16 (1989) (offering a functional taxonomy of transaction costs, including get-together costs, decision and execution costs, and information costs). Guido Calabresi and Douglas Melamed explicitly point out that exclusion costs are a part of negotiation costs-leaving unstated but obvious that enforcing the prebargaining entitlements is crucial to defining what is to be gained and transferred in the transaction itself. Guido Calabresi \& A. Douglas Melamed, Property Rules, Liability Rules, and Inalienability: One View of the Cathedral, 85 HARV. L. REV. 1089, 1095 (1971).

96. See supra note 91.

97. See supra note 77.

98. See supra note 6. 
algorithm that can be applied mechanically will require a minimal amount of information - that a transaction is sought. Selective partial exclusion will therefore only outperform nonselective partial exclusion when the selectivity provides some positive return as compared to nonselective partial exclusion. This is trivial in the case of markets because the selection criterion is willingness and ability to pay, and payment must be more than the cost of distinguishing those willing to pay more from those willing to pay less. Similarly, in the social exclusion model, the social rewards of selectivity must exceed the added cost of selection. Bestowing a benefit on loved ones is probably the most common benefit for social selectivity, as we prefer our family and friends to strangers when we decide to whom we will lend our car or book.

Imagine a small swimming pool in a backyard. The cost of perfect exclusion is the cost of building a fence at the perimeter (given a background investment in legal enforcement of and respect for property rights). This is nontrivial but not high. This cost is higher than the direct cost of permitting free access by not putting up a fence. But given congestion costs, displacement, dirt, risk of liability, and so on, the option of open access is probably more costly than the option of perfect exclusion. The cost of partial exclusion includes (1) the cost of perfect exclusion plus (2) the cost of selective admission. It is, then, greater than the cost of perfect exclusion. Selective admission will nonetheless be granted when its return is higher than the added cost. Admitting friends and family members is relatively low cost. It is easy to identify and differentiate those who have permission from those who do not, and doing so requires little or no additional monitoring, contracting, or enforcement costs because it relies on a preexisting set of social relations that exist independently of the decision to admit to the swimming pool. The rewards are social-psychological in nature, and perhaps reciprocal for in-kind exchanges. Admitting strangers who are willing to pay is more expensive. It requires identification, contracting, collection, and enforcement. Rewards are, obviously, monetary. Given the small size of the pool and its likely rapid congestion, there is a low ceiling on the monetary rewards obtainable from marketbased admission. While thoroughly culture- and class-specific, the example offers an intuitive sense of the shape of the analysis involved.

A similar framework can be mapped onto our motivating problems: carpooling and Internet-based distributed computing. In both cases, the marginal cost of perfect exclusion for any given time frame is negligible. Both types of goods have built-in exclusion mechanisms as part of the lumpy "unit," be they door locks or an operating system that requires a user's initiation to run programs on the processor. Both could suffer substantial congestion costs, as well as degradation, if given over to open 
sharing. Both are therefore only likely to be shared, if at all, on a partial exclusion basis. In both cases the primary perceived cost of nonselective partial exclusion is security, be it picking up hitchhikers on a first-comefirst-served basis or allowing anyone who wishes to run any program he or she wishes on one's computer.

Otherwise, the comparative costs of selective versus nonselective partial exclusion are more ambiguous. Which of the two approaches will fill three or four empty seats in a commuter car more efficiently? Will a habit of picking up at one or two meeting points decrease the marginal coordination cost such that it will be lower than stopping for the first hitchhiker, and will it be sufficiently low cost to outperform a stable set of commuting relationships, as is the case with slugging? Which approach, selective or nonselective partial exclusion, will require greater intervention on the part of the computer's owner to assure that the resource is shared up to, but not beyond, the excess capacity? For example, in the case of WiFi access points-currently the most popular standard for wireless Internet access - the owner of the gateway (the device that connects the home wireless network to the cable or DSL modem) can easily set the gateway to full sharing, enabling any user to connect automatically. Selectively admitting only some users requires the owner either to select a password and provide it to all whom the owner wishes to admit, and those others to change their configurations to meet this one access point, or to get unique identifying numbers of each admitted user and exclude others. For WiFi access points, then, perfect exclusion, open sharing, and selective exclusion are all feasible. Indeed, we observe commercial WiFi hotspots and password-protected WiFi gateways shared with friends, but also an increasingly dense network of openly shared access points in major cities like New York and San Francisco, ${ }^{99}$ suggesting that many owners decline to incur the costs of selective exclusion. For automobiles and for personal computers, perfect exclusion is a simple and cheap choice, open sharing is not a strong contender, and partial exclusion is possible both nonselectively (picking up any hitchhiker or slug on a first-come-first-served basis, sharing storage with other participants in a peer-to-peer file sharing network like KaZaa) and selectively, through means either market or social (taxis and carpools, project-specific CPU-cycle sales like Gómez Performance Networks and donations like SETI@home or Folding@home).

99. See, for example, the far-from-complete database lists for New York City, The Wireless Node Database Project, http://www.nodedb.com/unitedstates/ny/newyork (last visited Sept. 29, 2004); and San Francisco, The Wireless Node Database Project, http://www.nodedb.com/ unitedstates/ca/san_francisco (last visited Sept. 29, 2004). 


\section{Transaction Costs Analysis of Markets and Sharing}

Both markets and social exchange are forms of selective exclusion. They share many of the basic costs of physical exclusion, dictated by the technology related to the resource in question and its use. The primary systematic differences between the transaction costs of these two forms of selective exclusion are related to information and enforcement costs. Different transactional frameworks perform differently in terms of the information they allow participants to gain about what resources are available, how they function, how desirable their function is, etc. Markets use a combination of the price system and managerial hierarchical reporting and command flows to manage information about the universe of potential actions on resources in the world. Social frameworks use social cues that are usually less formal and less focused on crisply delineating the alternative courses of action open to participants in these frameworks. In this Subsection, I focus on the implications of this difference in the crispness and formality of information flows within markets and firms, on the one hand, and social relations, on the other.

The other main transaction cost difference between markets and social sharing systems is enforcement costs. Assuming the information has been generated in each system, markets rely more heavily (though not exclusively) on formal enforcement, while social relations rely on informal enforcement mechanisms studied in the literature on social norms and reciprocity. Which will be more costly depends on how costly punishing is in the social system relative to the enforcement process for property and contract claims in the particular market, how well developed the market or legal system is relative to the relevant social system, and so on. These are largely empirical questions that I will not further pursue here.

\section{a. Crispness}

A market transaction, in order to be efficient, must be clearly demarcated as to what it includes so that it can be priced efficiently. That price must then be paid in equally crisply delineated currency. Even if a transaction may initially be declared to involve sale of "an amount reasonably required to produce the required output" for a price "ranging from $x$ to $y$," at some point what was provided and what is owed must be crystallized and fixed for a formal exchange. The crispness is a functional requirement of the price system, which derives from the precision and formality of the medium of exchange-currency-and the ambition to provide refined representations of the comparative value of marginal 
decisions through denomination in the exchange medium that represents these incremental value differences.

Social exchange, on the other hand, does not require the same degree of crispness. As Maurice Godelier put it, "[T] he mark of the gift between close friends and relatives ... is not the absence of obligations, it is the absence of "calculation." 100 There are, obviously, elaborate and formally ritualistic systems of social exchange, in societies both ancient and modern. There are common property regimes that monitor and record calls on the common pool very crisply. These tend to resemble markets and market-based firms as the crispness increases. ${ }^{101}$ But in many of the common property regimes one finds mechanisms for bounding or fairly allocating access to the common pool that more coarsely delineate the entitlements, behaviors, and consequences. ${ }^{102}$ In modern market society, where money is a formal medium of precise exchange and where social relations are more fluid than in traditional societies, social exchange is certainly a fuzzier medium of exchange. In many cultures, generosity is understood as imposing a debt of obligation, but neither the precise amount of value given nor the precise nature of the debt to be repaid or its date of repayment need necessarily be specified. ${ }^{103}$ Actions enter into a cloud of good will or membership, out of which each agent can understand himself as being entitled to a certain flow of dependencies or benefits in exchange for continued cooperative behavior. This flow may be an ongoing relationship between two people, sharing among members of a small group like a family or circle of friends, and more broadly, the general level of generosity among strangers that makes for a decent society.

100. GODELIER, supra note 6 , at 5 .

101. A classic extreme case of a system described as a "commons" arrangement that seemed to be more of a market in scrip than a common property regime was the case of water scrip in Alicante, Spain. As Ostrom described that irrigation system, water availability was divided up into increments of fractions of minutes of open irrigation gates, represented by paper scrip, for which there was a highly liquid market, facilitated by both auctions and two-party exchanges, and which was used as collateral and as an otherwise fungible medium of exchange. See OSTROM, supra note 77 , at 78-82.

102. Acheson's classic study of the lobster gangs of Maine, ACHESON, supra note 77, for example, describes a much coarser and more collectivist system of entitlements than those of Alicante. There, harbor gangs' entitlements were collective to a fishing area broadly defined. Internal division was usufruct based, leaving substantial room for internal allocation on a combination of unilateral action-each fisherman could "grab" within limits-and social standing-older, more respected fishermen had better locations somewhat reserved to them without grabbing. Similarly, the time-division techniques used in Swiss pastures that Ostrom describes have a coarser outline than the Alicante scrip system or even the other, more closely policed Spanish irrigation systems she describes. See OSTROM, supra note 77, at 61-65.

103. See, $e_{\mathrm{t}} \rightarrow$ Joseph Henrich et al., In Search of Homo Economicus: Behavioral Experiments in 15 Small-Scale Societies, 91 AM. ECON. REV. (PAPERS \& PROC.) 73 (2001) (suggesting that this type of indebtedness is responsible for an unusually high rejection rate of offers in a wide-ranging dictator game experiment, in those cultures where receiving gifts was most clearly associated with unpredictable indebtedness). 
The point is that social exchange does not require precise terms like, "I will lend you my car and help you move these five boxes on Monday, and in exchange you will feed my fish next July," while markets would require terms like, "I will move five boxes on Tuesday for $\$ 100$ and six boxes for $\$ 120$." This does not mean that social systems are cost free-far from it. They require tremendous investment, acculturation, and maintenance, every bit as much as markets or states do. Once functional, however, social exchanges require less crispness at the margin. Both social and market exchange systems entail large fixed costs - the setting up of legal institutions and enforcement systems for markets and the setting up of social networks, norms, and institutions for social exchange. Once these initial costs have been invested, however, market transactions systematically require a greater degree of precise information about the content of actions, goods, and obligations, and greater precision of monitoring and enforcement on a per-transaction basis than do social exchange systems.

Because the difference in cost is at the margin per transaction, it increases linearly with the number of discrete transactions necessary to obtain a sufficient quantum of functionality flow to achieve the goals of a person relying on functionality flows from the owners of units. In other words, imagine that in order to run one computation one needs the excess capacity of only one computer, and the difference in transaction costs between using market-based clearance and social exchange is one dollar. If, instead, in order to run one computation the person seeking to use the excess capacity of others needs to pool the excess processing power of two idle computers, then the cost difference is two dollars per computation, and so forth. This pattern suggests that when slack capacity is located in small quanta distributed among many owners, it becomes increasingly more costly to harness that excess capacity through markets than through social exchange systems. Each additional processor, wireless node, or similar unit added through a social transaction framework requires less information exchange than it would have had that same node been added through a market-based system, because the social transaction need not exchange the crisp information required for efficient pricing and contracting. Given that the interest of each individual owner to buy as little excess capacity as technically feasible places a downward pressure on the expected amount of each unit's excess capacity, many shareable goods are likely to have this characteristic-widespread distribution of excess capacity in smallish dollops. This is precisely the domain in which shareable goods become very interesting as objects of social sharing, rather than market exchange-the domain of carpooling, distributed computing, file sharing, and ad hoc mesh wireless networks. 


\section{b. Rendering Requirements and Lossiness}

Both markets and state-based production have rendering requirements that are "lossy" in comparison to social production and exchange systems. That is, they lose information in the translation-from the way the world is perceived by the agents most immediately affected by it and most capable of acting, to the language in which the decision must be rendered given the requirements of the decision mechanism used to direct the action.

Each modality of production has its own ways of encoding, storing, and transmitting information from those observing the conditions and opportunities for action to those calculating the comparative attractiveness of possible actions and deciding what action should be taken-be they centralized or distributed, be it from the eyes to the brain or from the sentries to the general. This takes the form of prices in the market, of reports to management in firms, or of administrative reports in the state. In these cases, the actual richness of the world is transposed into formally structured modalities of representation whose logic is defined by the internal requirements of representation and processing in the system into which the information is fed-be it price in the market, managerial decision in the firm, or administrative decision in the state.

By contrast, information about social relations relies not on formal structure but on tacit, learned, and culturally reproduced capacities to read and interpret social settings. This may well present problems of clarity, comparability, and formal computability of problems, but it allows more "analog," storytelling-like modalities of communicating information with great subtlety and nuance. Social communications are more textured than the more formal systems of organizing information in market and state production. The texture can come from direct express communication about details, as opposed to translation into prices or formal categories, or from narratives that tap into culturally accessible reasons for action ("help fight AIDS," "find extraterrestrial life"). It can also come from observation of others or of the context of action understood through a common cultural filter that allows the observer to treat the actions or observed facts about the world as legible and intelligible cues about context, reasons for action, and desirability of action. Texture also comes from practice and from the tacit learning or information acquisition that occurs as part of practice in and adaptation to the social and material environment.

The tradeoff between formal clarity and computability on the one hand and texture on the other suggests that social systems will be relatively weaker in organizing actions for which there are clear, computable, but fine differences between alternative courses of action. Conversely, social systems will be particularly valuable as information-processing systems 
where the context, precise nature of the alternative possible actions, and range of possible outcomes are persistently vague or difficult to specify formally. ${ }^{104}$ To the extent that information about production opportunities, cooperative actions, and motivational inputs can be represented effectively through social communications systems, the result would offer a more complete statement of the factors relevant to agents' decisions than would information available in systems-like the state and the market-that require formalization of the data so that they can be represented adequately for the particular process of computation necessary to a decision in those systems. ${ }^{105}$ This is particularly important under conditions of persistent uncertainty (where uncertainty cannot be eliminated at an acceptable cost).

104. The value of nonmarket systems in the presence of high uncertainty is not original here. Kenneth Arrow mentions it, $\rightarrow$ Kenneth J. Arrow, Gifts and Exchanges, 1 PHIL. \& PUB. AFF. 343, 351-57 (1972) [hereinafter Arrow, Gifts and Exchanges], as an explanation for Richard Titmuss's finding that market-based blood is more tainted than donated blood. For a more complete discussion of the Titmuss-Arrow debate, see infra Section III.B. Arrow also mentions it as a reason that nonprofit hospitals may be better than for-profit hospitals. $\rightarrow$ Kenneth J. Arrow, Uncertainty and the Welfare Economics of Medical Care, 53 AM. ECON. REV. 941 (1963). Henry Hansmann developed this latter position into a full-blown theory of the comparative advantage of nonprofits:

[N]onprofit firms commonly arise where customers are in a peculiarly poor position to determine, with reasonable cost or effort, the quality or the quantity of the services they receive from a firm. As a consequence, assigning ownership to anyone other than these customers would create both the incentive and the opportunity for the customers to be severely exploited. Yet at the same time, the customers are so situated that the costs to them of exercising effective control over the firm are unacceptably large relative to the value of their transactions with the firm. The solution is to create a firm without owners-or, more accurately, to create a firm whose managers hold it in trust for their customers. In essence, the nonprofit form abandons any benefits of full ownership in favor of stricter fiduciary constraints on management.

HENRY HANSMANN, THE OWNERSHIP OF ENTERPRISE 228 (1996). These claims about nonprofit and nonmarket donation and uncertainty differ from my own focus in one crucial way. Both Arrow and Hansmann locate the "fix" that nonprofits or nonmarket actors provide in the alignment of incentives of the agents and "principals" or "customers." In the case of nonprofits, the nondistribution constraint means that no class of "owner"-patrons governs the firm and can capture the gains from exploiting the ill-informed class of patrons, and hence there is no class whose interests are severely misaligned with the potentially exploitable class. In the case of Arrow and blood donation, without payment for tainted blood, the donative motivation to help others no longer drives the person with disease-carrying blood to provide it. My own focus here is not on the alignment of incentives when operating through a market (though nothing in my approach denies this effect), but on the idea that embedding an uncertain transaction in social exchange introduces social signals into the transaction, thereby reducing uncertainty and information asymmetry. It is not only aligning incentives that is at stake, but also freeing the transaction from the strictures of price-mediated information exchange, which improves the quality of action in the face of uncertainty.

105. Note that, to the extent that a nonprofit is run like a firm and interacts with its "patrons" as a firm would, it would not have this uncertainty-reduction characteristic. It is when nonmarket behavior occurs through social interactions among individual participants that socially legible information can be communicated. A market-based actor who can communicate socially (a "chic" nightclub) will reduce uncertainty (as to whether to go into this club or that, or whether to go to a club or stay at home), while a nonmarket actor communicating bureaucratically or through market pricing will not. 
Presumably, there will be ranges where decisions could be improved by formal representation and computation, ranges where these will systematically fail to represent all factors relevant to an agent, and ranges where any two or three of the systems could render the decisions clearly enough for a decision-easy cases-where their comparative advantage must be found elsewhere.

\section{c. Decentralized Systems and Information}

Finally, the phenomenon I focus on in this Essay is systematically decentralized. Shareable goods are private goods controlled by their private owners, shared in broad social patterns among more or less weakly related individuals-much as idealized markets (and some actual markets, like eBay) might work. In this, they are different from many, though not all, real-world market-based production processes, which tend to be more centralized in firms, and from state bureaucracies.

The "centralized/distributed" distinction as I use it here is not binary. It is a range property of systems of human action in context. It describes the distance between the occurrence of an opportunity for human action in an environment and the authority for directing whether and how the agent confronted with the opportunity will act on it. "Distance" describes any parameter that separates the authority from the capacity to identify the presence of, and act on, the opportunity-organizational and institutional characteristics, geographic distance, technical constraints of information and authorization flow, etc. The more a system is organized centrally, the more room there is for information loss between the actual state of the world as perceived by those agents closest to the opportunity for action and the state of the world as perceived by agents with authority to decide that an action should be undertaken, and vice versa. Any system, whether a marketbased firm, a state-based bureaucracy, or a social organization like the Catholic Church, can be centralized. So too can there be distributed models of production in each, though in the case of the state, the formal constraints of accountability and legal authority constrain true devolution of state power to individual agents who act on the state's behalf.

Decentralized systems trade information for control. The more uncertainty there is about the best courses of action for any given agent or group of agents, the more valuable is information relative to the value of control. This is the basic claim in favor of ideal markets in comparison to command-and-control systems. To the extent that shareable goods are shared in practices that are closer to the distributed end of the spectrum, we have additional reason to think that sharing in social production systems loses less information: Distributed systems in general lose less information. 
To the extent they "compete" not with decentralized market actors functioning through ideal markets but with more centralized firms, particularly in regulated industries like telecommunications and the copyright- and patent-dependent industries so prevalent in the networked information environment, they can provide substantial information efficiencies. This overarching claim about sharing systems captures within it the many empirical claims about local knowledge, active monitoring and enforcement, etc. that have been made on behalf of common property regimes and community-production systems in the literature that has described and explained the sustainability and, indeed, efficiency, of these non-market-based organizational forms. ${ }^{106}$

\section{B. Motivation}

Institutional analysis based on transaction costs normally stops hereidentifying and comparing transaction costs across institutional settings. There is, however, another, independent dimension to understanding sharing: motivation. The organizers of distributed computing projects, for example, explicitly focus on how to motivate contributions. ${ }^{107}$ Practitioners of free software development, ${ }^{108}$ as well as the academics who study them, ${ }^{109}$ similarly spend a good bit of energy studying motivations. One question is the source and form of nonmonetary rewards. The other is the question of crowding out-that is, whether the presence of market-based, monetary rewards for an action undermines or improves nonmonetary motivations for that action.

The theoretical and empirical debate over whether monetary motivations and some set of social-psychological motivations crowd each other out emerged initially in the debates of the early 1970s over bloodcollection policy. Until the early 1970s, the vast majority of blood donors in the United States were compensated in cash or indirectly, via some type of blood exchange or insurance system. ${ }^{110}$ In a major work, Richard Titmuss

106. See OSTROM, supra note 77; Bowles \& Gintis, supra note 91.

107. See supra text accompanying notes 68-76.

108. See Eric S. Raymond, The Cathedral and the Bazaar, FIRST MONDAY, Mar. 2, 1998, http://www.firstmonday.dk/issues/issue3_3/raymond/; Eric S. Raymond, Homesteading the Noosphere, FIRST MONDAY, Oct. 5, 1998, http://www.firstmonday.dk/issues/issue3_10/raymond/.

109. See, $e \rightarrow$ Josh Lerner \& Jean Tirole, Some Simple Economics of Open Source, $50 \mathrm{~J}$. INDUS. ECON. 197 (2002). Eric von Hippel in particular has provided both theoretical and empirical support for the importance of the use value gained by users in a user-driven innovation environment, both in software and elsewhere. See, e.g., Eric von Hippel, Innovation by User Communities: Learning from Open-Source Software, MIT SLOAN MGMT. REV., Summer 2001, at 82 .

110. See Richard M. Titmuss, The Gift Relationship: From Human Blood to Social POLICY 94 (1971); see also DOUglas STARR, BLOOD: AN EPIC HISTORY OF MEDICINE AND 
compared the U.S. and British blood-supply systems, the former largely commercial at the time, organized by a mix of private for-profit and nonprofit actors, the latter entirely voluntary and organized by the National Health Service. Titmuss found that the British system had higher-quality blood, as measured by the likelihood of recipients contracting hepatitis from transfusions; ${ }^{11}$ less blood waste; and fewer blood shortages at hospitals. Titmuss also attacked the U.S. system as inequitable, arguing that the rich exploited the poor and desperate by buying their blood. $\mathrm{He}$ concluded that an altruistic blood-procurement system is both more ethical and more efficient than a market system, and recommended that the market be kept out of blood donation to protect the right to give. ${ }^{112}$

Titmuss's argument came under immediate attack from economists. Most relevant for our purposes here, Kenneth Arrow agreed that the differences in blood quality indicated that the U.S. blood system was flawed, but rejected Titmuss's central theoretical claim that markets reduce donative activity. ${ }^{113}$ Arrow reported the alternative hypothesis held by "economists typically," that if some people respond to exhortation or moral incentives (donors) while others respond to prices and market incentives (sellers), these two groups likely behave independently - neither responds to the other's incentives. ${ }^{114}$ Thus the decision to allow or ban markets should have no effect on donative behavior-though removing a market could in fact remove incentives of the "bad blood" suppliers to give blood, thereby improving the overall quality of the blood supply. ${ }^{115}$ Titmuss's work had not established his hypothesis analytically, Arrow argued, and its

COMMERCE 174-75 (1998) (explaining that fees for blood donors were approximately twenty-five dollars per pint in the late 1940s).

111. In the United Kingdom, this rate was less than $1 \%$, and in one study was as low as $0.16 \%$. TITMUSS, supra note 110 , at $154-55$. In the United States, the rate may have been as high as $3.6 \%$. Id. at $145-46$.

112. Id. at 245-46. At least one contemporary historian casts some doubt on Titmuss's analysis:

In retrospect, Titmuss's critique was unfair. His thesis largely ignored the American Red Cross, which accounted for about 40 percent of the blood collected in America.... Instead he focused on the booming plasma industry and the rising number of for-profit blood banks. What he criticized was not the complex reality of America's blood resource, but a caricature ... . Titmuss's book hit a public nerve.

STARR, supra note 110 , at 225 .

113. Arrow, Gifts and Exchanges, supra note 104, at 361.

114. Id. at $349-50$.

115. Id. at 351-55. This was similar to Robert Solow's critique. Solow took issue with much of Titmuss's empirical work and ascribed the United Kingdom's advantage over the United States in part to the "the tight little island['s] ... tradition of civic-mindedne $\rightarrow$ Robert M. Solow, Blood and Thunder, 80 YALE L.J. 1696, 1705 (1971) (reviewing TITMUSS, supra note 110). Because hepatitis had to be self-reported-no hepatitis test existed at the time--Solow found the lower quality of blood in the U.S. system to be largely unsurprising: Compared to voluntary blood donors, blood sellers (1) are more likely to have hepatitis and (2) face incentives to conceal their illness. Id. at 1702-05. 
proof or refutation would lie in empirical study. ${ }^{116}$ Theoretical differences aside, the U.S. blood-supply system did in fact transition to an all-volunteer system of social donation in the 1970s. ${ }^{117}$ In surveys since, blood donors have reported that they "enjoy helping" others, experience a sense of moral obligation or responsibility, or exhibit characteristics of reciprocators after they or their relatives received blood. ${ }^{118}$

A number of scholars, primarily in psychology and economics, have attempted to resolve this question both empirically and theoretically. ${ }^{119}$ The most systematic work within economics is that of Bruno Frey and various collaborators. ${ }^{120}$ Frey imports a model of motivations from psychology ${ }^{121}$ and combines it with both analytic modeling and empirical evidence to show that the introduction of money, or prices, for an activity may in fact lower the level of that activity. He calls this "the crowding-out effect."

A simple statement of this model is that individuals have intrinsic and extrinsic motivations. Extrinsic motivations are imposed on individuals

116. Arrow, Gifts and Exchanges, supra note 104, at 351.

117. See Jane Allyn Piliavin \& Peter L. Callero, Giving Blood: The Development OF AN ALTRUISTIC IDENTITY 2 (1991) (explaining that the Department of Health, Education and Welfare announced a policy strongly discouraging blood sales in 1973 and that a subsequent regulation requiring differential labeling of blood from voluntary and paid donors also contributed to the "virtual elimination of commercial whole-blood banks"); Kieran Healy, Embedded Altruism: Blood Collection Regimes and the European Union's Donor Population, 105 AM. J. SoC. 1633, 1637 (2000); Am. Ass'n of Blood Banks, All About Blood: FAQ, http://www.aabb.org/All_About_Blood/FAQs/aabb_faqs.htm (last visited Sept. 29, 2004). Since the 1970s there has been essentially no commercial collection of whole blood in the United States, and insurance-based individual responsibility systems are becoming rarer. See STARR, supra note 110 , at 216-27. In 2001, eight million volunteers donated fifteen million units of whole blood and red blood cells in the United States. See Am. Ass'n of Blood Banks, supra. These donors likely represent more than five percent of the age-eligible population, see PILIAVIN \& CALLERO, supra, at 2, and approximately forty percent of Americans have given blood at some point in their lives, see id. at 24. European countries also appear to collect whole blood exclusively from voluntary donors, following an official European Union policy announced in 1989. Healy, supra, at 1638. Survey research shows that blood donors are common in some European countries, such as France, where forty-four percent of age-eligible residents have given blood, and much rarer in others, such as Luxembourg, where only fourteen percent of age-eligible residents are donors. See id.

118. See PILIAVIN \& CALLERO, supra note 117, at 35-36 (describing motivations of first-time donors); id. at 181-90 (describing social norms around donation).

119. See Bruno S. Frey \& Reto Jegen, Motivation Crowding Theory, 15 J. ECON. SURvs. 589 (2001) (surveying the literature).

120. See BRUNO S. FREY, INSPIRING ECONOMICS 52-72 (2001) [hereinafter FREY, INSPIRING ECONOMICS]; BRUNO S. FREY, NOT JUST FOR MONEY (1997) [hereinafter FREY, NOT JUST FOR MONEY].

121. He traces the origin of the line of psychology literature he follows to Edward L. Deci, Effects of Externally Mediated Rewards on Intrinsic Motivation, 18 J. PERSONALITY \& SOC. PSYCHOL. 105 (1971). FREY, NOT JUST FOR MONEY, supra note 120, at 13-14. Ironically, then, at least one answer to Arrow's critique of the lack of a theoretical causal mechanism for crowding out already existed, but in another field. The line of literature is crystallized in EDWARD L. DECI \& RICHARD M. RYAN, INTRINSIC MOTIVATION AND SELF-DETERMINATION IN HUMAN BEHAVIOR (1985). 
from the outside, taking the form either of offers of money for, or prices imposed on, behavior, or of threats of punishment or promises of reward from a manager or a judge for complying with, or failing to comply with, specifically prescribed behavior. Intrinsic motivations are reasons for action that come from within the person, such as pleasure or personal satisfaction. ${ }^{122}$ Extrinsic motivations are said to "crowd out" intrinsic motivations because they (a) impair self-determination-that is, a person feels pressured by an external force, and therefore feels overjustified in maintaining her intrinsic motivation rather than complying with the will of the source of the extrinsic reward; or (b) impair self-esteem-they cause an individual to feel that his internal motivation is rejected, not valued, leading him to reduce his self-esteem and thus to reduce effort. ${ }^{123}$ It is not selfevident in Frey's own rendition why offering to pay money for an activity that an agent is free to forgo impairs self-determination or self-esteem in the same way as imposing a penalty or price on the agent's failure to act, which the agent cannot avoid, but the intuition is not difficult to explain. It depends on a culturally contingent notion of what one "ought" to do if one is a well-adjusted human being and member of a decent society. Being offered money to do something you know you "ought" to do, and that selfrespecting members of society do, implies that the offeror believes that you are not a well-adjusted human being or an equally respectable member of society. An alternative causal explanation is formalized by Roland Bénabou and Jean Tirole: The person receiving the monetary incentives infers that the person offering her the compensation does not trust her to do the right thing, or to do it well of her own accord, and her self-confidence and intrinsic motivation to succeed are reduced to the extent that she believes that the offeror-a manager or parent, for example-is better situated to judge her abilities. ${ }^{124}$

A substantial empirical literature-including field and laboratory experiments, econometrics, and surveys-has tested the hypotheses of this model of human motivation and found substantial evidence that, under some circumstances, adding money for an activity previously undertaken without price compensation reduces, rather than increases, the level of activity. ${ }^{125}$ The work has covered contexts as diverse as employees

122. See FrEY, INSPIRING ECONOMICS, supra note 120, at 55; FREY, NOT JUST FOR MONEY, supra note 120 , at 13-14.

123. See Frey \& Jegen, supra note 119, at 594.

124. Roland BÉNABOU \& JEAN TIROLE, SElF-CONFIDENCE AND SOCIAL INTERACTIONS 23, 7-10 (Nat'l Bureau of Econ. Research, Working Paper No. 7585, 2000).

125. See Frey \& Jegen, supra note 119. 
supplying labor ${ }^{126}$ or sharing their knowledge with team members, ${ }^{127}$ communities accepting locally undesirable land uses (NIMBY behavior increases, rather than decreases, with the addition of incentives in place of commonweal arguments), ${ }^{128}$ or adults picking up children from day care centers (parents come later, rather than earlier, when a price is imposed on coming late). ${ }^{129}$ The results of this work strongly suggest that some displacement, or crowding out, can be identified across various domains between monetary rewards and nonmonetary motivations. This does not mean that offering monetary incentives does not increase extrinsic rewards. It does, and where extrinsic rewards dominate, this will increase the rewarded activity as usually predicted in economics. But the effect on intrinsic motivation at least sometimes operates in the opposite direction. Where intrinsic motivation is an important factor, because pricing and contracting are difficult to achieve or because the payment is relatively low, the aggregate effect may be negative. Inducing transfers of tacit knowledge from employees to the teams they work with is a good example of the former type of condition, ${ }^{130}$ while low payments for otherwise volunteerbased activities are an example of the latter. ${ }^{131}$

Frey's psychologically based extrinsic-/intrinsic-motivation distinction is helpful, and the empirical evidence is powerful. The psychological construct does not, however, seem fully to account for motivation in social sharing frameworks. As Frey himself implies, recognition by friends is plainly a form of extrinsic motivation, ${ }^{132}$ while the attainment of wealth is not purely functional and extrinsic but, as Veblen explained long ago, plays a role in providing social recognition, ${ }^{133}$ which in turn is likely quite central to people's sense of intrinsic satisfaction. In the social capital literature, social interactions are very often understood in functional rather than symbolic and psychological terms-their value lies in providing future

126. $\rightarrow$ Truman F. Bewley, A Depressed Labor Market as Explained by Participants, 85 AM. ECON. REV. (PAPERS \& PROC.) 250, 252 (1995) (providing survey data about managers' beliefs about the effects of incentive contracts).

127. $S \rightarrow$ Margit Osterloh \& Bruno S. Frey, Motivation, Knowledge Transfer, and Organizational Forms, 11 ORG. SCI. 538, 546-47 (2000).

128. See Bruno S. Frey \& Felix Oberholzer-Gee, The Cost of Price Incentives: An Empirical Analysis of Motivation Crowding-Out, 87 AM. ECON. REV. 746 (1997); Howard Kunreuther \& Douglas Easterling, Are Risk-Benefit Tradeoffs Possible in Siting Hazardous Facilities?, 80 AM. ECON. REV. (PAPERS \& PROC.) 252, 252-86 (1990).

129. See Uri Gneezy \& Aldo Rustichini, A Fine Is a Price, 29 J. Legal Stud. 1 (2000) (finding that introducing a fine for tardy pickup increased, rather than decreased, tardiness by parents).

130. See Osterloh \& Frey, supra note 127.

131. See Frey \& Jegen, supra note 119, at 601-02.

132. See FREY, NOT JUST FOR MONEY, supra note 120, at 14.

133. ThORSTEIN VeBlen, THE THEORY OF THE LEISURE ClASS 52-75 (Modern Library 2001) (1899) (explaining conspicuous consumption). 
access to information, resources, and opportunities for action. ${ }^{134}$ This social-functional thesis of why people might behave sociably and share does not require a psychological explanation, but might still have a similar relationship with money, where paid cooperative behavior demands less nonmonetary reciprocation than uncompensated cooperation. Such an interpretation would equally well explain empirical findings that payments crowd out reciprocating cooperation. ${ }^{135}$ The social capital literature, in any event, seems to assume that what can be attained through social position and relations is not substitutable, at least not perfectly, with what can be bought. That is what makes social relations a form of capital distinct from financial capital.

For purposes of my analysis here it is not necessary to pin down precisely the correct and most complete theory of motivation or the full extent and dimensions of crowding out. All that is required to outline the framework for analysis is the recognition that there is some form of socialpsychological motivation that is neither fungible with money nor simply cumulative with it. ${ }^{136}$ Transacting within the price system may either increase or decrease the social-psychological rewards-be they intrinsic or extrinsic, functional or symbolic. ${ }^{137}$

134. See, e.g., LIN, supra note 85 , at $149-50,149-51$ (claiming that "[t]here are two ultimate (or primitive) rewards for human beings in a social structure: economic standing and social standing," and elaborating a thesis where in both cases these represent relational standing, in terms of capacity to mobilize resources, some that can be mobilized by money, others that can be mobilized by social relations). James Coleman similarly focuses on the functional characteristics of social networks, see Coleman, supra note 85 , as do other major versions of the social capital literature, see MARK GRANOVETTER, GETTING A JOB: A STUDY OF CONTRACTS AND CAREERS $(2 \mathrm{~d}$ ed. $199 \rightarrow$ Yoram Ben-Porath, The F-Connection: Families, Friends, and Firms and the Organization of Exchange, 6 POPULATION \& DEV. REV. 1 (1980); Mark S. Granovetter, The Strength of Weak Ties, 78 AM. J. SOC. 1360 (1973).

135. In particular, studies that focus on the crowding out of reciprocity support a social causal theory. See, e.g., ERNST FEHR \& SIMON GÄCHTER, DO INCENTIVE CONTRACTS UNDERMINE VOLUNTARY COOPERATION? (Inst. for Empirical Research in Econ., Univ. of Zurich, Working Paper No. 34, 2002) (describing laboratory experimental results for the effects of incentives on cooperation).

136. One sees this assumption in operation in the nonprofit literature. See WEISBROD, supra note 4, at 31-33 (describing the motivational profile of nonprofit entrepreneurs and providing empirical evidence that the nonprofit sector draws individuals with different motivational profiles than the for-profit sector); Dennis R. Young, Entrepreneurship and the Behavior of Nonprofit Organizations: Elements of a Theory, in THE ECONOMICS OF NONPROFIT INSTITUTIONS, supra note 4 , at 161 (describing the nonprofit sector precisely in terms of motivational profiles of nonprofit entrepreneurs).

137. Crowding out may not, however, be an important effect in the relationship of government provisioning to volunteer donation. Susan Rose-Ackerman has shown that the relationship is ambiguous and that government provisioning may not crowd out private donation, but merely change its focus and shape. See Susan Rose-Ackerman, Do Government Grants to Charity Reduce Private Donations?, in THE ECONOMICS OF NONPROFIT INSTITUTIONS, supra note 4, at 313; see also Burton A. Abrams \& Mark D. Schmitz, The Crowding Out Effect of Governmental Transfers on Private Charitable Contributions, in THE ECONOMICS OF NONPROFIT 
The intuition is simple. Leaving a fifty-dollar bill on the table after one has finished a pleasant dinner at a friend's house would not increase the host's social and psychological gains from the evening. Most likely it would so diminish them that one would never again be invited. A bottle of wine or bouquet would, to the contrary, improve the social gains. And if dinner is not intuitively obvious, think of sex. The point is simple. Moneyoriented motivations are different from socially oriented motivations. Sometimes they align. Sometimes they collide. Which of the two will be the case is historically and culturally contingent. The presence of money in sports or entertainment reduced the social-psychological gains from performance in Victorian England, at least for members of the middle and upper classes. This is reflected in the longstanding insistence on the amateur status of the Olympics, or the dubious status of actors in that society. This has changed dramatically over a century later, when athletes' and popular entertainers' social standing is practically measured by the millions of dollars their performances can command.

The relative relationships of money and social-psychological rewards depend on culture and context. Similar actions may have different meanings in different social or cultural contexts. While I have elsewhere offered more detailed descriptions, ${ }^{138}$ one example illustrates how these components interact. Consider three lawyers contemplating whether to write a paper presenting their opinions. One is a practicing attorney. The second is a judge. The third is an academic. For the first, money and honor are often, though not always, positively correlated. Being able to command a very high hourly fee for writing the requested paper is one mode of expressing one's standing in the profession. And yet, there are modes of acquiring esteem-like writing the paper as a report for a bar committee-that not only are not improved by the presence of money, but are in fact undermined by it. This latter effect is sharpest for the judge. If a judge is approached with an offer of money for writing an opinion, not only is this not a mark of honor, it is a subversion of the social role and would render corrupt the writing of the opinion. The intrinsic rewards for the judge from writing the opinion when matched by a payment for the product would be guilt and shame, and the offer therefore an expression of disrespect. Finally, if the same paper is requested of the academic, the effect of the money falls somewhere in between the judge and the practitioner. To a high degree, like the judge, the academic who writes for money is rendered suspect in her community of scholarship. A paper clearly funded by a party, the results of

INSTITUTIONS, supra note 4, at 304, 311 (finding somewhat ambiguously a partial displacement of private contributions by public funding).

138. See Benkler, supra note 3. 
which support the party's regulatory or litigation position, is practically worthless as an academic work. But in a mirror image of the practitioner, there are some forms of money that add to an academic's socialpsychological rewards, peer-reviewed grants and prizes most prominent among them. Pursuing them reinforces rather than undermines the academic's social-psychological rewards.

A comparison of market and social systems for organizing production by utilizing shareable goods in terms of motivation, then, will reveal money (or any other expression of market exchange value) and socialpsychological rewards as alternative sources of motivation. The pursuit of one sometimes complements, but sometimes undermines, the value of the action as measured in terms of the other. The relationship of the two is culturally and historically contingent. Capturing the potential for human action that could be motivated by the exchange of love, status, and esteem, ${ }^{139}$ a personal sense of worth in relations with others, is the strong suit of social production (and sometimes, depending on time and context, the state-as in "Uncle Sam Wants You!"). Social production rewards action either solely in these forms or, if it adds money, organizes its flow in such a way that it at least does not conflict with and undermine the quantum of self-confidence, love, esteem, or social networking value obtained by the agent from acting.

\section{Motivation and Information}

To compare the attractiveness of market and social exchange systems, then, we should compare (1) the transaction costs of using one or the other system of exchange and (2) the likely reward flows to individuals from participating in one or the other of the two systems. The two considerations are independent of each other. If one is concerned with welfare optimization, then what needs to be optimized is the combined effect of both. Comparing them is a context-specific, empirical exercise that depends on the characteristics of the good, the use, and the extant social and market practices and institutions in the society for which the two are compared. The answers may be different for apples than for oranges, ${ }^{140}$ for economists than for Melanesian islanders. ${ }^{141}$ These questions provide rich grounds for

139. See Richard H. McAdams, The Origin, Development, and Regulation of Norms, 96 MICH. L. REV. 338 (1997).

140. The latter have lower transaction costs for sharing because of their morphology.

141. Melanesian islanders have appeared as all but the personification of gift economies ever since Bronislaw Malinowski's Argonauts of the Western Pacific. MALINOWSKI, supra note 6. Economists, by contrast, have been the subject of claims that they systematically behave less prosocially than students of other disciplines. See John R. Carter \& Michael D. Irons, Are Economists Different, and if So, Why?, J. ECON. PERSP., Spring 1991, at 171; Björn Frank \& Günther G. 
empirical observations about sharing and secondary-market practices, but they do not give us an approximate general intuition about the modality that exchange of excess capacity generated by shareable goods will take, except in one instance of central importance: when excess capacity is widely distributed in small quanta.

When the state of technology results in excess capacity being widely distributed in small dollops, social sharing will outperform secondary markets. This is so because of both transaction costs and motivation. The difference between the transaction costs of a secondary market and those of a sharing system increases linearly with the number of transactions necessary to collect a usable amount of functionality. The smaller the amount of excess capacity held by each unit owner relative to the total amount required for the functionality, the higher the number of transactions necessary to achieve the functionality, and the larger the gap in transaction costs between market-based clearance and social sharing. Furthermore, the smaller the amount of excess capacity each unit owner owns relative to the total required, the smaller the payment that each owner can get. It is precisely where payments are low that their introduction is likely to have only a minor positive effect on contributions, and therefore to leave the crowding-out effect to dominate the overall level of participation. Fewer owners will be willing to sell their excess capacity cheaply than to give it away for free, and the transaction costs of selling will be higher than those of sharing.

Recognizing that social sharing can under some circumstances be more efficient than market-based models of production has substantial policy implications. At a broad policy level, we could focus on one of two goals. The first goal is relevant when we can say with some degree of confidence that a particular problem is particularly amenable to solution within one or another of the systems of production. It focuses on providing stronger institutional guides toward funneling the behavior into that system-either a market or a social production system, respectively. The second, more widely applicable goal, until we have learned more about the contours of social production and exchange, is to study changes in law and policy so as

Schulze, Does Economics Make Citizens Corrupt?, 43 J. ECON. BEHAV. \& ORG. 101 (2000); Robert H. Frank et al., Do Economists Make Bad Citizens?, J. ECON. PERSP., Winter 1996, at 187; Bruno S. Frey et al., Economics Indoctrination or Selection? Some Empirical Results, 24 J. ECON. EDUC. 271 (1993); Gerald Marwell \& Ruth E. Ames, Economists Free Ride, Does Anyone Else? Experiments on the Provision of Public Goods IV, 15 J. PUB. ECON. 295 (1981); Anthony M. Yezer et al., Does Studying Economics Discourage Cooperation? Watch What We Do, Not What We Say or How We Play, J. ECON. PERSP., Winter 1996, at 177. This observation may, however, reflect a selection bias-that is, it is more likely that selfish people self-select into the discipline than that exposure to the discipline causes selfishness. See FREY \& MEIER, supra note 2, at 14-16, 31 tbl.6. 
to avoid tipping the production system toward one or another of these competing systems -in particular, in favor of the one with which we are more familiar, the market-before we have good reason to think that the preferred system is the better one.

The basic point is that for any given resource that exists in an institutional-cultural space at a moment in history, there will be different costs to move from no transactions to either a secondary market system or a social exchange system. These costs partly depend on the technological characteristics of the good. Some things may have very small quanta of excess capacity, so that aggregation into a usable amount of capacity would generate many transactions with many individuals. The high transaction costs of markets could rule out efficiency-seeking policy through secondary markets. Partly, however, the costs depend on social practices and cultural values of the people in the relevant society. For example, if market institutions are prevalent and people are culturally attuned to making every penny they can, then moving to a secondary market will (1) incur lower fixed transaction costs for institution building and repurposing, (2) require fewer attitudinal and social practice adjustments, and (3) hit the right motivational pitch to which people in this society are attuned. And vice versa - in a society where sharing or other nonmarket cooperation among non-kin is widespread and where social institutions and attitudes are more readily available to support a sharing system for impersonal interactions, the transition costs from perfect exclusion to social sharing will be lower than the transition costs from the same perfect exclusion to secondary markets.

When we are faced with policy proposals for institutional changes that affect practices involved in production and exchange, we should consider their effects not only on market production, but also on social production. To the extent that policy is properly concerned with increasing production of a given desideratum, it should be driven by an analysis of how the policy change will affect total production in both systems (or all three, including state-based production), not only on how it will affect one of them.

\section{SHARING AS A MODALITY OF PRODUCTION}

Up to this point this Essay has been focused on sharing of material goods that appear to be "traditional" economic goods-rival and privatebut that are nonetheless amenable to sharing. We can now integrate these observations with work done in a number of related areas of study, as well as with my own earlier work on online peer production, to consider sharing at a broader level of abstraction as an alternative modality of economic production. In this Part, I will attempt to outline what "sharing" as a 
modality of economic production might mean and how we could think of locating its role in the economy. The last Part will be devoted to outlining how recognizing sharing as an important form of production can affect some contemporary policy debates.

The claim is that sharing is a pervasive modality of economic production. By "economic production," I mean the provisioning of goods and services that people value. By "pervasive," I mean that it is an approach to organizing economic production integral to many daily contextswhether we think of it or not.

Under certain technological circumstances, practically feasible opportunities for action are distributed in such a pattern that they are amenable to execution by a class of approaches to organizing production that rely on sharing. These are typified by (1) radical decentralization of the capacity to contribute to effective action and the authority to decide on the contribution and (2) reliance on social information flows, organizational approaches, and motivation structures, rather than on prices or commands, to motivate and direct productive contributions.

Most practices of production - social or market based — are already embedded in a given technological context. They present no visible "problem" to solve or policy choice to make. We do not need to focus consciously on improving the conditions under which friends lend each other a hand to move boxes, make dinner, or take kids to school, and we feel no need to reconsider the appropriateness of the production of automobiles by market-based firms. However, in moments when a field of action is undergoing a technological transition that changes the opportunities for sharing as a modality of production, understanding that sharing is a modality of production becomes more important, as does understanding how it functions as such. This is so, as we are seeing today, when prior technologies have already set up market- or state-based production systems that have law and policymaking systems already designed to fit their requirements. While the old arrangements may have once been the most efficient, or may even have been absolutely necessary for the incumbent production systems, their extension under new technological conditions may undermine, rather than improve, the capacity of a society to produce and provision the goods, resources, or functionalities that are the object of policy analysis. Today this is true of wireless communications regulation, or "spectrum management," as it is usually called; it is true of the regulation of information, knowledge, and cultural production, or "intellectual property," as it is usually now called; and it may be true of policies for computation and wired communications networks, as distributed computing and the emerging peer-to-peer architectures are suggesting. I will consider these policy areas in Part V. 


\section{A. Sharing Is a Common and Underappreciated Modality of Production}

There is a curious congruence between the anthropologists of the gift and mainstream economists today. Both treat the gift literature as being about the periphery, about societies starkly different from modern capitalist ones. As Godelier puts it,

What a contrast between these types of society, these social and mental universes, and today's capitalist society where the majority of social relations are impersonal (involving the individual as citizen and the state, for instance), and where the exchange of things and services is conducted for the most part in an anonymous marketplace, leaving little room for an economy and a moral code based on gift-giving. ${ }^{142}$

And yet, sharing is everywhere around us in the advanced economies. The past two decades or so have seen an increasing focus in a number of literatures on production processes that rely heavily on social relations, rather than on price-based signals or governmental policies. These include, initially, the literature on social norms ${ }^{143}$ and social capital, or trust. ${ }^{144}$ Both literatures, however, are statements of the institutional role that social mechanisms play in enabling market exchange and production. ${ }^{145}$ More

142. GODELIER, supra note 6, at 106-07 (internal quotation marks omitted).

143. In the legal literature, ROBERT C. ELLICKSON, ORDER WITHOUT LAW: HOW NEIGHBORS SETTLE DISPUTES (1991) is the locus classicus for showing how social norms can substitute for law. For a bibliography of the social norms literature outside of law, see McAdams, supra note 139, at $339 \mathrm{nn} .1$-2. Early contributions were EDNA UlLMANN-MARGALIT, THE EMERGENCE OF NORMS (1977); James S. Coleman, Norms as Social Capital, in ECONOMIC IMPERIALISM 133 (Peter Bernholz \& Gerard Radnitzky eds., 1987); and Sally Engle Merry, Rethinking Gossip and Scandal, in 1 TOWARD A GENERAL THEORY OF SOCIAL CONTROL: FUNDAMENTALS 271 (Donald Black ed., 1984).

144. Samuel Bowles and Herbert Gintis trace to Kenneth Arrow the argument that social trust compensates for market failures in enabling cooperation. "In the absence of trust . . opportunities for mutually beneficial co-operation would have to be foregone." Kenneth J. Arrow, Political and Economic Evaluation of Social Effects and Externalities, in FRONTIERS OF QUANTITATIVE ECONOMICS 3, 22 (Michael D. Intriligator ed., 1971). "[N]orms of social behavior, including ethical and moral codes . . . [may be] reactions of society to compensate for market failures." Id.

145. The ranchers of Shasta County in Ellickson's classic study were producing norms socially. They were not producing beef in response to social motivations or signals, in the way that, for example, the participants in SETI@home produce computation socially, or the programmers who coauthor free software projects do. They were provisioning governance through social mechanisms. The governance issues they tackled were the conflicts that arose from their market-based behavior. The problem that has been the focus of economic claims about social capital is that trust relations provide an important social context for markets, in lowering transaction costs and improving production in market systems. But they are in the first instance understood as means of smoothing the operations of a market production and exchange system. These are to be distinguished from the political claims about the relationship between social capital and democracy, which were central to Robert Putnam's treatment. ROBERT D. PUTNAM, BOWLING AlONE: THE COLlaPSE AND REVIVAL OF AMERICAN COMMUNITY (2000). 
direct observations of social production and exchange systems are provided by the literature on social provisioning of public goods-like the literature on social norm enforcement as a dimension of policing criminality ${ }^{146}$ and that on common property regimes. ${ }^{147}$ The former is limited by its focus on the provisioning of public goods. The latter is usually limited by its focus on discretely identifiable types of resources-common pool resources-that must be managed as among a group of claimants while retaining a proprietary outer boundary toward nonmembers. ${ }^{148}$ The broadest set of claims similar to those I make here comes from Samuel Bowles and Herbert Gintis, who describe "community governance" as a complementary system for solving problems, some of which take the form of production problems, some the form of public-goods provisioning. ${ }^{149}$ Their claim is that communities can have advantages: The prevalence of repeat interactions improves incentives to cooperate, the ability to acquire information about past and present and to predict likely future behavior of other participants reduces risk of defection or failure, and the organizational spaces provide a platform for practicing the empirically tested fact that many people have a taste for enforcing against antisocial behavior. Along these dimensions, they claim that community governance systems exist alongside, and complement, markets and states where their relative advantages make them better than markets and states at solving governance problems. ${ }^{150}$

My own aim is to generalize this claim, such that we understand "community governance" aimed at production as a special case of social sharing, one that gains robustness because it involves tightly connected social groups. But social sharing is a broader phenomenon, one that includes cooperative enterprises that can be pursued by weakly connected participants or even by total strangers and yet function as a sustainable and substantial modality of economic production. Indeed, in the context of the digitally networked environment, it is this type of sharing and cooperative

146. See, $e \rightarrow$ Robert C. Ellickson, Controlling Chronic Misconduct in City Spaces: Of Panhandlers, Skid Rows, and Public-Space Zoning, 105 YALE L.J. 1165, 1194-201 (1996); Dan M. Kahan, Between Economics and Sociology: The New Path of Deterrence, $95 \mathrm{MiCH}$. L. REV. 2477 (1997).

147. See supra note 77; see also Carol M. Rose, Left Brain, Right Brain and History in the New Law and Economics of Property, 79 OR. L. REV. 479 (2000); Carol M. Rose, The Several Futures of Property: Of Cyberspace and Folk Tales, Emission Trades and Ecosystems, 83 MiNN. L. REV. 129 (1998).

148. See OSTROM, supra note 77 , at $91-92$ (listing clearly defined boundaries as crucial to success). Plainly, however, the provisioning of a dam in Ostrom's description of the Philippine zanjeiras, id. at $82-88$, organized around claims to the resulting water flow, none of which is price based or legal fiat based, describes a richly detailed social production system.

149. See Bowles \& Gintis, supra note 91.

150. See id. 
production among strangers and weakly connected participants that holds the greatest economic promise.

The most visible set of practices that typify this broader claim is what I have called commons-based peer production-large-scale cooperative efforts in which the thing shared among the participants is their creative effort. ${ }^{151}$ Most prominent among these is free software. A sharing-based approach to software development, free software or open source software depends on many individuals contributing to a common project out of a variety of motivations and then sharing their respective contributions without any one entity or person asserting a right of exclusion to either the contributed components or the resulting whole. In order to avoid the joint product being appropriated by any single party, participants usually retain copyrights in their contributions but license them to anyone-participant or stranger-on a model that joins a universal license to use the materials with constraints that make its reappropriation by either the contributor or a third party difficult, if not impossible. While there have been many arguments about how widely the provisions that prevent appropriation should be used, the practical adoption patterns have been dominated by forms of licensing that prevent reappropriation of the contributions or the joint product. ${ }^{152}$

Free software has played an important role in the recognition of peer production because software is a functional good with measurable qualities. It can be more or less authoritatively tested, quantitatively, against its market-based competitors. And in many instances free software has prevailed. Over sixty percent of web server software, in particular for critical e-commerce sites, runs on the Apache web server-free software. ${ }^{153}$ More than half of all back-office e-mail functions are run by one free software program or another. ${ }^{154}$ These are mission-critical applications for

151. See Benkler, supra note 3; James Boyle, The Second Enclosure Movement and the Construction of the Public Domain, LAW \& CONTEMP. PROBS., Winter/Spring 2003, at 33, 44-49.

152. Josh Lerner \& Jean Tirole, The Scope of Open Source Licensing, 21 J.L. ECON. \& ORG. (forthcoming Spring 2005) (manuscript at 37 tbl.1) (identifying roughly eighty-five percent of the licenses in active projects on SourceForge, the biggest site for clearance of free software development projects, as having "restrictive" or "very restrictive" licenses - that is, largely speaking, as being copylefted).

153. Netcraft, Web Server Survey Archives, http://news.netcraft.com/archives/web_server_ survey.html (last visited Sept. 29, 2004).

154. E-mail server surveys are less common and regularized than web server surveys. For much of the 1990s, the dominant e-mail server was Sendmail, see GLYN MOODY, REBEL CODE 243 (2001), which was distributed mostly under a Berkeley Software Design (BSD) license and is currently available under that license to all but those who intend to be commercial redistributors of the software when unaccompanied by its source code, see Sendmail License, $\mathrm{ftp}: / / \mathrm{ftp}$. sendmail.org/pub/sendmail/license (last visited Sept. 29, 2004). In the past few years, Sendmail has lost market share, partly to other free software projects and partly to a new proprietary e-mail server, iMail, which seems to have risen in usage to around $19 \%$ of market share. Compare Credentia, E-Mail Server Survey Results for April 2003, http://www.credentia.cc/surveys/smtp/200304/ (last visited Sept. 29, 2004) (noting iMail's 8.4\% 
the organizations that adopt them, applications that most organizations would not jeopardize to save a few thousand dollars in licensing fees. Google, Amazon, and CNN.com, for example, are not running their web servers on the GNU/Linux operating system ${ }^{155}$ in order to save licensing fees at the risk of a higher failure rate for their core businesses. The measurable efficacy of free software has made dismissing the phenomenon harder. The centrality of software to production in the information and communications environment has made its success impossible to ignore and important to preserve and emulate.

While free software is the most visible instance of peer production, with areas of measurably superior performance, it is not its only locus. I have described these other phenomena in detail elsewhere, ${ }^{156}$ but will encapsulate one example here. Slashdot is a technology-news site coauthored by a quarter of a million users. ${ }^{157}$ It is far from perfect, but it has become something of a must-read for anyone seriously interested in information and communications technology. The site allows its hundreds of thousands of users to scour the Internet for news, to identify what is relevant and what is not, and to post links with commentary for others to read. Users then comment and elaborate, work that itself is peer reviewed by other users through a system of technologically mediated recording of quality judgments. The peer reviewers are themselves reviewed by other users periodically, and may be removed if enough other users find their judgments lacking. The whole system of posting of stories, commentary on stories posted, and recursive peer review of the commentary and of the quality of the peer reviewers runs on a free software platform. Together

market share in April 2003), with FalkoTimme, Mail Server Survey March 2004, http://www.falkotimme.com/projects/survey_smtp_032004.php (last visited Sept. 29, 2004) (noting iMail's $18.75 \%$ share in March 2004). At the same time, however, a free software project supported by IBM, Postfix, also rose from $2.53 \%$ to $20.55 \%$. Compare Credentia, supra, with FalkoTimme, supra. Postfix is a particularly interesting case because it was developed as an alternative to Sendmail but also self-consciously as a competitor to Qmail. See Postfix Overview, http://www.postfix.org/motivation.html (last visited Sept. 29, 2004). Qmail, in turn, was developed as an alternative to Sendmail, and for a while was believed to have been developed by Daniel Bernstein for release as free software. Bernstein, however, has chosen to release the software at no charge, but under terms that give him strong authorial control. See D.J. Bernstein, Information for Distributors, http://cr.yp.to/qmail/dist.html (last visited Sept. 29, 2004). Qmail's use declined dramatically between the two surveys cited above, suggesting a preference in the community of adopters for free software over software that is offered at no charge, but nonetheless controlled.

155. Information about the operating system used by a website can be obtained by querying the site. A simple tool is available at Netcraft, About the Netcraft Web Server Query Form, http://uptime.netcraft.com/up/graph (last visited Sept. 29, 2004). The three sites are selected purely for anecdotal intuitive reasons, with no special claim to being representative of broader usage statistics.

156. See Benkler, supra note 3, at 381-400.

157. Slashdot, http://slashdot.org/ (last visited Sept. 29, 2004). 
these provide an identifiable information good, co-produced by many users, in a manner that is efficacious and yet based on social motivations and structures of participation, not on prices or hierarchical commands. The users contribute and share in each other's time and judgments about what is relevant to this community of interest and how to evaluate the events of the day in its fields of coverage. In this case, the "shareable good" involved is the time, education, and effort of the users who participate. It is combined with a public good-existing information - to form what is also itself a public good-a topical news and commentary source. Other similar endeavors have provisioned an encyclopedia coauthored by a few thousand volunteers, ${ }^{158}$ a comprehensive human-edited directory of websites, on the model of the Yahoo! directory but provisioned by over 60,000 volunteers, ${ }^{159}$ and many other examples. ${ }^{160}$

Creative labor in the context of peer production can be harnessed when a project is broken up into discrete modules, whose granularity is varied and sufficiently fine grained to allow individuals with diverse motivations to engage in the effort at levels appropriate for their motivations but still provide stable contributions to the whole. ${ }^{161}$ In this, the modularity and granularity of the individual effort and time required by a project allow individuals to segment their own days, weeks, or months such that they can find "excess capacity" that they can contribute to the common effort. The relative efficiency of peer production and markets, as with the case of social sharing of shareable goods, is analyzed in terms similar to those offered here-concerning information, transaction costs, and motivations-but with changes appropriate for the case of human creative labor, which is different in many ways from the material goods that were the subject of the first three Parts of this Essay.

These lines of literature point to an emerging understanding of social production and exchange. This phenomenon is not limited to public goods, to exotic out-of-the-way places like surviving medieval Spanish irrigation regions ${ }^{162}$ or the shores of Maine's lobster-fishing grounds, ${ }^{163}$ or even to the ubiquitous phenomenon of the household. ${ }^{164}$ Nor, as SETI@home and the body snatchers and slugs of Northern Virginia suggest, is it necessarily limited to stable communities of individuals who interact often and know

158. Wikipedia: The Free Encyclopedia, http://www.wikipedia.org (last visited Sept. 29, 2004).

159. Open Directory Project, http://www.dmoz.org (last visited Sept. 29, 2004).

160. See Benkler, supra note 3.

161. See id. at 400-43.

162. See OSTROM, supra note 77, at 69-81.

163. See ACHESON, supra note 77.

164. See At the InTERface: The Household AND Beyond (David B. Small \& Nicola Tannenbaum eds., 1999); THE HOUSEHOLD ECONOMY: RECONSIDERING THE DOMESTIC MODE OF PRODUCTION (Richard R. Wilk ed., 1989); Ellickson, supra note 83. 
each other or expect to continue to interact personally. Social production of goods and services, both public and private, is pervasive, though unnoticed. It sometimes substitutes for, and sometimes complements, market and state production everywhere. It is, to be fanciful, the dark matter of our economic production universe.

Consider the way in which the following sentences are intuitively familiar, yet as a practical matter describe the provisioning of goods or services that have well-defined NAICS categories. ${ }^{165}$ Their provisioning through the markets is accounted for in the economic census, but they are commonly provisioned in a form consistent with the definition of sharingon a radically distributed model, without price or command.

NAICS 624410 [Babysitting services, child day care]

"John, could you pick up Bobby today when you take Lauren to soccer? I have a conference call I have to make."

"Are you doing homework with Zoe today, or shall I?"

NAICS 484210 [Trucking used household, office, or institutional furniture and equiptment]

"Jane, could you lend a hand moving this table to the dining room?"

"Here, let me hold the elevator door for you, that looks heavy."

NAICS 484122 [Trucking, general freight trucking, long distance, less than truckload]

"Jack, do you mind if I load my box of books in your trunk so you can drop it off at my brother's on your way to Boston?"

NAICS 519110 [Traffic reporting services]

"Oh, don't take I-95, it's got horrible construction traffic to exit 39."

NAICS 711510 [Newspaper columnists, independent (freelance)]

"I don't know about Clark, he doesn't move me, I think he should be more aggressive in criticizing Bush on Iraq."

NAICS 621610 [Home health care services]

"Can you please get me my medicine? I'm too wiped to get up."

"Would you like a cup of tea?" 
NAICS 561591 [Tourist information bureaus]

"Excuse me, how do I get to Carnegie Hall?"

NAICS 561320 [Temporary help services]

"I've got a real crunch on the farm, can you come over on Saturday and lend a hand?"

"This is crazy, I've got to get this document out tonight. Could you lend me a hand with proofing and pulling it all together?"

NAICS 71 [Arts, entertainment, and recreation]

"Did you hear the one about the Buddhist monk, the rabbi, and the Catholic priest?"

"Roger, bring out your guitar!"

"Anybody up for a game of . . .?"

The litany of examples reveals a conception of social sharing that differs from the current foci of the literature along four different dimensions. First, the examples relate to production of goods and services, not only of norms or rules. Social relations provide the very motivations for, and information relating to, production and exchange, not only the institutional framework for organizing action that itself is motivated, informed, and organized by markets or managerial commands. Second, they relate to all kinds of goods, not only public goods. In particular, the paradigm cases of free software development, distributed computing, and carpooling involve labor and shareable goods-each plainly using private goods as inputs and, in the case of carpooling and distributed computing, producing private goods as outputs. Third, at least some of them relate not only to relations of production within well-defined communities of individuals who have repeated interactions, but extend to cover baseline standards of human decency. These standards enable passersby to ask one another for the time or for directions, enable drivers to cede the road to each other, and enable strangers to collaborate on software projects, on coauthoring an online encyclopedia, or on running simulations of how proteins fold. Fourth, they may either complement or substitute for market and state production systems, depending on the social construction of mixed provisioning.

What weight social and sharing-based production has in the economy is hard to measure. Our intuitions about capillary systems would suggest that the total volume of boxes or books moved or lifted; instructions given; news relayed; and meals prepared by family, friends, neighbors, and minimally decent strangers would be high relative to the amount of 
substitutable activity carried on through market exchanges or state provisioning.

\section{B. Sharing Is Sensitive to Technology Because Individual Efficacy Is Subject to Physical-Capital Constraints}

A threshold requirement for social sharing to be a modality of economic production, as opposed to purely one of social reproduction, is that sharing-based action be effective. Efficacy of individual action depends on the physical-capital requirements for action to become materially effective, which in turn depend on technology. When effective action has very low physical-capital requirements, so that every individual possesses, by natural capacity, the physical capital necessary for action, social production or sharing can be (though may in practice not become) ubiquitous. Voice cords to participate in a sing-along and muscles to lift a box are obvious examples. When the capital requirements are nontrivial, but the capital good is still widely distributed and available, sharing can similarly be ubiquitous and effective. This is true whether the shared resource or good is the capacity of the capital good itself-as in the case of shareable goods - or some widely distributed human capacity capable of being made effective through the use of the widely distributed capital goods - as in the case of the human creativity, judgment, experience, and labor that are shared in online peer production processes, for which participants rely on the widespread availability of connected computers to participate.

When some larger-scale physical-capital requirement is a threshold requirement of effective action, however, we should not expect to see widespread reliance on decentralized sharing as a standard modality of production. Industrial mass manufacture of automobiles, steel, and plastic toys is not the sort of thing likely to be produced on a social sharing basis, because of the capital constraints. This is not to say that even for large-scale capital projects, like irrigation systems and dams, social production systems cannot step into the breach. We have those core examples in the common property regime literature, and we have worker-owned firms as examples of mixed systems. But those systems tend to replicate the characteristics of firm, state, or market production - using various combinations of quotas, scrip systems, formal policing by "professional" officers, quasi-formal systems for adjudicating disputes, and midlevel management within 
worker-owned firms. ${ }^{166}$ By comparison, the lobster gangs of Maine ${ }^{167}$ or fishing groups in Japan, ${ }^{168}$ whose capital requirements are much lower, tend to be more social-relations-based systems, with less formalized or crisp measurement of contributions to and calls on the production system.

It is important to emphasize that technology imposes threshold constraints on effective sharing, but it cannot unilaterally determine the level of sharing practiced in a society. At any given level of technically feasible sharing, societies may differ in their cultural practices and tastes. These differences can be expressed in the approach I offered in Part III as (1) the level of background investment in any one of the alternative transactional frameworks and (2) the shape of the demand for socialpsychological rewards. Differences in these elements will result in different levels of sharing in societies that share a technological state but differ in their cultures of sharing. A change in technology, however, that increases the supply of opportunities for sharing should, other things being equal, increase the prevalence of sharing practices. Moreover, if culture is endogenous, then the taste for sharing will also change with the increase in feasible opportunities for sharing. For example, one possible interpretation of the survey data about preferences of carpoolers ${ }^{169}$ is that it is an indication of coherence-seeking attitudinal changes toward the benefits of sociability, time saving, etc. that carpoolers adopt to make their practice cohere with their beliefs, rather than of attitudinal priors that individuals hold before participating in the practice. ${ }^{170}$ If this were so, and we believed that by practicing sharing people come to value it more, or come to learn to trust other participants, then an increase in opportunities to share will dynamically increase the taste for sharing as well, ${ }^{171}$ which will increase the

166. See, e.g., HANSMANN, supra note 104 (describing the worker-owned firm as simply a species of firm ownership); OSTROM, supra note 77, at 69-82 (describing the governance mechanisms of the complex irrigation systems).

167. See ACHESON, supra note 77.

168. See Jean-Philippe Platteau \& Erika Seki, Community Arrangements To Overcome Market Failures: Pooling Groups in Japanese Fisheries, in COMMUNITIES AND MARKETS IN ECONOMIC DEVELOPMENT 344 (Masahiko Aoki \& Yujiro Hayami eds., 2001).

169. See supra notes 52-53 and accompanying text.

170. See Simon, supra note 54.

171. I have been criticized on this point with the claim that if sharing becomes more widespread, perhaps it will be "cheapened": The ubiquity of sharing and giving will drain these acts of the status they derive from being exceptional, thus effectively crowding itself out. This is of course an empirical prediction, not an analytic objection, but one that comports neither with intuition nor with evidence. As for intuition, imagine that taking a friend home in your car after a party is an uncommon practice, so that when you take someone and drop them off three blocks from home you get great kudos. Now imagine that the practice grows, and people often take each other home. When a friend says, "I have no car," what happens? (1) You think to yourself, "Ah, everyone is taking people home in their cars now, so I won't get kudos," and then say, "Sorry, I can't," and the friend thinks and says, "Oh, that's fine"; or, (2) you think and say the same as in (1), but the friend thinks to herself, "What a selfish sociopath," the expectation of which actually 
amount of sharing practiced. This is a virtuous cycle, at least from the perspective of anyone who holds that a society that practices trust and sharing is normatively more attractive than a society where agents treat each other at arm's length. ${ }^{172}$

To say that sharing is technology dependent is not to deny that it is a ubiquitous human phenomenon. Sharing is so deeply ingrained in so many of our cultures that it would be difficult to argue that with the "right" (or perhaps "wrong") technological contingencies, it would simply disappear. My claim is much narrower. It is that the relative economic role of sharing changes with technology. There are technological conditions that require more or less capital, in larger or smaller packets, for effective provisioning of goods, services, and resources valued functionally. As these conditions change, the relative scope for social sharing practices to play a role in production changes too. When goods, services, and resources are widely dispersed, their owners can choose to engage with each other through social sharing instead of through markets or a formal state-based relationship, because individuals have available to them the resources necessary to engage in such behavior without recourse to capital markets or the taxation power of the state. If technological changes make the resources necessary for effective action rare or expensive, individuals may wish to interact in social relations but will only be able to do so ineffectively, or in different fields of endeavor that do not similarly require high capitalization. Largegrained, expensive physical capital draws behavior into one or the other of the modalities of production that can concentrate financial capital. Nothing, however, prevents change from happening in the opposite direction. Goods, services, and resources that in the industrial stage of the information economy required large-scale, concentrated capital investment to provision are now subject to a changing technological environment that can make sharing a better way of achieving the same results today than can states, markets, or their hybrid, regulated industries.

Music, for instance, was a relational good in the nineteenth century. ${ }^{173}$ It was something people did in the physical presence of one another: in the folk way of hearing, repeating, and improvising; in the middle-class 'vay of buying sheet music and playing for guests or attending public

results in (3) your saying in the first place, "Sure, I'd love to," and if you want to earn the kudos, you go three blocks out of your way and drop her off at the front door. Beyond the intuition, both analytic models and empirical evidence support the proposition that as kind, sharing, and reciprocal behavior increases in society, so does the tendency to trust others, reciprocate, and behave pro-socially. See, e.g., KAHAN, supra note 2, at 2-6.

172. See Helen Nissenbaum \& Yochai Benkler, Commons Based Peer Production and Virtue (May 26, 2004) (unpublished manuscript, on file with author).

173. Eben Moglen, The dotCommunist Manifesto 2-3 (Jan. 2003), available at http://moglen.law.columbia.edu/publications/dcm.pdf. 
performances; or in the upper-class way of hiring musicians. Market-based production depended on performance through presence. It provided opportunities for artists to live and perform locally. With the introduction of the phonograph, a particular relationship to played music was made possible, one that was more passive, relying on the high capital requirements of recording, copying, and distributing instantiations of recorded music. What developed was a concentrated industry, based on massive investments in preference formation, which crowded out some, but not all, of the sharing practices and many of the presence-performancebased markets, though not all of them (like jazz clubs, piano bars, or wedding bands). Conversely, as computers became more music capable and digital networks became a ubiquitously available distribution network, we saw the emergence of the present conflict over the regulation of cultural production - the law of copyright-between the twentieth-century industrial-model recording industry and the emerging amateur distribution systems coupled, at least according to supporters, to a reemergence of decentralized, relation-based markets for professional performance artists.

\section{Decentralized, Loosely Coupled Social Sharing Is an Economically Attractive Modality of Production}

The kind of social interaction typified by peer production like free software development, or by distributed computing, has remarkably marketlike characteristics that make it particularly attractive as a social modality of production from the perspective of economic efficiency. The decentralization of these processes underlies agents' capacity to retain a great degree of individual autonomy within the social interaction. This autonomy - to choose to participate, to select opportunities for action, and to act when the participant wishes and in the fashion that she chooses-is central to the informational advantage of peer-production efforts over firms. Individual agents can act, by contributing labor or a unit of excess capacity, without the need for formalization of their role or contribution, either for contracting or for managerial assignment. The modularity-of the incremental material contributions in shareable goods or of the work tasks in peer production-keeps individual actions discrete and fairly fine grained. This modularity again allows individuals to make decisions at the margin for each contribution or cluster of contributions, without undermining the whole and without incurring high social costs. These characteristics make the availability of resources-either labor or materials-relatively fluid. The weakness of the social relations, usually thought harmful to the sustainability of cooperation in the absence of property rights or managerial oversight, improves the fluidity of 
deployment of goods and actions and bolsters the degree of agent autonomy in the relationship.

This does not mean that individuals do not get emotionally and socially engaged in peer-production projects. They do. Nor does it mean that participants do not derive a sense of meaning and connectedness to others from participation. They do. It does, however, mean that the particular shape of this form of social production is relatively fluid, leaving tremendous room for autonomous individual action, in concert with others but not subject to them. The normative implications of these characteristics of peer production and large-scale social sharing behaviors are ambiguous. To a communitarian, the fluidity, the capacity to be involved in many projects at once, to ratchet one's participation up or down on an ad hoc basis, and to cabin the cooperative enterprise in one small or large compartment of one's life would render this mode relatively unattractive. But to liberals, libertarians, and postmodernists, various characteristics of this modality of production should be very congenial-it respects autonomy and allows for the creation of varied and diverse social relations of production, relatively free of the structuring effects of property rights and the distribution of wealth. Irrespective of one's position on the normative attractiveness of peer production as compared to Amish barn raisings, functionally it allows larger-scale participation by many more people, who can shift their efforts and contributions dynamically as need and interest arise and change. It is, in other words, likely to be more economically effective and efficient on a larger scale.

The claim, then, is that phenomena I describe here and elsewheresharing of material shareable goods and peer production of software, information, and cultural goods more generally-resemble an ideal market in their social characteristics, but with social cues and motivations replacing prices as a means to generate information and motivate action. These phenomena rely on relatively impersonal, or loosely coupled, cooperation, are generally focused on a particular functional project, and are based on quite radically decentralized action. Their impersonality is what allows them to scale to very large groups, which can nonetheless maintain effective action, because intimacy, or even substantial familiarity, is highly limited by each individual's time, memory, and emotional capacities. Their relatively project-specific pattern is what allows for moderately impersonal exchange to suffice. Increasing the relational scope, which would require greater dedication from each individual, would make participants more vulnerable to each other and require greater stability and control over inputs and outputs. The absence of these stronger, "stickier" bonds makes these phenomena attractive as a modality of production because they allow greater flexibility and liquidity in the deployment of resources-whether 
human or material-through these systems, more so than systems that depend on more centralized organizational infrastructures or that claim broader scope over the participation of participants.

\section{SOME CURRENT POLICY IMPLICATIONS}

What are the policy implications of recognizing sharing as a sustainable and potentially efficient modality of economic production? Where is there now a policy battle between market-based, hierarchical organizations and social production through sharing? I will note here three areas with substantial implications for how our society produces, records, and communicates information, knowledge, and culture.

\section{A. Wireless Communications Regulation}

Perhaps the most counterintuitive policy shift, yet the one most likely to represent a fundamental change in our approach to provisioning a basic resource, is in the area of wireless communications. Early in the first decade and a half of radio, radios were relatively specialized but not sophisticated. Wireless communications capacity, such as existed, was therefore largely decentralized. Marconi operated large shore-to-ship stations on a monopoly service model, alongside much small-scale experimentation of the type that would come to be known as amateur radio. From World War I through the mid-1920s, improvements in the capacity of expensive transmitters and a series of strategic moves by the owners of the core patents in radio transmission-GE, RCA, AT\&T, and Westinghouse-led by 1926 to the emergence of the industrial model of radio communications that typified the twentieth century. Radio came to be dominated by a small number of professional, commercial networks, based on high-capital-cost transmitters, supported by a regulatory framework tailored to making passive reception with simple receivers of commercial programming delivered through highpowered transmitters the primary model of radio for most Americans. This development crowded out the more widely distributed, local infrastructure of nonmarket broadcasting that blossomed in the first half of the 1920s in the United States. ${ }^{174}$

174. A condensed version of this history can be found in Yochai Benkler, Overcoming Agoraphobia: Building the Commons of the Digitally Networked Environment, 11 HARV J.L. \& TECH. 287, 301-14 (1998). The most comprehensive history on which this story is based is 1 ERIK BARNOUW, A HISTORY OF BROADCASTING IN THE UNITED STATES: A TOWER IN BABEL (1966). There are, needless to say, other historiographies of this period, some covered in Benkler, supra, at 298-301. The most distinctly different story, focusing more on the politics of grass-roots activism versus corporate corruption of the process and locating the origins of the system in the mid-1930s instead of the mid-1920s, is ROBERT W. MCCHESNEY, TELECOMMUNICATIONS, MASS 
The industrial model, which assumes a large-scale capital investment in the core of the network and small-scale investments at the edges, optimized for receiving what is generated at the core, was imprinted on wireless communications systems both at the level of design and of regulatory theory. When mobile telephony came along, it replicated the same model, using relatively cheap handsets oriented toward an infrastructure-centric deployment of towers. The economic analysis of wireless communications adopted the same model, and it spent four decades criticizing the incumbent approach only on the basis that it inefficiently regulated the legal right to construct a wireless system by regulating spectrum use instead of creating a market in "spectrum use" rights. ${ }^{175}$

By the time that legislatures in the United States and around the world had begun to accede to the wisdom of the economists' critique, however, the industrial model had been rendered obsolete by technology. ${ }^{176}$ In

MEDIA, AND DEMOCRACY: THE BATTLE FOR THE CONTROL OF U.S. BROADCASTING, 1928-1935 (1993). While McChesney's history is a gripping and important one, it is consistent, rather than inconsistent, with the hypothesis that the U.S. system was "tipped" by 1926 . The power of the networks, which had captured the political process in the 1930s, is rooted in the business history of the first half of the 1920s. McChesney describes how that earlier moment, when we were locked into the regulated, concentrated commercial-industry model, worked itself out over almost a decade, rather than describing a moment of true openness and missed opportunity.

The stakes of this interpretation for understanding Internet policy today are high. My version, the version I ascribe to Barnouw, requires an immediate focus on economic and technical structure while the technological and business organization of the Internet communications environment is still open. Time is of the essence, business structure and technology the objectives. McChesney's version would suggest that political action to attain regulatory control of an already embedded technical-business structure is potentially effective. Time is then a little looser, and behavioral regulation of an otherwise unattractive business and technical framework is a feasible path of reform.

175. The locus classicus of the economists' critique $\rightarrow$ R.H. Coase, The Federal Communications Commission, 2 J.L. \& ECON. 1 (1959). The best-worked-out version of how these property rights would look remains Arthur S. De Vany et al., A Property System for Market Allocation of the Electromagnetic Spectrum: A Legal-Economic-Engineering Study, 21 STAN. L. REV. 1499 (1969). While those works were deeply revolutionary for their time, and coherent with the then-prevailing technological-economic conditions and the state of the radio engineering discipline, the position that "spectrum" had to be "managed" by someone, and that that someone must be either the government or an owner of property rights defined in RF frequency bands, turns out, in hindsight, to have been technologically contingent rather than generally stable.

176. For the full argument, see Benkler, supra note 174; and Yochai Benkler, Some Economics of Wireless Communications, 16 HARV. J.L. \& TECH. 25 (2002). For an excellent overview of the intellectual history of this debate, a detailed explanation of the emerging business models around sharing radios, and a contribution to the institutional design necessary to make space for this change, see Kevin Werbach, Supercommons: Toward a Unified Theory of Wireless Communication, 82 TEX. L. REV. 863 (2004). The policy implications of computationally intensive radios using wide bands were first raised, to my knowledge, by George Gilder, The New Rule of Wireless, FORBES ASAP, Mar. 29, 1993, at 96s, and by Paul Baran, Visions of the 21st Century Communications: Is the Shortage of Radio Spectrum for Broadband Networks of the Future a Self Made Problem?, Keynote Address Before the Eighth Annual Conference on Next Generation Networks (Nov. 9, 1994), available at http://www.eff.org/Infrastructure/Wireless cellular_radio/false_scarcity_baran_cngn94.transcript. Both statements focused on the potential abundance of spectrum and how it renders "spectrum management" obsolete. Eli Noam was the 
particular, the declining cost of computation and the increasing sophistication of communications protocols among end-user devices in a network made possible new sharing-based solutions to the problem of how to allow users to communicate without wires. Now, instead of having a regulation-determined exclusive right to transmit, which may or may not itself be subject to market reallocation, it is possible to have a market in small-scale capital goods-smart radio equipment owned by individuals, much like automobiles and PCs-which embed in the devices the technical ability to share capacity and cooperate in the creation of capacity. These radios can cooperate by relaying each other's messages or by temporarily "lending" their antennae to neighbors to help them decipher messages of senders who are not entitled to exclusive use of the spectrum. ${ }^{177}$

Described in terms of this Essay, radio and computer technology has changed. Where once we had capital goods (radio transmitters and antenna towers) and consumer goods (radio receivers), now we have shareable goods (new radio "transceivers"). These transceivers have excess capacity to generate wireless transport capacity, which, like distributed computers and automobiles, their owners can share in order to produce wireless communications systems.

The reasons that the owners share are relatively straightforward in this case. Users want to have wireless connectivity all the time, to be reachable and immediately available everywhere. But they do not actually want to communicate every few microseconds. They are therefore willing to

first to point out that, even if one did not buy the idea that computationally intensive radios eliminated scarcity, they still rendered property rights in spectrum obsolete, and enabled instead a fluid, dynamic, real-time market in spectrum clearance rights. See Eli M. Noam, Taking the Next Step Beyond Spectrum Auctions: Open Spectrum Access, IEEE COMM. MAG., Dec. 1995, at 66; see $a \rightarrow$ Eli Noam, Spectrum Auctions: Yesterday's Heresy, Today's Orthodoxy, Tomorrow's Anachronism. Taking the Next Step to Open Spectrum Access, 41 J.L. \& ECON. 765, 778-80 (1998) (elaborating the author's earlier work). The argument that equipment markets based on a spectrum commons or free access to frequencies could replace the role planned for markets in spectrum property rights with computationally intensive equipment and sophisticated network sharing protocols, and would likely be more efficient even assuming that scarcity persists, is presented in Benkler, supra note 174. LAWRENCE LESSIG, CODE AND OTHER LAWS OF CYBERSPACE (1999) [hereinafter LESSIG, CODE], and LAWRENCE LESSIG, THE FUTURE OF IDEAS (2001), develop an argument relying on the parallel structure of innovation in the original Internet end-to-end design architecture and of open wireless networks that offers a rationale based on the innovation dynamic in support of the economic value of open wireless networks. David P. Reed, Why Spectrum Is Not Property: The Case for an Entirely New Regime of Wireless Communications Policy (Feb. 27, 2001), http://www.reed.com/Papers/openspec.html, and David P. Reed, Comments for FCC Spectrum Policy Task Force on Spectrum Policy (July 8, 2002), http://gullfoss2.fcc.gov/prod/ecfs/retrieve.cgi?native_or_pdf-pdf\&id_document $=6513202407$ [hereinafter Reed, Comments for FCC], crystallized the technical underpinnings and limitations of the idea that spectrum can be regarded as property. Reed's was the first substantial set of public comments in favor of a spectrum commons.

177. For a reasonably accessible description of the various techniques, see Andrea $\mathrm{J}$. Goldsmith \& Stephen B. Wicker, Design Challenges for Energy-Constrained Ad Hoc Wireless Networks, IEEE WIRELESS COMM., Aug. 2002, at 8. 
purchase and keep turned on equipment that makes them always available and instantaneously connected from wherever they are. Manufacturers, in turn, develop and adhere to standards that improve capacity and connectivity. Given that "cooperation gain" is the most promising source of better-than-linear capacity scaling for distributed wireless systems, ${ }^{178}$ these standards should gravitate toward interoperability and mutual awareness of requirements. Whether there are technically robust ways of "cheating" on a standard to improve performance by not cooperating is debatable, ${ }^{179}$ but it is doubtful that, even if achievable in principle, cheating could be done on a commercial scale without detection and in compliance with interoperability standards. Users, then, have incentives to keep systems turned on, manufacturers have incentives to "share nicely," and defections from sharing are likely to be reasonably identifiable. What remains for consideration in the regulatory process is how much, if any, background regulation of systems is necessary to constrain specifically strategic defections from cooperative standards, and in what flavors-as precertification rules, as liability rules, etc. This is a hard problem that will likely not be solved theoretically, but rather through practical experimentation with different regimes in different parts of the alreadyregulated spectrum.

Cooperative, sharing-based wireless connectivity can emerge if it is not illegal for the vendors of wireless equipment to produce and sell the machines that let people share their capacity and help each other to communicate. The past few years have seen at first slow, and more recently quite dramatic, change in the extent to which the FCC and Congress have recognized this opportunity and begun to make regulatory space for its development. Indeed, in the past two years alone a major shift has occurred, and what have been called "commons-based" approaches to wireless

178. See Benkler, supra note 176 , at $44-47$ (providing definition and underlying technical citations). The term "cooperation gain" was developed by David Reed, see Reed, Comments for FCC, supra note 176 , to describe a concept similar to, but somewhat broader than, what is known as "diversity gain" in multi-user information theory.

179. Compare Durga P. Satapathy \& Jon M. Peha, Spectrum Sharing Without Licenses: Opportunities and Dangers, in INTERCONNECTION AND THE INTERNET 49 (Gregory L. Rosston \& David Waterman eds., 1997) (modeling defection in unlicensed wireless systems), with Timothy J. Shepard, Comments to the FCC Taskforce, http://gullfoss 2 .fcc.gov/prod/ecfs/retrieve.cgi? native_or_pdf $=$ pdf\&id_document $=6513201206$ (last visited Sept. 29, 2004), and Timothy J. Shepard, Additional Comments, http://gullfoss2.fcc.gov/prod/ecfs/retrieve.cgi?native_or_pdf= pdf\&id_document=6513405081 (last visited Sept. 29, 2004). Shepard, who was the first theoretical engineer to build a workable model of municipal-level scalable networks in a mesh architecture, explains why adding power-the quintessential strategy that would lead to tragedy and require regulation - is not the only, and indeed not the most desirable, mechanism of dealing with increased power by antisocial neighbors. See Timothy Jason Shepard, Decentralized Channel Management in Scalable Multi-Hop Spread Spectrum Packet Radio Networks (1995) (unpublished Ph.D. dissertation, MIT) (on file with the MIT library). 
communications policy have come to be seen as a legitimate, indeed a central, component of the FCC's wireless policy ${ }^{180} \mathrm{We}$ are beginning to see in this space the most prominent example of a system once entirely oriented toward improving the institutional conditions of market-based production of wireless transport capacity as functionality flows (connectivity minutes) now shifting to enable the emergence of a market in shareable goods (smart radios) designed to provision transport on a sharing model.

\section{B. Information, Knowledge, and Cultural Production Policy}

Another area of policy where sharing is coming into conflict with market- or firm-based production that is based on a particular regulatory environment is in cultural production. ${ }^{181}$ The story of music that I told in Section IV.B is the paradigmatic case of the pressure that the ubiquity of networked computers places on our understanding of how information, knowledge, and culture are produced, of the potential these networks have for increasing the relative role of sharing systems in that production process, and of efforts to use law to squelch the technological conditions and practices of sharing and the social production of distribution.

In many senses, it is odd to think of cultural production as an area that ever came to be thought of as "dominated," in any useful meaning of the word, by market production. As an analytic matter, music, films, and books are forms of information, public goods, and could not, even in principle, be provisioned efficiently by markets alone. ${ }^{182}$ As a practical matter, we have always relied heavily on organizational and institutional forms insulated from both state and markets to produce information, knowledge, and culture. That is what the university and academic freedom are centrally about. That is what underlies the heavy reliance of the arts on philanthropy and on a culture of esteem and status as crucial motivating forces. That is what public schools and libraries are about. Our understanding of information, knowledge, and culture as "public goods" in the formal

180. See FCC, Spectrum Policy TASK ForCe RePort to THE COMMission (2002), available at $\mathrm{http}: / /$ hraunfoss.fcc.gov/edocs_public/attachmatch/DOC-228542A1.pdf; Michael K. Powell, Broadband Migration III: New Directions in Wireless Policy, Remarks at the Silicon Flatiron Telecommunications Program, University of Colorado at Boulder (Oct. 30, 2002), available at $\mathrm{http}: / / \mathrm{www} . \mathrm{fcc}$.gov/Speeches/Powell/2002/spmkp212.html.

181. The conflict is brilliantly described and engaged in LAWRENCE LESSIG, FREE CULTURE: HOW BIG MEDIA USES TECHNOLOGY AND THE LAW TO LOCK DOWN CULTURE AND CONTROL CREATIVITY (2004); JESSICA LITMAN, DIGITAL COPYRIGHT (2001); and SIVA VAIDHYANATHAN, COPYRIGHTS AND COPYWRONGS: THE RISE OF INTEllECTUAL PROPERTY AND HOW IT THREATENS CREATIVITY (2001).

182. See Kenneth J. Arrow, Economic Welfare and the Allocation of Resources for Invention, in NAT'L BUREAU OF ECON. RESEARCH, THE RATE AND DIRECTION OF INVENTIVE ACTIVITY: ECONOMIC AND SOCIAL FACTORS 609, 616-17 (1962). 
economic sense should have immunized us from mistaking the presence of important market-based approaches for the whole, or even the core, of the story of information and cultural production. And yet, it does seem that our perception of where information generally, and culture in particular, comes from came to be dominated over the second half of the twentieth century by a vision of Hollywood and the recording industry.

The rise of Hollywood and the recording industry is a happenstance of the twentieth-century economics of film and music recording and distribution. The relative capital intensity involved in recording, distribution, and production underlies the industrial structure of these industries. This structure, in turn, and the political force of its industries, underlies the steady but inexorable changes in copyright law, from a relatively brief period of statutory exclusivity over commercial distribution at the turn of the twentieth century to a broad, practically perpetual right over almost any use of copyrighted information, knowledge, or cultural materials by the close of that century.

Against the background of the iconic role of movies and recorded music in framing how we understand our cultural production system, Napster emerged at the close of the century as the counter-icon of the technological shift that radically disrupted that model. In the legal battles that have followed, the industry has ever more virulently invoked the powers of the state to squelch the use of this technology and its attendant social-cultural attitudes. In these battles, the revolutionary effect of peer-topeer technologies and of sharing as a modality of production-in the case of music, distribution, relevance, and accreditation-have been overshadowed. ${ }^{183}$

Free software development, and peer production more generally, combine two features that make them the polar opposite of Hollywood and the recording industry. First, they decentralize the legal privilege to decide to act upon information resources in pursuit of information production projects. One needs no permission to participate in a peer-production project, to use any particular piece of software as an input, or to combine it with any other. Second, the capital costs necessary to obtain, rework, and communicate the products of one's work to others with whom one is cooperating in production are low and are already owned for a variety of reasons by the participants. Neither capital nor legal rights provide a condensation point for hierarchical or property-based relations.

183. For an overview of the state of the music and film industries in the twentieth century, and of the battles since its closing years between the industrial producers and the emerging online technologies, see William W. Fisher III, PROMISES TO KEEP: TECHNOLOGY, LAW, AND THE FUTURE OF ENTERTAINMENT (2004). 
The policy conflict between these modes of production has emerged in two domains. First, and more immediately tractable to policy, is the question of government procurement policy vis-à-vis free software. Led by Microsoft, ${ }^{184}$ some software producers who depend on copyright have fought a battle to persuade governments to eschew free software in their procurement policies, as against an opposite political move to embrace free software-whether as a method to lower government software costs, a development policy to allow local programmers to develop skills and opportunities in free software markets, ${ }^{185}$ or a strategy to assure a diversity of sources for mission-critical applications. ${ }^{186}$ An understanding and appreciation of the ubiquity and stability of social-sharing-based production is important as an input into this debate.

More complex is the debate over the industrial structure of cultural production, in particular music and movies. Unlike the peer-production enterprises I mention here, Napster and its successors, from Gnutella to $\mathrm{KaZaa}$, are not involved in the creation of music. In what way, then, are Napster and KaZaa "productive"? In the same sense that the recording industry deems its role in stamping CDs, promoting them on radio stations, and placing them on distribution chain shelves to be productive. That is, they produce both the physical and informational aspects of the distribution system collaboratively, on a social sharing basis. This is what Eben Moglen has called anarchist distribution, which he claims has the perfectly plausible advantage that it puts the music people want into the hands of those who want it most, based on the six-degrees-of-separation principle. ${ }^{187}$ Jane's friends and friends of friends are more likely to know exactly what music would make her happy than are recording executives trying to predict

184. See Dave Newbart, Microsoft CEO Take[s] Launch Break with the Sun-Times, CHI. SUN-TIMES, June 1, 2001, at 57. According to Microsoft CEO Steve Ballmer,

The only thing we have a problem with is when the government funds open source work. Government funding should be for work that is available to everybody. Open source is not available to commercial companies. The way the license is written, if you use any open source software you have to make the rest of your software open source. If the government wants to put something in the public domain, it should. Linux is not in the public domain. Linux is a cancer that attaches itself in an intellectual property Id. sense to everything it touches. That's the way that the license works.

185. See Open Source Initiative, Use of Free Software in Government Agencies, http://www.opensource.org/docs/bill-EngTrans.php (last visited Sept. 29, 2004) (giving text of proposed Peruvian legislation).

186. See PANel on Open Source Software for Highend Computing, Report to the President: Developing Open Source SofTWARE To AdVANCE High END COMPUTING (2000), http://www.itrd.gov/pubs/pitac/pres-oss-11 sep00.pdf.

187. See Eben Moglen, Freeing the Mind: Free Software and the Death of Proprietary Culture, Address at the University of Maine Law School's Fourth Annual Technology and Law Conference (June 29, 2003), available at http://emoglen.law.columbia.edu/publications/mainespeech.html. 
which song to place, on which station, and on which shelf, to expose her to exactly the music she is most likely to buy in a context where she would buy it.

So KaZaa produces distribution of music on a sharing modality. Distribution is indeed a separate economic good from music creation, and yet was centrally tied to the way the production of music and movies has been paid for throughout the twentieth century. The ties were so close, in fact, that in displacing industrial distribution, peer-to-peer distribution is thought both by its critics and by some of its adherents to be likely to undermine the very possibility of industrial production of music. Now, there are some artists who welcomed this development, understanding that the model of production they were part of was industrial, and believing that artistic expression was being constrained by it. ${ }^{188}$ But others were perfectly happy with industrial distribution and the millions of dollars that they reaped from it, or believed that they might one day reap. Certainly there are recording industry executives whose roles have no existence outside of the industrial organization of music production and distribution.

Needless to say, it is not my purpose here to "solve" the question of peer-to-peer networks and their effect on the music industry. As free software has taught us, there is little doubt that social provisioning through sharing can at least partially displace market provisioning. We have no reason to believe that it could not, in principle, crowd that modality out entirely-despite the current ambiguity as to whether peer-to-peer sharing indeed crowds out CD sales. ${ }^{189}$ Is there a future for sharing-based music distribution? Is the displacement of industrial distribution by sharing-based distribution necessarily the end of market-based music production? Much of the actual flow of revenue to artists-from performances and other sources-is stable even assuming a complete displacement of the CD market by peer-to-peer distribution, suggesting that there will still be room for musicians to play for their dinner. Perhaps there will be fewer millionaires. Perhaps fewer mediocre musicians with attractive physiques will be sold as "geniuses," and more good musicians will be heard than otherwise would have and will as a result be able to get paying gigs instead of waiting tables or "getting a job." In any event, no one seriously claims that the market in distribution cannot be sustained in a radically

188. See, e.g., Courtney Love, Courtney Love Does the Math, SALON, June 14, 2000, http://dir.salon.com/tech/feature/2000/06/14/love/index.html; see also Future of Music Coalition, The Future of Music Manifesto, http://www.futureofmusic.org/manifesto (last visited Sept. 29, 2004).

189. See Felix Oberholzer \& Koleman Strumpf, The Effect of File Sharing on Record Sales: An Empirical Analysis (Mar. 2004), available at http://www.unc.edu/ cigar/papers/FileSharing March2004.pdf. 
decentralized mode. As long as songs-intrinsically public goods-are encoded in digital bits that are non-scarce, as long as users have computers that allow them temporarily to share their play lists and hard drives with others, sharing will be sustainable, indeed likely more efficient, as a means of distributing music.

As for creation, it would be silly to think that music, a cultural form without which no human society has existed, will cease to be in our world because we shall abandon the industrial form it took for the blink of a historical eye that was the twentieth century. Music was not born with the phonograph, nor will it die with the peer-to-peer network. The terms of the debate, then, are about cultural policy, perhaps about industrial policy. Will we get the kind of music we want in this system, whoever "we" are? Will American recording companies continue to get the export revenue streams they currently enjoy? Will artists be able to live from making music? Some of these arguments are serious. Some are but a tempest in a monopoly-rent teapot. What is clear is that a technological change has rendered obsolete a particular mode of distributing information and culture. Distribution, which used to be the sole domain of market-based firms, can now be produced by decentralized networks of users, sharing with others instantiations of music they deem attractive, using equipment they own and generic network connections. That is, users combine public goods (songs) with shareable goods (storage media and bandwidth) to provision the core good that was the bread and butter of the traditional industrial producers of music.

Policy is concerned now with whether and to what extent it should try to squelch this new modality of production to preserve the operating conditions of the old. Understanding the causes of the challenge suggests that three powerful elements will have to be, practically speaking, regulated away in order to preserve the old industrial structure. The newly emerging modality of production relies on (1) the most fundamental technical characteristics of digital communications networks-their flexibility and adaptability; (2) a technological-economic trend toward lower-cost, highercapacity processors that has been a stable feature of the computer industry for four decades; and (3) the ubiquitous and deeply ingrained cultural practices and social-psychological mindsets that form the transactional framework for an enormous amount of productive activity in our society, on- and off-line: sharing.

The practices of, and taste for, sharing are not epiphenomenal to the economy. They are not a hip new thing kids are doing, which will pass like 
any fad. ${ }^{190}$ They are as much a part of capillary production-"Jack, could you put the brown box on the high shelf?"- -as the incentives of money and the contract and property systems are central to the arteries- "Allied Vans, could you move the brown box to the bedroom in California?" It is breathtaking to imagine that all this would be legislated away in order to preserve the margins of two industries with total revenues of seventy-six billion dollars a year ${ }^{191}$ - slightly more than Verizon's annual revenue. ${ }^{192}$ The solution must assume that peer-to-peer file sharing is here to stay and that attempting to stamp out flexible, adaptive, general-purpose personal computers and criminalize one of our most basic social-cultural practices will, and ought to, fail. Once we understand that, we can focus our energies on the range of solutions that have been suggested - from government funding ${ }^{193}$ to tip jars and performances ${ }^{194}$ - that aim at preserving the livelihood of artists, not the twentieth-century business model of industrial cultural production.

\section{Network Design for a Network of Shareable Goods}

Not all policy is legal. As Larry Lessig has taught so many of us so well, the architecture of "code" is also policy. ${ }^{195}$ A large domain of communications policy operates at the level of network architecture, and the assumptions engineers make about what practices are socially sustainable inform their design choices. If engineers believe that people can be made to cooperate only through pricing, then where a network calls for

190. On the centrality of sharing as a modality of cultural production on the Net and its conflict with the notion of "stealing" music, see Jessica Litman, Sharing and Stealing (Apr. 13, 2004), available at http://www.law.wayne.edu/litman/papers/sharing\&stealing.pdf.

191. See Census Bureau, 2002 Economic Census, Table 1: Advance Summary STATISTICS FOR THE UNITED STATES (2004), available at http://www.census.gov/econ/ census02/advance/TABLE1.HTM (providing 2002 data for the motion picture and sound recording industries).

192. See Verizon, Verizon's 2003 Interactive Annual Report, http://investor.verizon.com/ 2003annual/financials/finnotes3.shtml (last visited Sept. 29, 2004) (noting 2002 revenues of $\$ 67.3$ billion dollars).

193. Two state-oriented solutions, based on taxing devices and remunerating artists and labels, are outlined in FISHER, supra note 183, at 199-258, and Neil Weinstock Netanel, Impose a Noncommercial Use Levy To Allow Free Peer-to-Peer File Sharing, 17 HARV. J.L. \& TECH. 1 (2003).

194. Artists themselves seem focused on building on a variety of self-help mechanisms based on their relationships with fans, ranging from live performances to web-based distribution on a tip jar model. See the now-classic John Perry Barlow, The Economy of Ideas, WIRED, Mar. 1994, at 84, available at http://www.wired.com/wired/archive/2.03/economy.ideas.html; and Love, supra note 188. The Future of Music Coalition, for example, provides artists with instructions on how to implement tip jars. See Future of Music Coalition, How Can Musicians and Artists Collect Real Money in an "Electronic Tip Jar"?, http://www.futureofmusic.org/tipjars/index.cfm (last visited Sept. 29, 2004).

195. LESSIG, CODE, supra note 176. 
cooperation, they will seek to implement a pricing mechanism. If they believed that social sharing was possible and sustainable, they could build networks to assume that possibility and to facilitate social sharing. The actual practice of Internet design has been ambivalent on this question. The basic Internet protocol design itself does not make it possible to prioritize traffic using pricing. It relies exclusively, at the transmission control protocol layer-that is, at the congestion-control mechanism--on best efforts and undifferentiated service. Predictions that the Internet would therefore melt down were followed by assiduous development of pricing schemes for traffic prioritization at the packet level. ${ }^{196}$

And yet, per-packet pricing has not been implemented, and the Internet has not melted down. Users have not adopted any of the more or less sophisticated pricing schemes proposed over the past decade or more. Instead, ever more demanding applications for real-time streaming, and even the most latency-sensitive of applications-like voice-over-Internet protocol (VoIP) - have begun to be implemented without introducing pricing. I suggest that this may be occurring because communicating through the Internet systematically involves using shareable goods. When this is so, algorithms designed to let people share their capacity and balance load among units that have overcapacity offer a better solution than algorithms designed to enable the millions of transactions necessary to achieve a comparably efficient network service. Demand for units with overcapacity increases capacity over time, and sharing and load balancing allocate extant capacity in the short term. Let me illustrate with one VoIP application, which makes clear the possibilities of generalized, impersonal social exchange as a means of provisioning resources over a priceinsensitive network made of shareable goods.

The application is Skype. ${ }^{197}$ It is proprietary software provided by the makers of KaZaa, currently the most popular peer-to-peer music-sharing platform. ${ }^{198}$ There are no published performance studies of this network

196. $\rightarrow$ F.P. Kelly et al., Rate Control for Communications Networks: Shadow Prices, Proportional Fairness, and Stability, 49 J. OPERATIONAL RES. SOC'Y 237 (1998); Jeffrey K. MacKie-Mason \& Hal Varian, Economic FAQs About the Internet, J. ECON. PERSP., Summer 1994, at 75 (1994); Scott Shenker et al., Pricing in Computer Networks: Reshaping the Research Agenda, 20 TELECOMM. POL'Y 183 (1996); Andrew Odlyzko, Paris Metro Pricing for the Internet (1997), available at http://www.dtc.umn.edu/ odlyzko/doc/paris.metro.pricing.pdf.

197. Skype, http://www.skype.com (last visited Sept. 29, 2004).

198. See Peter Biddle et al., The Darknet and the Future of Content Distribution, http://crypto.stanford.edu/DRM2002/darknet5.doc (last visited Sept. 29, 2004); Clay Shirky, PCs are the Dark Matter of the Internet, http://www.shirky.com/writings/dark_matter.html (last visited Sept. 29, 2004). Skype runs on a structured decentralized peer-to-peer network on the model of KaZaa. The first major peer-to-peer network, Napster, relied on a centralized server to store information about which peer had what music. While peers then communicated directly with each other and downloaded music from one another's computers from one end of the network to another, no peer could communicate directly with another without first identifying the relevant 
relative to the telephone network and other PC-to-PC voice-telephony-overInternet applications. As of early 2004, however, while still in beta testing, the software was downloaded by over ten million users, and used at any one time by over 300,000 . Anecdotally the software seems to function well, offering voice quality and reliability-again, anecdotally-on par with cordless phones, if not quite plain old telephone service. What is fascinating about this application, if it proves capable of scaling technically (leaving the business model to one side), ${ }^{199}$ is that it relies on a peer-to-peer network. The capacity used to deliver the service is purely combined from capacitygenerating components that have the characteristics of shareable goods. Users put these components into service for reasons other than voice-grade telephony, but Skype allows them to share their overcapacity so as to coprovision a telephony system. In an always-on, or even mostly-on, universe, where PCs have large amounts of unused memory and bandwidth and a client like Skype's runs in the background, taking up proportionally miniscule amounts of CPU power, bandwidth, and electricity, there will be little need to provide incentives to avoid shirking. Every user's interest in being reachable by her friends should provide enough incentive to keep her client on and connected. Except for the rare individuals who speak for more hours than they do not in any given twenty-four-hour period, and who are capable of using their computer to its capacity while at the same time talking, so that they take resources from the VoIP network without contributing at least as much back into it of their own excess processing, caching, and bandwidth capacities, the system capacity should scale well from the perspective of the willingness of participants to contribute as much as they take or more.

other by reference to a central listing. This made the communications protocol simple to design and execute, but the system vulnerable to attack and failure. The particular attack on that server was legal action, and the failure was a court-ordered closure. But the weakness was architectural-there was a single point of attack that could bring the system down. The response of the community of technology developers was to treat the legal attack like any other failure and to design around it. The result was Gnutella, and a class of approaches to peer-to-peer network design that avoided creating a center that would be vulnerable to attack but that had very high overhead, because it had no central clearing point detailing who had what information stored where. FastTrack, with its best-known clients Morpheus and KaZaa, introduced Supernodes, which added structure to the network of peers but still was insufficiently centralized to suffer the failure of Napster. The software dynamically assigns to users "Supernode" status based on their available resources, and instead of every node telling every other node everything it has and everything it wants, every node tells these things to its nearest Supernode, and Supernodes tell each other, keeping network traffic and information overhead low while retaining redundancy, flexibility in the distribution of the location of information, load balancing among nodes with more or less free capacity, and flexible rerouting around points of failure. The result is a system that is much more popular than Napster was, but offers no single point of failure for attack.

199. We can afford to leave the business model aside because Skype is an architecture and software, not a physical network. It hence could, in principle, be developed on a free software model should one company or another fail. 
The policy point of the Skype story is fairly simple. VoIP is one of the most demanding applications, insofar as quality-of-service assurance is concerned, because we have such remarkably low tolerance for latency in voice communications. VoIP has therefore been the primary excuse for schemes aimed at implementing pricing at the transmission control protocol level so as to manage congestion. Skype suggests that pricing is unnecessary if the machinery necessary for VoIP is sufficiently widespread and is a shareable good. PCs and, increasingly, broadband connections in the advanced economies indeed have the core characteristics of shareable goods. They are provisioned by individuals for their individual use in lumpy units that mostly exhibit substantial overcapacity. Given that requirements for human voice communications are limited by human capacity to comprehend and engage in real-time communications, but capacity is generated by demand for a much wider host of applications, most of them allowing asynchronous use, the lumpiness of these units should persist. Given also that one needs to have such an overcapacitygenerating good or resource to participate in PC-to-PC communications in the first place, demand will outstrip capacity only in the very unlikely case that the total demand for capacity by all owners of units systematically outstrips total capacity of all units put in place by owners, even though the units are put in service only if they indeed provide some threshold capacity that equals or exceeds the requirements of the owner of the unit. This is not theoretically impossible, ${ }^{200}$ but is probabilistically insignificant. In parallel to my observations about open wireless networks, if the devices necessary to take advantage of a functionality have the characteristics of shareable goods, it is possible that a market in capacity-generating units with overcapacity, sold on a per-unit basis, coupled with a technical platform that allows them to share their overcapacity and balance the load among units, will increase capacity better than an approach that assumes a fixed capacity provisioned through a market in capacity flows.

\section{CONCLUSION}

This Essay has two primary goals. The particular goal is to identify a class of resources or goods that are amenable to being shared within social sharing systems rather than allocated through markets. The general goal is to suggest that the particular observation, together with a growing body of literature on social norms, social capital, common property regimes, and

200. The units meet prior demand exactly-Skype adds exactly so much demand that it overwhelms the system capacity, but not enough added demand to make enough people buy enough new units with even greater overcapacity to achieve sufficient total capacity in the new state. 
the emergence of peer production, outlines the contours of social sharing as a third mode of organizing economic production, alongside markets and the state.

I suggest in this Essay that there is a class of material resources or goods that are lumpy and of medium granularity. These goods exhibit systematic overcapacity, which is often subject to sharing practices. Lumpiness is a technologically determined characteristic of these resources. Granularity is a function of technology and the extant demand and wealth in a society. It describes the divergence between the package size of a unit of a good capable of producing functionality and the demand individuals have for that functionality. Mid-grained lumpy goods are large enough so that each unit has systematically more capacity than one person requires over the lifetime of the good, and small enough that one person can justify putting a unit into operation to serve his demand for the functionality over the lifetime of the unit, given his ability and willingness to pay. One could think of them as consumption goods that for technical reasons come bundled with capital goods as a byproduct. Such units will generally have an overcapacity on an aggregate basis, in the sense that they will be able to deliver more functionality over their lifetime than the owners of units will demand in that time period. Goods with these characteristics will systematically represent a pool of potentially idled physical-capital resources. The problem is whether and how these idle resources will come to be used when their owners do not demand their capacity.

Information and transaction costs, and the practical diversity of individual motivations, limit the efficacy of secondary markets to harness this excess capacity. The comparative efficiency of social sharing systems and secondary markets is a context-specific, empirical matter, but one can generalize that markets (1) will have higher marginal transaction costs per transaction, because social exchanges can operate with systematically fuzzier boundaries than market transactions require if they are to be efficient; (2) will have less information, organized in a more formally computable form, at the expense of more textured, detailed information that can be computed in less formal, culturally transmitted modalities; and (3) may, by using pricing, crowd out social-psychological rewards that would elicit sharing patterns. We can predict that sharing is likely to be more efficient than markets when shareable goods are widely owned and have only small amounts of excess capacity per unit, relative to the total amount of capacity necessary to produce an economically valuable output. In those cases, the number of transactions necessary to accumulate the excess capacity into a usable amount of functionality, on the one hand, and the likely low price that small incremental contributions will command, on the 
other, suggest that both transaction costs and the crowding-out effect will be substantial if a secondary market is used in these situations.

More generally, I suggest that shareable goods are but one instance of a broader phenomenon outlined by the literature on social norms, social capital, and, most directly, common property regimes. Social production and exchange comprises a third system of production, a class of solutions to production problems that is separate from, and can complement or substitute for, the two more commonly studied systems: markets-through both the price system and the firm-and the state. The relative salience of social production or sharing as an economic phenomenon is technology dependent. In particular, the form of sharing that we observe today occurring in information and communications production-relatively impersonal, project- or function-specific, radically decentralized cooperation-depends on the technologically contingent physical-capital requirements for effective action. As capital requirements have declined and access to the relevant capital goods has become widely disseminated in advanced economies, the scope of sharing as a modality of production has increased. This requires that we invest greater effort in further research into the internal dynamics of social sharing and exchange systems, focused not so much on their characteristics as modes of social reproduction as on their characteristics as transactional frameworks and modes of economic production. The anthropology of gift and economic anthropology literature, the sociology and economics of reciprocity, and the literature on common property regimes seem particularly valuable sources for further exploration of these modes of cooperation.

It is crucial that we understand this fundamental change in the material conditions of production in the networked information economy. We find ourselves faced with policy and design questions that assume that the role of market production is fixed, rather than technologically contingent. We observe in many contexts policy choices and design impulses that take assumptions appropriate to the capital requirements of industrial economies and try to force behavior in the networked information economy into the social and market behavioral patterns that were appropriate for that technological stage and capital structure, rather than for the one we live in today. We must learn instead how to adjust our expectations, assumptions, and, ultimately, policy prescriptions to accommodate the emerging importance of social relations in general, and sharing in particular, as a modality of economic production. 